\title{
Effect of dai training on maternal and neonatal care: An operations research study
}

\author{
Peter C. Miller \\ Population Council \\ Gul Rashida \\ Population Council \\ Abdul Wajid \\ Population Council \\ Zeba Tasneem \\ Population Council \\ Lubna Mahmood \\ Population Council
}

See next page for additional authors

Follow this and additional works at: https://knowledgecommons.popcouncil.org/departments_sbsr-rh

Part of the International Public Health Commons, Maternal and Child Health Commons, Obstetrics and Gynecology Commons, Social and Behavioral Sciences Commons, and the Women's Health Commons

How does access to this work benefit you? Let us know!

\section{Recommended Citation}

Miller, Peter C., Gul Rashida, Abdul Wajid, Zeba Tasneem, Lubna Mahmood, and Minhaj ul Haque. 2010. "Effect of dai training on maternal and neonatal care: An operations research study." Islamabad: Population Council. 


\section{Authors}

Peter C. Miller, Gul Rashida, Abdul Wajid, Zeba Tasneem, Lubna Mahmood, and Minhaj ul Haque 


\section{Effect of Dai Training on Maternal and Neonatal Care}

\section{An Operations Research Study}

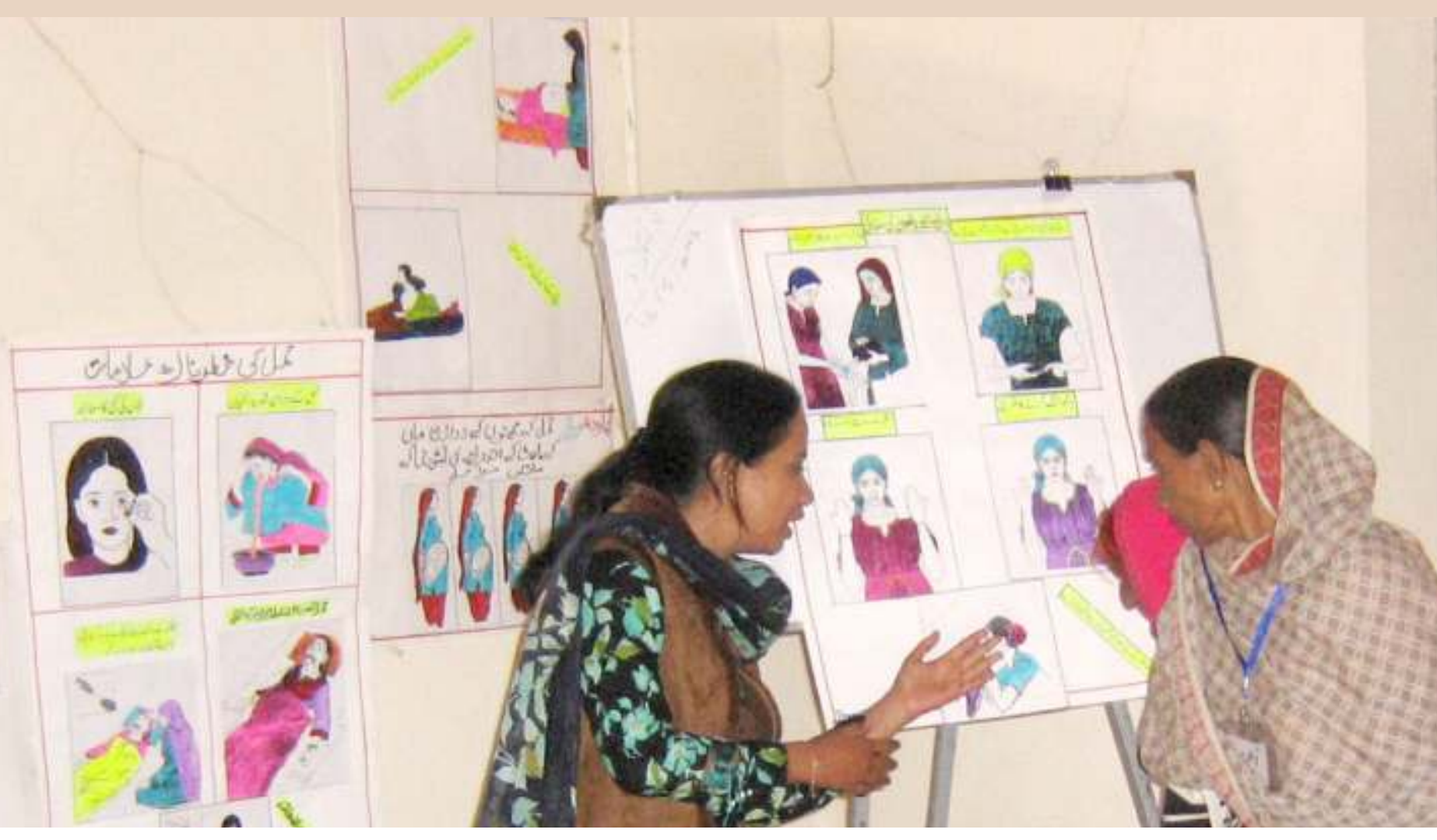




\title{
Effect of Dai Training on
}

\section{Maternal and Neonatal Care}

\section{An Operations Research Study}

\author{
Peter Miller \\ Gul Rashida \\ Abdul Wajid \\ Zeba Tasneem \\ Lubna Mahmood \\ Minhaj ul Haque
}

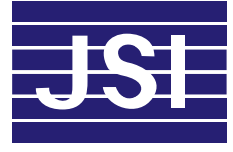

12 Population Council 


\section{(1) Population Council}

The Population Council, an international, non-profit, non-governmental organization established in 1952, seeks to improve the well-being and reproductive health of current and future generations around the world and to help achieve a humane, equitable, and sustainable balance between people and resources.

The Council analyzes population issues and trends; conducts research in the reproductive sciences; develops new contraceptives; works with public and private agencies to improve the quality and outreach of family planning and reproductive health services; helps governments design and implement effective population policies; communicates the results of research in the population field to diverse audiences; and helps strengthen professional resources in developing countries through collaborative research and programs, technical exchange, awards, and fellowships.

The Population Council reserves all rights of ownership of this document. No part of this publication may be reproduced, stored or transmitted in any form by any meanselectronic, photocopying, recording or otherwise-without the permission of the Population Council.

\section{For inquiries, please contact:}

Population Council

\# 7, Street 62, F-6/3, Islamabad, Pakistan

Tel: 92518445566

Fax: 92512821401

Email: pcpak@popcouncil.org

Web: http://www.popcouncil.org

http://www.paiman.org.pk

\section{Layout and Design: Ali Ammad}

Published: March 2010

\section{Disclaimer}

"This study/report is made possible by the generous support of the American people through the United States Agency for International Development (USAID). The contents are the responsibility of JSI Research $\mathcal{E}$ Training Institute, Inc and do not necessarily reflect the views of USAID or the United States Government. 


\section{Table of Contents}

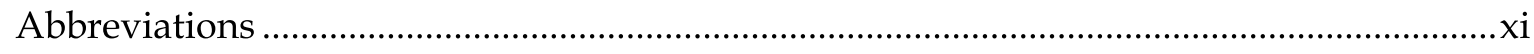

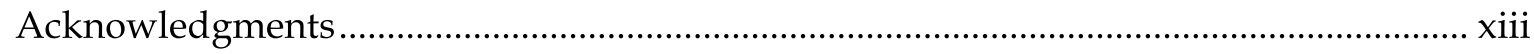

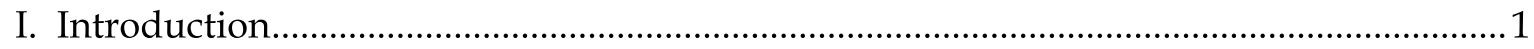

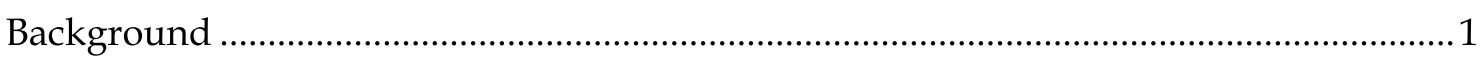

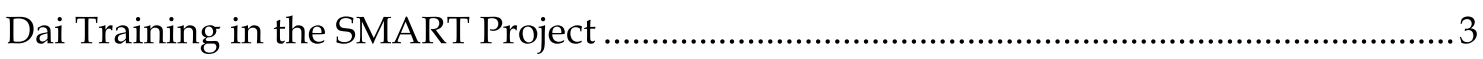

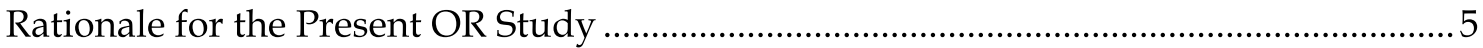

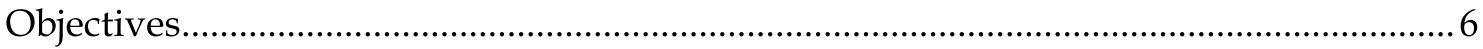

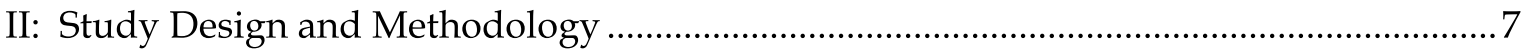

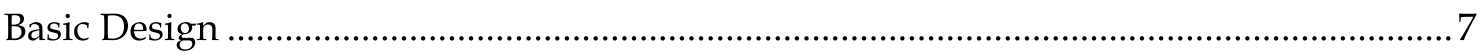

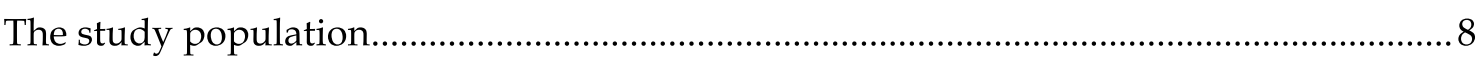

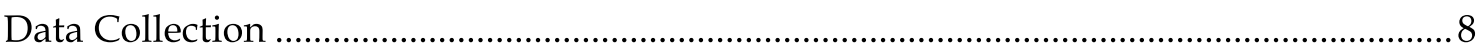

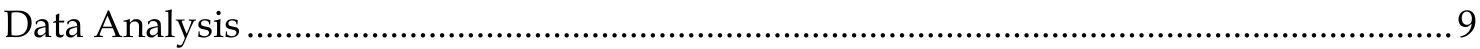

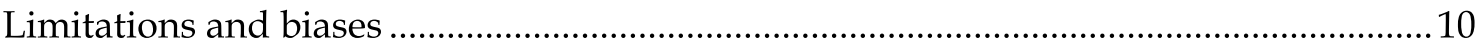

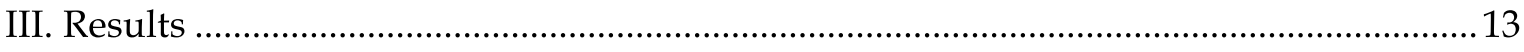

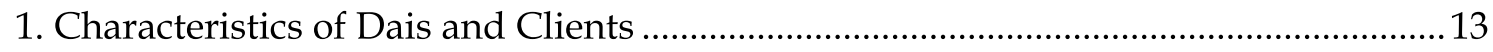

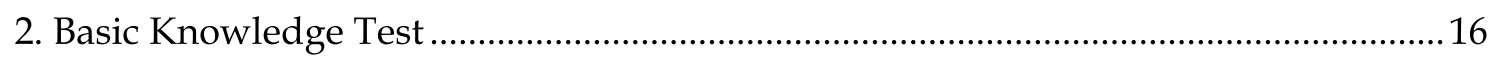

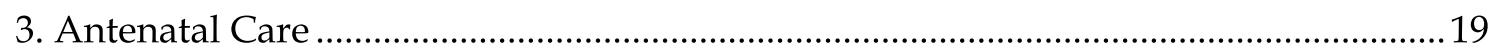

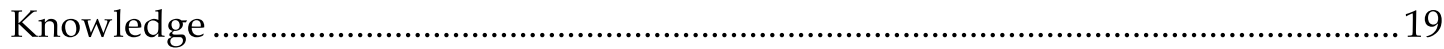

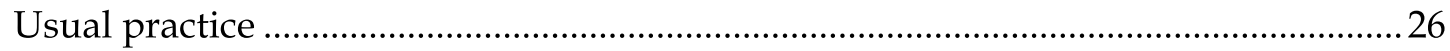

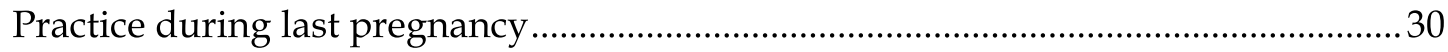

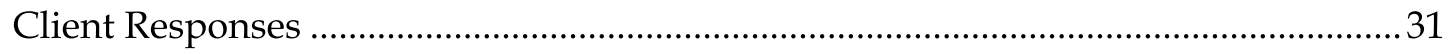

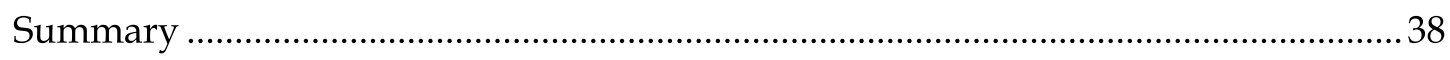

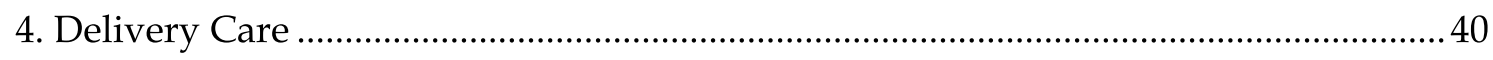

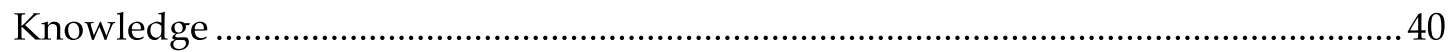

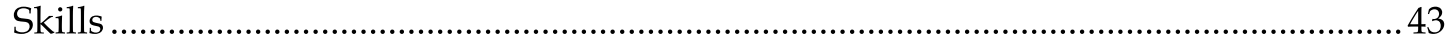

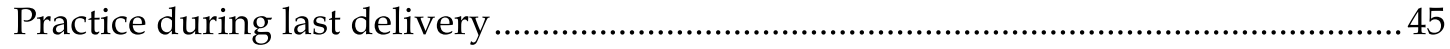

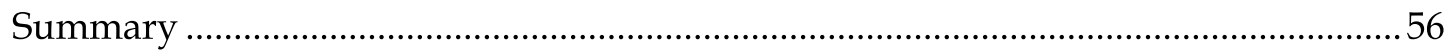

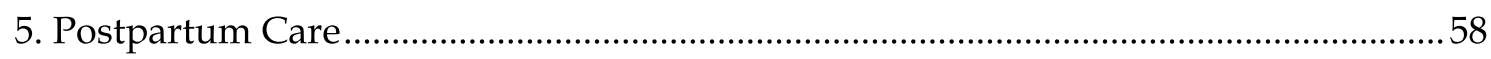

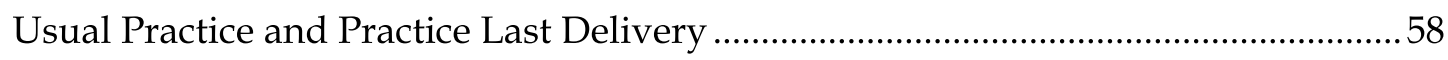

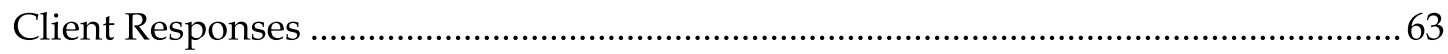

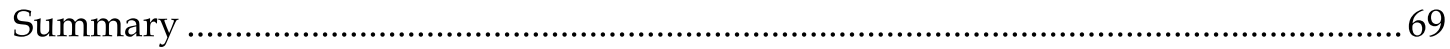

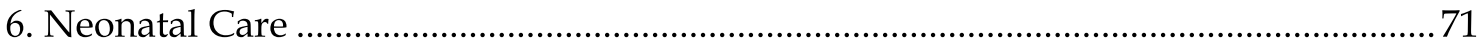

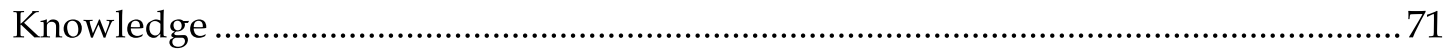




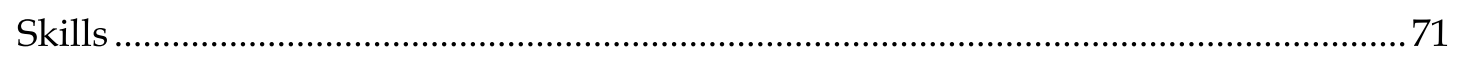

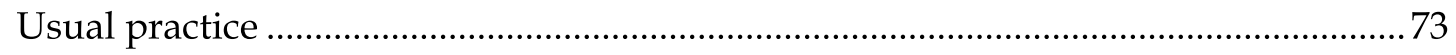

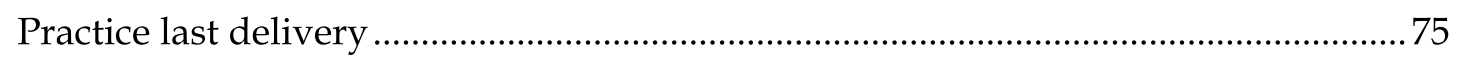

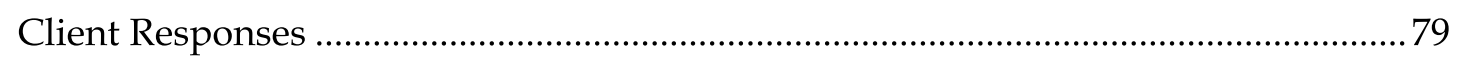

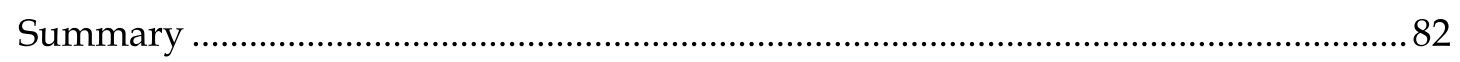

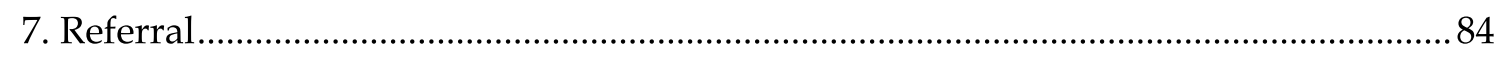

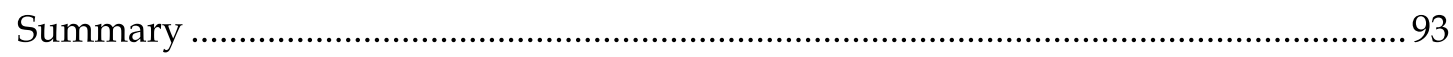

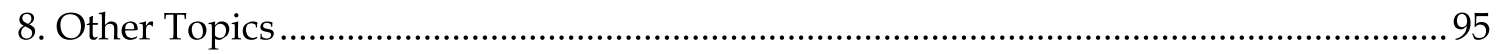

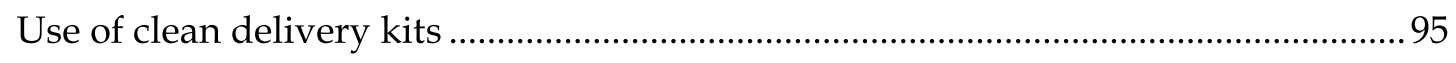

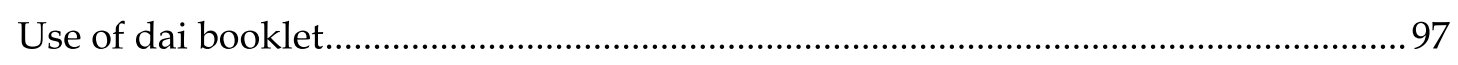

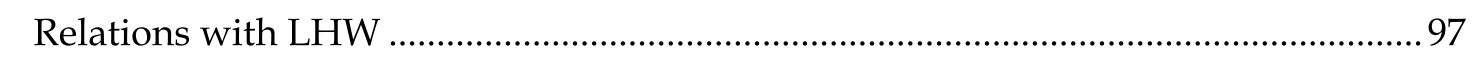

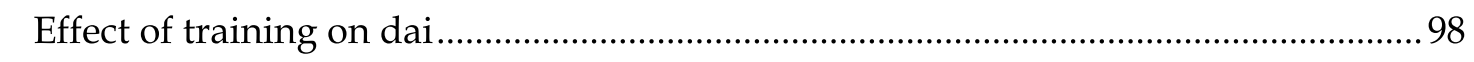

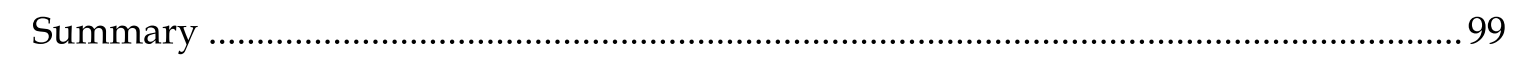

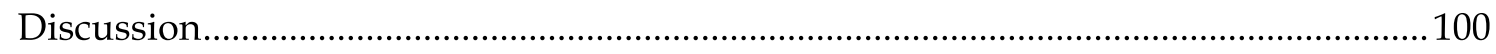

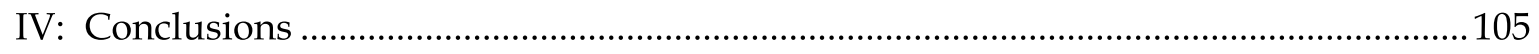

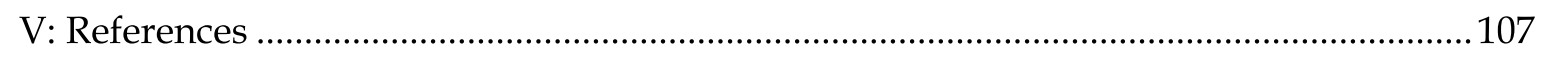

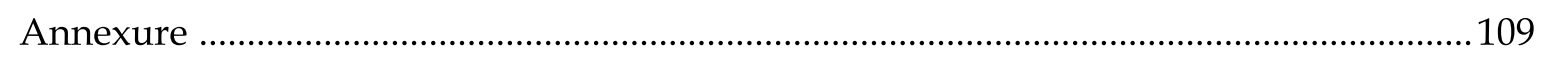

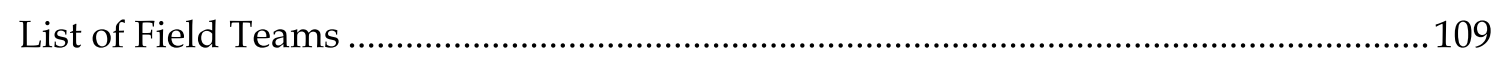




\section{List of Tables}

Table 1.1: Percentage distribution of dais by age, according to training status...................13

Table 1.2: Percentage distribution of clients by age, according to training status of dai 14

Table 1.3: Percentage distribution of clients by number of living children, according to

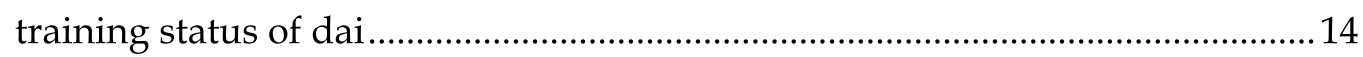

Table 1.4: Percentage distribution of dais by number of deliveries in previous 6 months, according to training status.

Table 2.1: Percentage of trained and untrained dais by score on basic knowledge test

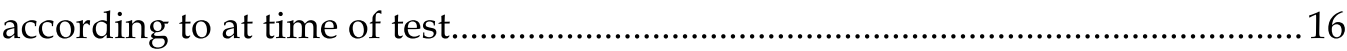

Table 2.2: Percentage of Correct Scores for Trained and Untrained Dais on Basic Knowledge Test according to individual item, by training status.

Table 3.1: Percentage of dais spontaneously naming specified danger signs of pregnancy, by training status.

Table 3.2: Percentage distribution of specific antenatal risk factors spontaneously named by dais, by training status

Table: 3.3: Percentage distribution of dais' responses regarding immediate actions to take in case of bleeding, by training status

Table: 3.4: Dais' knowledge of immediate actions to take in case of eclampsia, in percentages

Table 3.5: Percentage of dais demonstrating wrong, prompted correct and spontaneous correct responses on checking for anemia in a pregnant woman by training status (no. of observations: trained $=275$, untrained $=255$ ).

Table 3.6: Percentage of dais demonstrating wrong, prompted correct and spontaneous correct checks for jaundice, by training status (no. of observations: trained = 275 , untrained $=254$ )

Table 3.7: Percentage of dais demonstrating wrong, prompted correct and spontaneous correct procedures on abdominal checkup, by training status (no. of observations: trained $=275$, untrained $=274$ ) .

Table: 3.8: Percentage of dais according to reason for antenatal visits, according to training status.

Table: 3.9: Percentage of dais reporting individual components of antenatal check-up, by training status.

Table: 3.10: Percentage of dais by advice given to a pregnant woman during antenatal check-ups, by training status 
Table 3.11: Percentage of dais according to action taken when their client bled during pregnancy, by training status

Table 3.12: Percentage distribution of client reports regarding dai visits during pregnancy, by dai training status

Table 3.13: Responses of clients of trained and untrained dais regarding the content of antenatal check-up, in percentages.

Table 3.14: Responses of clients of trained and untrained dais on advice provided by dai during antenatal visits, in percentages

Table 3.15: Responses of clients of trained and untrained dais regarding action by dais in response to serious pregnancy complications, in percentages.

Table 3.16: Responses of clients of trained and untrained dais regarding sources of antenatal care, in percentages.

Table 3.17: Responses of clients of trained and untrained dais regarding the source of advice to get TT vaccination, in percentages....

Table 3.18: Responses of clients of trained and untrained dais regarding reasons for not receiving TT vaccination, in percentages

Table 4.1: Percentage of correct dai responses regarding stages of labor, by training status.

Table 4.2: Percentage of dais according to spontaneous reporting of complications of labor, by training status

Table 4.3: Percentage of dais, according to action, to be taken if placenta not completely expelled, by training status

Table 4.4: Percentage of dais demonstrating wrong, prompted correct and spontaneous correct practices on hand washing prior to delivery, by training status (no. of observations: trained $=275$, untrained $=251$ ) .

Table 4.5: Percentage of dais demonstrating wrong, prompted correct and spontaneous correct practices on use of clean delivery kit, by training status (no. of observations: trained $=264$, untrained $=248$ )

Table 4.6: Percentage of dais demonstrating wrong, prompted correct and spontaneous correct practices selected aspects of delivery, by training status (no. of observations: trained $=265$, untrained $=250$ )

Table 4.7: Percentage responses of dais regarding preparations at home before last delivery, by training status.....

Table 4.8: Percentage of dais by usual steps at delivery reported sponanteously, after prompting, or not usually taken, by training status

vi 
Table 4.9: Distribution of dais according to practice of pelvic examination, by training status.

Table 4.10: Percentage distribution of dais according to reason for not giving injections during the last delivery, by training status.

Table 4.11: Percentage of dais according to reported usual practices regarding intravenous drip during labor, by training status . 52

Table 4.12: Percentage of dais according to action taken in last delivery to determine if placenta was completely expelled, by training. 53

Table 4.13: Percentage of dais reporting selected clean delivery practices, by training status

Table 4.14: Percentage of clients reporting use of injections or drip during last delivery, by training status

Table 4.15: Distribution of dais according to practice of pelvic examination, by training status.... 55

Table 4.16: Percentage distribution of client reports of dai actions in case the placenta was not expelled spontaneously, by training status. 56

Table 4.17: Percentage distribution of client reports of placenta examination methods, by training status

Table 5.1: Percentage distribution of dais according to usual postpartum visiting schedule, by training status.

Table 5.2: Percentage distribution of dais according to postpartum visiting schedule after last delivery, by training status.....

Table 5.3: Percentage of dais according to person referred after the last delivery, by training status

Table 5.4: Percentage of dais according to maternal conditions checked postpartum, by training status

Table 5.5: Percentage of dais according to postpartum advice given during last delivery, by training status.

Table 5.6: Percentage of dais according to family planning methods discussed with clients in previous six months, by training status.....

Table 5.7: Percentage distribution of clients according to reported length of dais' usual stay with clients immediately after delivery, by dai training status

Table 5.8: Percentage of client responses according to actions taken immediately following delivery, by dai training status 65 
Table 5.9: Percentage distribution of client responses of which day trained and untrained dais visited them post-partum, by dai training status

Table 5.10: Percentage of client responses according to specific checks performed by dais post-partum, by dai training status

Table 5.11: Percentage of client responses according to advice given dais during post partum visits, by dai training status.

Table 5.12: Percentage of client responses according to family planning method mentioned in postpartum visits, by dai training

Table 5.13: Percentage of client responses according to reason for not adopting family planning, by dai training status

Table 6.1: Percentage of dais demonstrating wrong, prompted correct and spontaneous correct responses on cleaning of neonates, by training status (no. of observations: trained $=271$, untrained $=253$ )

Table 6.2: Percentage of dais demonstrating wrong, prompted correct and spontaneous correct responses on examination of neonates, by training status (no. of observations: trained $=272$, untrained $=252$ )

Table 6.3. Percentage of dais according to usual practice during neonatal period, by training status

Table 6.4: Percentage of dais according usual practice if a newborn is not breathing properly, by training status

Table 6.5: Percentage of dais by neonatal body parts cleaned after last delivery, by training status

Table 6.6: Percentage of dais according to components of neonatal examination done in last delivery, by training status.

Table 6.7: Percentage of dais according to cord care practice during last delivery, by training status

Table 6.8: Percentage of clients reporting neonatal body parts cleaned by dai after last delivery, by dai training status 79

Table 6.9: Percentage of clients reporting specified cord care practices by dais after last delivery, by training status.

Table 6.10: Percentage of clients reporting specified practices regarding initial establishment of breastfeeding, by dai training status

Table 7.1: Number and percentage distribution of dais according to number of deliveries referred in six months prior to interview, by training status 85 
Table 7.2: Percentage distribution of referred clients according to reason for referral, by source of report and training status

Table 7.3: Percentage distribution of referred clients according to timing of referrals by source of report and dai training status

Table 7.4: Percentage distribution of referred clients according to referred facility by source of report and dai training status.

Table 7.5: Percentage distribution of referred clients according to time required to arrange money for emergency referral, by source of report and dai training status

Table 7.6: Percentage distribution of referred clients according to time required to arrange transport for emergency referral, by source of report and dai training status

Table 7.7: Percentage distribution of referred clients according to time required to reach referral facility, by dai training status

Table 7.8: Percentage distribution of referred clients according to referral place where treatment was given, by source of report and dai training status 90

Table 7.9: Percentage distribution of clients according to time between reaching treatment facility and initiation of treatment, by source of report and training status

Table 7.10: Percentage distribution of referred clients according to procedures taken at delivery facility, by source of report and training status .92

Table 7.11: Percentage distribution of referred deliveries according to outcome of delivery, by source of report and training status 92

Table 7.12: Distribution of expenditure for client referrals, by dai training status

Table 8.1: Percentage reporting use of clean delivery kits according to situation, by source of report and dai training status 96

Table 8.2: Percentage of dais according to response on questions related to the dai booklet, by training status 97 


\section{List of Figures}

Figure 3.1: Percentage distribution of number of antenatal danger signs known, by training status

Figure 3.2: Percentage distribution of dais by number of antenatal risk factors named,

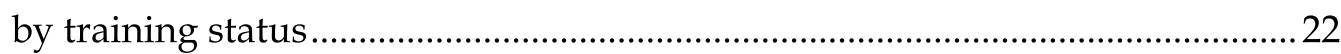

Figure 3.3: Percentage of dais according to reported usual number of antenatal visits and by training status

Figure 3.4: Percentage distribution of dais according to frequency of antenatal visits, by training status, from client reports

Figure 3.5: Percentage of clients reporting advice received regarding TT vaccination, by dai training status

Figure 4.1: Percentage distribution of numbers of delivery complications cited by dais, by training status

Figure 4.2: Distribution of dais by number of times usually performing pelvic examinations, by training status

Figure 4.3: Distribution of dais by number of times pelvic examinations performed during last delivery, by training status.....

Figure 4.4: Distribution of dais by number of times usually giving injections, by training status

Figure 4.5: Distribution of dais by number of times injections given during last delivery, by training status

Figure 5.1: Percentage distribution of dais according to number of hours usually remaining with client after delivery, by training status

Figure 5.2: Percentage distribution of dais according to number of hours remaining with client after most recent delivery, by training status

Figure 6.1: Percentage distribution of dais according to material used to clean the newborn, by training status

Figure 6.2: Percentage distribution of dais according to timing of first bath for the newborn, by training status 


\section{Abbreviations}

$\begin{array}{ll}\text { SBA } & \text { Skilled Birth Attendant } \\ \text { MMR } & \text { Maternal Mortality Ratio } \\ \text { PSLAM } & \text { Pakistan Social and Living Standards Measurement Survey } \\ \text { MVA } & \text { Manual Vacuum Aspiration } \\ \text { TBA } & \text { Traditional Birth Attendant } \\ \text { MoH } & \text { Ministry of Health } \\ \text { PAIMAN } & \text { Pakistan Initiative of Mother and Newborn Health } \\ \text { SMART } & \text { Safe Motherhood Applied Research and Training } \\ \text { OR } & \text { Operations Research } \\ \text { LHWs } & \text { Lady Health Workers } \\ \text { KAB } & \text { Knowledge, Attitude and Behavior } \\ \text { SPSS } & \text { Statistical Package for Social Sciences } \\ \text { TT Vaccination } & \text { Tetanus Toxoid Vaccination } \\ \text { IV Drip } & \text { Intravenous Drip } \\ \text { IUD } & \text { Intra-uetrine Device } \\ \text { Cu -T } & \text { Copper-T } \\ \text { CDK } & \text { Clean Delivery Kit } \\ \text { CBI } & \text { Community Based Intervention } \\ \text { PNMR } & \text { Porinatal Mortality Rate } \\ \text { MNH } & \text { WHO }\end{array}$





\section{Acknowledgments}

The opportunity to implement this study came from a grant from the Pakistan Initiative for Mothers and Newborns (PAIMAN) project, which in turn was funded by the United States Agency for International Development (USAID). We are grateful for their financial support. In addition, we have appreciated the support of Dr. Nabeela Ali, the Chief of Party for PAIMAN, whose support for dai training has provided the rationale for funding this study. We have also appreciated the support of Dr. Arshad Mahmood, who as head of the Operations Research Thematic Group has provided technical support for this study.

Funding apart, this study was made possible by the Population Council's support of the SMART project. In particular, Dr. Zeba Sathar, as Country Director of the Council's Pakistan office, guided the project and nurtured it into being. Dr. Farid Midhet, the initial project director, conceived of the dai training and set in motion the formative research that provided its essential underpinnings. More important, he made the project staff believe that if we saved even one mother's life, the project was worth it.

The study was implemented by a team of dedicated staff, primarily from DG Khan district. Mr. Irfan Masood was responsible for designing and implementing the data entry system and assisted with the data analysis. We are most grateful to Ms. Momina Salim for proofreading the report. We acknowledge the hard work of Mr. Ali Ammad for formatting the report so it was completed in time.

Finally, we owe a considerable debt of admiration to the dais who participated in this study. In particular, the trained dais proved willing to work with us in good spirit, and to give up lifetime practices where needed to safeguard the health of mothers and newborns. This report is dedicated to them. 



\section{Introduction}

\section{Background}

There are more than half a million maternal deaths and four million neonatal deaths occurring in a year around the world. Among these, more than 98 percent of maternal deaths and 99 percent of neonatal deaths occur in developing countries. Pakistan ranks low even among developing countries, with a maternal mortality ratio (MMR) of 276 per 100,000 live births and a neonatal mortality rate (NMR) of about 54 per 1000 live births. Of all children who die before age five, 57 percent die in the first month (PDHS 2008).

It is widely agreed that the key to reducing maternal mortality in developing countries is to ensure appropriate treatment of obstetric emergencies (Maine and Rosenfield 1999). Since such emergencies are difficult to predict in advance, treatment must be available for all deliveries. In particular, two key indicators for a program's readiness to treat obstetric emergencies are delivery in a facility with the capability of treating or referring such emergencies, and assistance at delivery by a skilled birth attendant (SBA).

According to the Pakistan Demographic and Health Survey (PDHS), 34.2 percent of deliveries in Pakistan take place in health facilities, and 38.8 percent are assisted by a SBA (PDHS 2008). These proportions are lower in rural areas -- 25.0 percent and 29.8 percent, respectively. In rural DG Khan, where this study takes place, this situation is substantially worse; according to the Pakistan Social and Living Standards Measurement (PSLM) survey of 2004-05, 89 percent of rural deliveries were conducted at home, and 86 percent were delivered by traditional birth attendants (TBAs, known as dais in Pakistan) or family members (PSLM 2005). Similarly, the SMART project baseline survey for the project areas in rural DG Khan found that 85 percent of deliveries took place at home, and 85 percent were assisted by unskilled attendants. (Arif et al. 2006) Studies done for the Pakistan Initiative for Mothers and Newborns (PAIMAN) project in 10 districts of Pakistan indicate that, according to several measures, TBAs deliver a higher proportion of births, and are more influential, in DG Khan than elsewhere in the country (Population Council 2006).

In DG Khan Hashmi et al. have explored the reasons why women may favor TBAs as compared to other birth attendants. These include the likelihood that the dai may be the only option available; that clients are more comfortable with a local woman conducting 
delivery; that privacy is protected by the delivery being conducted at home; and that the dai performs tasks other than delivery, such as massage of the mother, care of the newborn and some household chores. Moreover, she is a well-known individual available in the community for carrying out this specific job, and she can be paid in cash or kind (Hashmi et al. 2005). Therefore expecting mothers and their families are dependent on the knowledge and skill of these TBAs. Unfortunately, much of their practice includes unacceptable practices such as frequent vaginal examinations, use of uterotonics during second stage labor, and poor hygiene for both mothers and newborns; also, for reasons of both logistics and professional competence it may be difficult to get the mother to an appropriate facility in case of emergency.

An influential model for reducing maternal mortality is known as the "three delays" model (Thaddeus and Maine 1994). This model states that there are three delays encountered by women during obstetric emergencies that account for most maternal deaths. The first delay involves recognition of complications and making the decision to transport the mother to a health facility. The second delay is in actually transporting the mother to an appropriate facility for specialized assistance. The third delay is in obtaining appropriate emergency care once the facility has been reached. From this perspective, if deliveries were routinely conducted in appropriate facilities, the first two delays would be eliminated, and the third greatly reduced. In a place like DG Khan, where this situation is far from reality, reducing the three delays is a major challenge.

There are important differences in the requirements for saving the lives of the newborn. While delivery in health facilities with neonatal care capabilities is highly desirable, it has also been shown in recent years (including important work in South Asia) that appropriate preventive measures and improved care of the newborn at home can reduce neonatal mortality substantially, even in the absence of facility-based emergency treatment (Bang et al., 2005; Bhutta et al. 2008). In principle, major improvements in neonatal health can be achieved in the context of home deliveries, even in the absence of sophisticated medical care.

In Pakistan, the Ministry of Health is well aware of the situation and is taking various steps to address it. In recent years the proportions of women delivered in facilities and by SBAs have increased significantly. In addition, the Ministry of Health has begun an initiative to train community midwives to become skilled birth attendants and eventually 
live and practice in rural areas. However, deployment of these community midwives is in its early stages, and it is difficult to predict how much time will they take to attain the position of the care provider of choice at the community level. It is therefore critical to address the question of how to improve maternal and neonatal health during the (probably lengthy) period when skilled birth attendance is not available to many women.

One obvious approach is to try to improve the practice of the TBAs, who are already trusted, experienced, and in place. If they can be persuaded to adopt safer routine delivery and newborn care practices, and to recognize and refer in case of emergencies, much can be accomplished. In the past, various programs for TBA training have been implemented without remarkable success. Pakistan's own experience and some international experience discourage further investment of resources for the capacity building of TBAs. However, a district-wide program in Larkana that both trained dais and linked them to the government's health system resulted in a significant decline in perinatal mortality and a suggestive decline in maternal mortality (Johkio et al. 2005). Criticisms of the failed programs include that the trainees were left without follow-up, supervision, or support systems for the dais (Bhutta et al. 2003); and that the quality of the training itself was insufficient.

Nevertheless, for the transitional period of training of community midwives and their acceptance in the community, Pakistani communities need a care provider with minimum level of required expertise to address the normal obstetrical processes and make timely referrals when need arises. The only viable options left for the Pakistan health system are to upgrade TBAs to a level where they are helpful to the community rather than letting them continue their dangerous and unskilled practices. With this in mind, the Safe Motherhood Applied Research and Training (SMART) project looked for ways to determine whether dai training could become an effective part of maternal and newborn health care in a difficult rural environment in Pakistan.

\section{Dai Training in the SMART Project}

The Safe Motherhood Applied Research and Training (SMART) project was an operations research project designed and implemented by the Population Council to develop and test interventions to reduce maternal and neonatal mortality in DG Khan district, Pakistan. SMART was a three-year project funded by the European Union, implemented from 
November 2002 to October 2006. The project was implemented in three sites (two intervention sites in Dera Ghazi Khan and one control site in Layyah district) and studied the impact of two different interventions, one at the community level and the health facility level combined, and the other at the health facility alone, in comparison with each other and with the control area. The two intervention sites each consisted of 60 villages with a total population of about 300,000 persons, assigned at random to one of the two intervention packages. This project is described in more detail in Rashida and Miller, 2006. An end-of-project survey revealed a reduction of 23 percent in the perinatal mortality rate (PNMR) in the community based intervention site, but no reduction in the health services only site (Arif et al., 2006).

An important part of the community based intervention was a set of intense community mobilization, information and education sessions on maternal and neonatal health $(\mathrm{MNH})$ issues that were carried out for women and men living in these communities (Wajid et al. 2006). As a result of this intervention, women at this site by the end of the project had better knowledge of $\mathrm{MNH}$, and were better informed and knowledgeable about what a dai should do, as compared to women in the non- intervention site.

Another aspect of the combined community and health facility intervention included the development and implementation of an eight-day training package for dais. This package was based on formative research, review of the existing training manuals, and inclusion of the Council's "client centered" approach, previously developed. The course was:

- respectful

- participatory

- client-centered

- hands-on

- appropriate in teaching methods, and

- inclusive of neonatal as well as maternal care

In this component 288 dais were trained. These dais were not "traditional" in the sense of practicing exactly as their elders had; roughly half of the dais reported having attended some form of training previously, and could cite some current "best practices." The training sessions of this training package were followed by supervision, follow up and getting feedback from the clients served by these TBAs. 
This training was well received by the dais. The combination of practical technical training, emphasizing having dais' practice of basic steps such as using models where appropriate, and the principles of the Council's "SAHR" approach to client-centered training, which involved a high level of participation, discussions of the dais' role vis-àvis her clients, how to work with clients, brainstorming, role-playing, and other approaches to involving the dais as actively as possible seemed to be effective. The enthusiasm of the dais as training progressed gave hope that they might apply their learning to a greater extent than our initial expectations. They were particularly positive about the training in neonatal care; they regarded their expertise as being only in delivery care, so this element was new and welcome.

Assessment of this training by pre- and immediate post-test results showed a substantial improvement in the knowledge of these dais (Wajid, 2006). The trained dais and a sample of their clients were followed up in the field at about 4-6 months after training. This follow up research activity showed encouraging results. On a test of 19 items, the mean score obtained by the dais at pre-test was 9.3, at first post-test 18.4 and at second post-test 16.9. Both the post-test scores were significantly different from the pre-test score $(p<.01)$. In addition, both the dais and their clients reported encouraging levels of sound practice.

\section{Rationale for the Present OR Study}

When the project ended and the endline survey results were available, speculation as to the specific reasons for the rapid decline in perinatal mortality, centered on dai training (Rashida and Miller 2006). However, such a conclusion could only be tentative, since the evaluation of the dai training lacked controls, especially for the behavioral components assessed in the field follow-up; there had been no quantitative baseline assessment of dai practice prior to training. Moreover, it is important to know how lasting the effects of the training might be, for which the 4- to 6-month period of the field follow-up seemed inadequate.

For control purposes, a nearly ideal control group was available in the form of the dais who practiced in the "health services only" site. Since the study communities had been allocated to the two sites at random, the dais were also, in effect, randomly allocated to treatment and control. Hence a post-project survey of both groups of dais could elicit the results of the training on both knowledge and practice. A proposal was prepared, and a 
small grant was received from the PAIMAN project, which had an interest in training the dais for its own activities. The study would involve both groups of dais, and measure knowledge through a survey of the dais, skills through tests performed on pelvic and neonatal models, and practice through both the dai survey and a survey of the most recent clients of the dais, both referred and non-referred.

\section{Objectives}

The objectives of the evaluation were:

- To determine whether dais substantially improve their performance after attending the "SMART dai" training course;

- To determine the knowledge, attitude and behavior (KAB) of dais regarding maternal and neonatal health care in the two sites;

- To assess the skills of dais regarding maternal and neonatal health care issues and compare these skills in the two sites; and

- To determine the perceptions of the clients regarding practices and behavior of dais who serve them, and to compare them in the two sites. 


\section{II: Study Design and Methodology}

\section{Basic Design}

This study compares responses of trained and untrained dais, at a time approximately 19 months after the dai training, on knowledge, skills, practice in general, and practice regarding the last delivered client. The study sample was taken from the 120 communities of DG Khan that were allocated randomly to the Community Based Intervention (CBI) and Health System Intervention (HSI) interventions. The sample involved all trained dais who could be located, as well as all untrained dais in the 60 "health services only" communities who met the original criteria for dai training. In addition, clients of both trained and untrained dais, experiencing normal as well as referred deliveries were also included in this study.

This is a prospective study design which allows for temporal sequence and therefore exposure to training may have been responsible to cause the change observed in the dais who received the training as opposed to those who were not exposed. The random allocation of dais for receiving CBI and HSI in their initial training under SMART program further strengthens this study design, though the dais themselves were not selected randomly.

One of the significant caveats to this is that the CBI communities received interventions other than the dai training; most important was mothers' education through mothers' support groups, therefore, clients of trained dais may have been more aware of proper maternal and neonatal health procedures than clients of untrained dais.

In addition to information gathered at the time of the survey, additional data are available for the trained dais from the pre-and post-tests of basic knowledge at the time of training, and from the follow-up study of the trained dais at 6 month after training, which involved similar methods. 


\section{The study population}

The study population included all SMART-trained dais who could be located the time of the survey, as well as all "active" dais practicing in the communities in control area who met the criteria for selection in the SMART dai training i.e., at least 5 deliveries per month, less than 60 years of age, who were located and agreed to be interviewed. Based on the number of qualified dais identified in the CBI area, it was anticipated that the sample size would be between 250 and 300. In fact, we were able to interview 277 trained dais (total trained 288) and 257 untrained dais. Among trained dais, eleven could not be interviewed for the following reasons. Six could not be contacted even after three consecutive visits; three stopped working; one refused and one dai had shifted to another place. The total number of clients of both trained and untrained dais included in this study was 968 . There were instances where only partial information could be retrieved by the participants therefore the total number in the results section varies according to the information received.

To locate these dais, two teams of two female staff members each who had previously worked for the SMART project visited the study communities in the control area. The teams met with community leaders such as the nazim, existing dais, teachers and women leaders and asked about the dais currently serving the community with addresses. The teams located the suggested dais and confirmed their eligibility for the study and willingness to participate.

\section{Data Collection}

Three questionnaires were used, two for dais and one for clients. For the dais, the brief knowledge test consisting of 19 item that was used in the pre- and post-testing for dai training, and repeated at the first follow-up, was again administered to the trained dais, and for the first time to the untrained dais. In addition, a much longer interview form was administered to dais, consisting of questions regarding knowledge, general practice, and practice for the most recent normal delivery during the previous 6 months. Also, a skills test was administered using dummy female and neonatal models. In addition, information was obtained on up to four referred cases during the previous 6 months, including contact information for the client. 
The dai also gave contact information for the client she reported on when describing practice for her most recent non-referred delivery in the past 6 months. The interviewers attempted to interview that client; if she was unable to locate or interview her, the next most recent case was sought, and so on until a case was located and interviewed. If the interviewed client was not the one referred to in the original interview as the "most recent" client, the dai was re-interviewed to recount the specific practices for that particular client, and the dai interview form was revised accordingly. These pairs of daiclient interviews could then be analyzed both in aggregate and in pairs. For referrals, we obtained data from the dais on up to four referrals in the previous six months, depending on how many she reported having done; of these, we attempted to interview one referred client for each dai who reported doing referrals. The numbers of cases available for analysis, and used in this report, is as follows. (As a result of missing data in a particular interview, the numbers available for any given table may be fewer.)

Number of dais and their clients, by training status

\begin{tabular}{l|cc}
\hline Type of case & Trained dais & Untrained dais \\
\hline Dais & 277 & 257 \\
$\quad$ Non-referred cases & 298 & 194 \\
$\quad$ Referral cases reported on & & \\
Clients & 252 & 237 \\
$\quad$ Interviews from non-referred cases & 169 & 114 \\
$\quad$ Interviews from referred cases & & \\
\hline
\end{tabular}

There were five teams involved in data collection task. Each consisted of three members: two lady health visitors (LHVs) and one male logistic coordinator. These teams were trained in data collection and interviewing techniques for one week which was followed by pretesting in the field. The survey continued for three months from end of June to the last week of September 2006. Data quality was enhanced by monitoring visits of Population Council field teams.

\section{Data Analysis}

The data were reviewed at the end of each day prior to entry, after which data were edited and entered using PC edit. The data were then analyzed utilizing SPSS version 15.0. 
Data are analyzed primarily in terms of comparisons of means and proportions between trained and untrained dais, with significance compared using t-tests and chi-square tests, as appropriate. For each of the four stages of maternal and neonatal health (antenatal, delivery, postpartum, and neonatal), comparisons are made on knowledge, skills, dais' reported general practice, dais' reported practice in last delivery, and client reports of dai practice in last delivery. Mean scores on the basic knowledge test are compared both overall and for specific portions of the test. Data on referral is analyzed for specific cases according to dai or client interviews, as appropriate. Data on other topics such as the usage of clean delivery kits and dai booklets, relations with Lady Health Workers (LHWs), and the dais' perceptions of the effect of their training, are analyzed in a separate section.

\section{Limitations and biases}

While the structure of the SMART project combined with the design of the Operations Research (OR) study has resulted in an assessment of dais who have, in effect, been randomly allocated to receive training or otherwise, the assessment tools were necessarily limited in various ways in determining whether there has been important change in the actual performance of the dais. It is important to bear in mind that there are several steps between training and performance based on training; knowledge superiority of trained dais on tests does not necessarily mean better performance. First, while we assume that all dais will try to do as well as they can on the knowledge and skills assessments, the trained dais have the advantage of terminology that they have been exposed to in the previous assessments, which provides familiarity with the expectations of the questions and procedures as well as knowledge based on the training. Second, there may also be tendency for trained or untrained dais, to report what they believe they should do rather than what they actually do. It may be assumed however, that the trained dais should have a better idea of what they should do, so their reported usual practice is likely to be positively biased to a greater extent than for the untrained dais. To some extent, this can be mitigated by asking about practice in last delivery, which is more specific and allows greater focus; but the bias probably still exists to some extent. Third, we anticipate that the clients, to the extent that they are not objective, are likely to report their dai in a favorable light. However, the clients of the trained dais live in villages subject to community education, so they may have had better knowledge of what to expect. (This should apply more to some questions - e.g, breastfeeding or warming the baby - than others, e.g., how 
to examine the baby.) In addition, the client was clearly in a physically and emotionally intense situation at delivery, and could not be expected to pay careful attention to the details of the dais' practice. To that extent, we might expect real differences between trained and untrained dais to be attenuated. How these various limitations combine to affect data accuracy doubtless varies among topics. At times we speculate on which limitations might particularly apply in a given situation, but readers will form their own opinions on how seriously to take these points.

While the limitations described above are potentially serious, the combination of different types of measures can also be a powerful check on the validity of the results. If, for example, a knowledge difference between groups is not reflected in differential practice by either trained or untrained dais, we may doubt that knowledge is effectively translated into behavior. If trained dais report both superior knowledge and practice, but that difference is not reflected in client reports, we may be skeptical. But if superior knowledge and skills of trained dais are reflected in better practice as reported by both dais and clients, this may be taken as strong evidence for a real difference in practice. 



\section{Results}

\section{Characteristics of Dais and Clients}

If the randomization of the communities was effective, we would expect that both the dais and their clients would be similar in terms of background variables. We have only a small amount of background information on each.

Table 1.1 shows the distribution of trained and untrained dais by age. More of the untrained dais were above 65 years old, as a result of which the mean age of untrained dais was 55 years, compared with 53 for trained dais; the difference is just significant at the .05 level $(p=.047)$.

Table 1.1: Percentage distribution of dais by age, according to training status

\begin{tabular}{lrr}
\hline Age group & $\begin{array}{r}\text { Trained } \\
(\mathbf{n = 2 7 6})\end{array}$ & $\begin{array}{c}\text { Untrained } \\
(\mathbf{n = 2 5 6})\end{array}$ \\
\hline Below 35 years & 2.9 & 2.0 \\
$35-39$ & 8.0 & 7.0 \\
$40-44$ & 10.9 & 9.0 \\
$45-49$ & 15.6 & 14.5 \\
$50-54$ & 15.9 & 11.3 \\
$55-59$ & 11.2 & 11.3 \\
$60-64$ & 15.9 & 17.2 \\
$65-69$ & 8.3 & 12.9 \\
Above 69 years & 11.2 & 14.8 \\
\hline
\end{tabular}

Table 1.2 shows the comparable distribution for the reference clients of the dais. Little systematic difference is apparent. The mean age of clients of trained dais is 25.6; of untrained dais, 25.8 (non-significant). 
Table 1.2: Percentage distribution of clients by age, according to training status of dai

\begin{tabular}{lcc}
\hline & \multicolumn{2}{c}{ Training status } \\
\cline { 2 - 3 } Client's age & 0.4 & $\begin{array}{c}\text { Clients of } \\
\text { trained dais }\end{array}$ \\
\hline Below 15 yrs & 13.6 & 0.9 \\
$15-19$ yrs & 27.6 & 14.2 \\
$20-24$ yrs & 26.8 & 22.3 \\
$25-29$ yrs & 17.2 & 33.5 \\
$30-34$ yrs & 11.6 & 18.0 \\
$35-39$ yrs & 2.8 & 8.6 \\
$40-44$ yrs & 0.0 & 1.7 \\
$45-49$ yrs & 100 & 0.9 \\
Total & $\mathbf{2 5 0}$ & 100 \\
No. of clients & & $\mathbf{2 3 3}$ \\
\hline
\end{tabular}

The distribution of clients by number of living children is shown in table 1.3. Although there appear to be more trained dais than untrained dais with five or more living children, and the mean for the trained dais is slightly greater (3.6) than for the untrained dais (3.4), the differences between the two distributions, and the two means, is not statistically significant.

Table 1.3: Percentage distribution of clients by number of living children, according to training status of dai

\begin{tabular}{ccc}
\hline Number of living children & Clients of trained dais & Clients of untrained dais \\
\hline 0 & 0.4 & 0.0 \\
1 & 20.4 & 24.6 \\
2 & 20.8 & 17.4 \\
3 & 15.6 & 14.4 \\
4 & 12.0 & 16.5 \\
5 & 7.6 & 11.0 \\
$>5$ & 23.2 & 16.1 \\
\hline Total & $\mathbf{1 0 0 . 0}$ & $\mathbf{1 0 0 . 0}$ \\
\hline No. of respondents & $\mathbf{2 5 0}$ & $\mathbf{2 3 6}$ \\
\hline
\end{tabular}

Education of clients served by the two groups of dais was also found to be quite similar. About 85 percent of clients of both trained and untrained dais had no formal education, whereas about 11 percent of both groups had primary education or above. These are 
similar to the general education level of married women of reproductive age in the study population in general (Arif et al., 2006). The home language of nearly 97 percent of clients was Seraiki, regardless of dai training status, with only about 2 percent speaking Balochi. This somewhat understates the proportion of Balochi speakers in these populations; perhaps the Baloch are more likely to be delivered by relatives rather than dais. In any case, clients are similar in both education and home language regardless of the training status of their dais.

Dais were asked how many deliveries they had conducted in the previous 6 months, both referred and not referred. Since they were selected in the same way from similar populations, it might be expected that they had similar numbers of clients. The researchers were, however, curious to know if the experience of being trained might have increased the clientele of the trained dais. The distribution by training status is shown in Table 1.4. The results do not indicate any significant difference in number of clients attended by trained and untrained dais for home deliveries (Details of referred cases are shown in the referral section). The distributions are similar; the means are 12.2 deliveries for trained dais, 12.0 for untrained ones (n.s.). The maximum number of deliveries for both trained and untrained dais is 106; this represents an extremely busy practice, but is not implausible. We will examine the referred cases separately.

Table 1.4: Percentage distribution of dais by number of deliveries in previous 6 months, according to training status.

\begin{tabular}{lrr}
\hline No. of deliveries & $\begin{array}{r}\text { Trained } \\
(\mathbf{n = 2 7 0 )}\end{array}$ & $\begin{array}{c}\text { Untrained } \\
(\mathbf{n = 2 5 5 )}\end{array}$ \\
\hline 0 & 5.6 & 5.1 \\
$1-4$ & 41.1 & 42.4 \\
$5-9$ & 19.3 & 21.2 \\
$10 /+$ & 34.1 & 31.4 \\
Mean number of deliveries & & \\
\hline
\end{tabular}




\section{Basic Knowledge Test}

A basic, 19-item knowledge test was administered to the trained dais four times:

immediately before and immediately after training, during the first follow-up, and during the OR interview for this study. The test was administered to the untrained dais only at the time of the OR interviews; but it should be expected that their aggregate scores should be very similar to those of the untrained dais prior to training. All 19 items were dichotomously correct or incorrect, so a dai's score on the test is a simple sum of her correct answers.

Table 2.1 shows the results of these five tests. First, the average score of the trained dais prior to training is nearly identical to the average for the untrained dais at the time of the OR interviews, i.e., slightly under 50 percent. Second, the scores of the trained dais for all three tests post-training are substantially higher than those of untrained dais $(\mathrm{p}<.01)$. The mean scores after training went from of 18.5 (97 percent) immediately after training to 16.9 (89 percent) at about 6 months to 15.7 (83 percent) at the OR interview after 19 months. Thus, the trained dais had retained about 70 percent of their increased gross knowledge at 19 months after training. Very few trained dais gave fewer than 10 correct answers at any time after training, whereas a majority of untrained dais, as well as trained dais before training, did so. Differences between trained and untrained dais at the time of the OR interviews are also highly significant.

Table 2.1: Percentage of trained and untrained dais by score on basic knowledge test according to at time of test

\begin{tabular}{lrrrrr}
\hline & \multicolumn{4}{c}{ Trained dais } & Untrained dais \\
\cline { 2 - 6 } Score range & $\begin{array}{r}\text { Before } \\
\text { training }\end{array}$ & $\begin{array}{r}\text { End of } \\
\text { training }\end{array}$ & $\begin{array}{r}\mathbf{6} \text { months } \\
\text { after training }\end{array}$ & $\begin{array}{r}\text { OR } \\
\text { interview }\end{array}$ & OR interview \\
\hline $0-4$ & 1.9 & 0.0 & 0.5 & 0.0 & 3.5 \\
$5-9$ & 57.5 & 0.0 & 1.0 & 3.3 & 50.6 \\
$10-14$ & 35.8 & 0.0 & 14.5 & 22.6 & 44.4 \\
$15-19$ & 4.9 & 100 & 83.9 & 74.1 & 1.6 \\
Mean & $\mathbf{9 . 3}$ & $\mathbf{1 8 . 5 ^ { * * }}$ & $\mathbf{1 6 . 9 * *}$ & $\mathbf{1 5 . 7}$ & $\mathbf{9 . 4}$ \\
No. of respondents & $\mathbf{2 6 8}$ & $\mathbf{2 6 8}$ & $\mathbf{1 9 3}$ & $\mathbf{2 7 4}$ & $\mathbf{2 5 7}$ \\
\hline
\end{tabular}

The trained dais scored significantly higher at the time of the OR interviews compared to the untrained dais on each individual item on this test (Table 2.2). Where the differences 
are relatively small, it is because the untrained dais already had high percentages of correct responses, leaving little room for improvement. For all other test items, differences were large.

Table 2.2: Percentage of Correct Scores for Trained and Untrained Dais on Basic Knowledge Test according to individual item, by training status

\begin{tabular}{|c|c|c|c|}
\hline \multirow[b]{2}{*}{ Test Item } & \multirow{2}{*}{$\begin{array}{l}\text { Correct } \\
\text { answer }\end{array}$} & \multicolumn{2}{|c|}{ Percent correct score } \\
\hline & & Trained & Untrained \\
\hline Proper way of drying hands after washing & In air & $89.8^{* *}$ & 18.3 \\
\hline Proper way of cutting the cord & New blade & $97.4^{* *}$ & 91.8 \\
\hline Should ghee, dung, or ash be applied to cord? & No & $81.4^{* *}$ & 36.6 \\
\hline Whether cord should be covered & No & $89.1^{* *}$ & 78.6 \\
\hline Whether colostrum is harmful to baby & No & $96.4^{\star *}$ & 73.2 \\
\hline Best first diet for baby & Colostrum & $96.4^{* *}$ & 54.5 \\
\hline Proper time for exclusive breastfeeding & 4-6 months & $86.5^{\star \star}$ & 65.0 \\
\hline Whether dai should examine mother internally & No & $44.2^{* *}$ & 5.1 \\
\hline Proper action if vomiting after 3 months of pregnancy & Refer & $89.0^{* *}$ & 70.0 \\
\hline Whether to pull cord if delivery of placenta is late & No & $91.2^{* *}$ & 65.4 \\
\hline Whether to push on abdomen to relieve labor pain & No & $90.5^{\star *}$ & 43.2 \\
\hline Whether to apply oil on birth canal to relieve labor pain & No & $87.2^{* *}$ & 26.2 \\
\hline \multirow[t]{2}{*}{ Whether to hold baby upside down and slap after birth } & No & $67.4^{\star \star}$ & 14.4 \\
\hline & Un-hygienic & & \\
\hline Common cause of tetanus & Cord cutting & $43.8^{* *}$ & 7.4 \\
\hline Whether to inject mother to accelerate delivery & No & $69.1^{* *}$ & 16.7 \\
\hline What to do if complication during delivery & Refer & $97.1^{*}$ & 93.4 \\
\hline Whether dai should help mother after delivery & Yes & $99.3^{* *}$ & 92.6 \\
\hline Proper treatment for diarrhea for children under 5 & ORS & $67.0^{\star *}$ & 22.2 \\
\hline Whether dai should advise mother about family planning & Yes & $94.1^{* *}$ & 63.4 \\
\hline No. of respondents & na & 274 & 257 \\
\hline
\end{tabular}

These results hold for each of the four main areas of evaluation: pregnancy, delivery, postpartum, and neonatal care.

Two of the 19 questions on the pretest were focused on this antenatal period. In both of these questions (examining the client internally, and proper action in case of vomiting), 
the trained dais responded with considerably more correct answers than the untrained dais.

Seven items related to delivery care: hand washing, cord cutting, whether to pull cord if delivery of placenta is delayed, whether to push on abdomen, whether to apply oil on birth canal, whether to inject mother to accelerate delivery, and what to do if complications develop. For all these questions, trained dais' score at the time of the OR interview were significantly higher for trained than for untrained dais; all were significant at the .01 level except for what to do if complication, for which significance was .05.

Two questions were asked regarding the postpartum period: whether the dai should help after delivery, and whether to advise on family planning. The trained dais scored significantly higher $(\mathrm{p}<.01)$ on both than the untrained dais; the difference regarding advice on family planning was substantial.

Seven questions primarily involved neonatal care: whether to apply substances to the cord, whether to cover the cord, whether colostrum is harmful, best first diet, proper time for exclusive breastfeeding, whether to hold baby upside down and slap after birth, and the common cause of tetanus. For all these questions, in the follow-up study the trained dais scored significantly higher $(\mathrm{p}<.01)$ than the untrained dais. For all questions except cord dressing (where more than 90 percent of even untrained dais answered correctly) the differences were substantial. The mean scores for the seven items combined were 5.6 for the trained dais and 3.3 for the untrained dais.

For assessing general knowledge, one question regarding the proper treatment for diarrhea was asked; knowledge of trained dais was significantly better than untrained dais.

About one fourth (24.5 percent) of trained dais got all questions right; no untrained dai did so. Conversely, 10.1 percent of untrained dais got 0 or 1 right answer, whereas only one trained dai did so poorly. 


\section{Antenatal Care}

\section{Knowledge}

Only about 54 percent of the rural women interviewed for the Pakistan Demographic and Health Survey 2006-7 had had at least one antenatal visit with a doctor, nurse, trained midwife, or lady health visitor (NIPS/DHS 2008). The training therefore included a substantial pregnancy component. The main components of the training were: understanding danger signs of pregnancy, identification of those danger signs, and appropriate care, including counseling and advice, during antental care.

\section{Danger signs in pregnancy}

There are several key danger signs during pregnancy, that dais need to recognize and act on quickly. These include: anemia, eclampsia, heavy bleeding, absence of fetal movement, high blood pressure, mal-position of the fetus, etc. Dais were asked to name (spontaneously) these danger signs of pregnancy. The data show that for each specific sign, the knowledge of the trained dais about pregnancy danger signs is better than that of the untrained dais. These differences are sometimes quite large, sometimes less so; of the 13 topics, the differences were significant or highly significant in 9. For example, almost three-quarters of the trained dais cited anemia as a major pregnancy danger sign, whilst less than half of the untrained dais did so; and two-thirds of the trained dais named heavy bleeding compared to only about a third of the untrained dais. However, for issues like high blood pressure or leukorrhea, the difference between the knowledge of trained and untrained dais was not so stark. Table 3.1 shows the results when dais were asked to spontaneously name pregnancy danger signs. 
Table 3.1: Percentage of dais spontaneously naming specified danger signs of pregnancy, by training status

\begin{tabular}{lrr}
\hline Knowledge topic & Trained & Untrained \\
\hline Anemia & $72.5^{* *}$ & 40.2 \\
Excessive vomiting (after third month) & $40.9^{* *}$ & 26.6 \\
Edema of face \& hands & $52.5^{* *}$ & 14.8 \\
High blood pressure & 11.2 & 6.6 \\
Mal-position of fetus & $35.1^{*}$ & 25.8 \\
Eclampsia & $37.7^{* *}$ & 11.3 \\
Heavy bleeding & $66.3^{* *}$ & 36.3 \\
Absence of, or decrease in, fetal movement & $14.5^{*}$ & 8.6 \\
Early rupture of membranes & 19.6 & 15.2 \\
Profuse vaginal discharge / Leucorrhoea & $22.8^{*}$ & 15.2 \\
Jaundice & $67.8^{* *}$ & 27.0 \\
Pneumonia or high temperature & 12.3 & 10.5 \\
Other (e.g. severe pain in legs, twins, placenta previa) & 14.1 & 13.7 \\
Don't remember & $0.4^{* *}$ & 16.8 \\
No. of respondents & $\mathbf{2 7 6}$ & $\mathbf{2 5 6}$ \\
\hline
\end{tabular}

${ }^{* *}=\mathrm{p}<.01 ;{ }^{*}=.01<\mathrm{p}<.05$.

Note: Percentages are greater than 100 percent due to multiple responses

Almost all (92 percent) of the trained dais knew three or more pregnancy danger signs, but only half of the untrained dais knew this many. Also, only 1 percent of the trained dais could not name a pregnancy danger sign, whilst 17percent of the untrained dais lacked any knowledge of pregnancy danger signs.

Figure 3.1: Percentage distribution of number of antenatal danger signs known, by training status

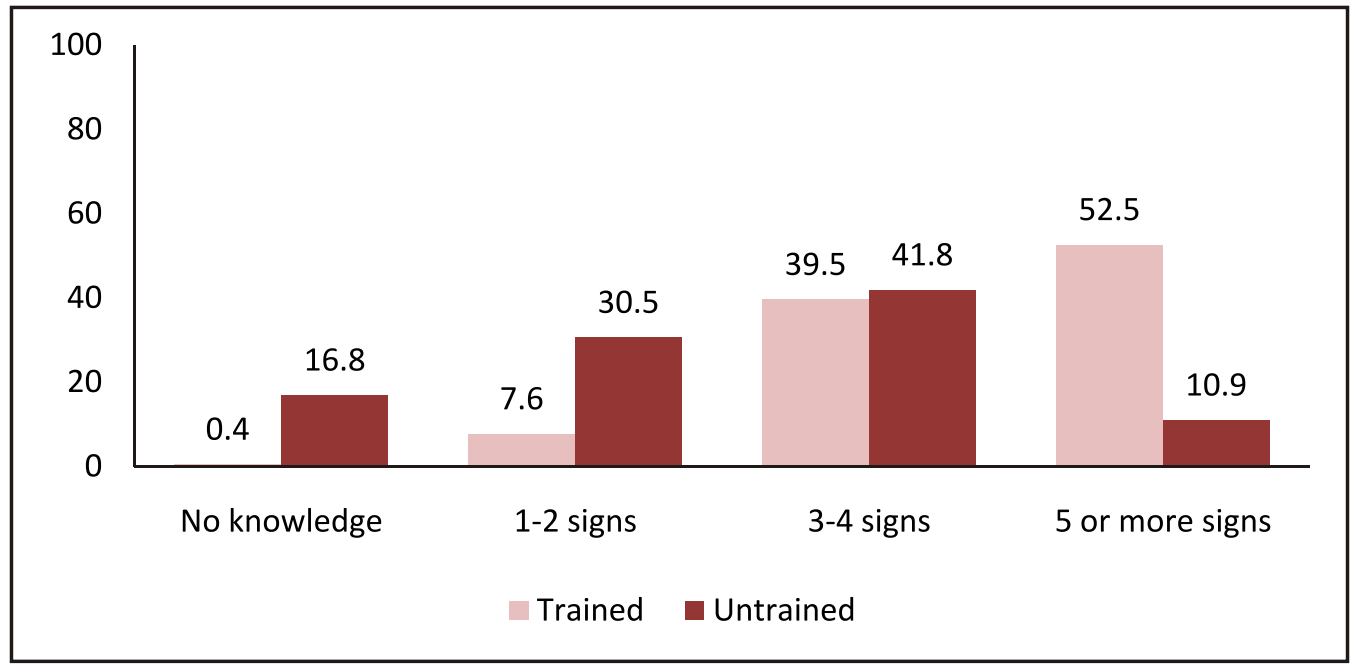




\section{Risk factors}

If a woman is likely to have complications during pregnancy or delivery, the pregnancy may be termed high risk. It is important that dais are aware of the concept of high risk, and that they are knowledgeable about the risk factors so that they take necessary precautions prior to, and during delivery. Dais were asked to name the high risk factors that they know. Table 3.2 shows the percentages of trained and untrained dais who spontaneously named different risk factors for pregnancy.

Table 3.2: Percentage distribution of specific antenatal risk factors spontaneously named by dais, by training status

\begin{tabular}{lcr}
\hline Risk factor & Trained & Untrained \\
\hline Age less than 18 years & $29.0^{* *}$ & 3.5 \\
Age more than 35 years & $38.8^{* *}$ & 3.1 \\
Height less than 5 feet & $44.2^{* *}$ & 3.5 \\
Previous Caesarian section & $8.0^{* *}$ & 1.6 \\
Abortion of the last pregnancy & 4.0 & 1.2 \\
Chronic disease & $27.5^{* *}$ & 8.2 \\
Small pubic bone & $54.7^{* *}$ & 27.6 \\
Stillbirth & 5.8 & 2.7 \\
More than 5 children & $15.2^{* *}$ & 0.0 \\
First pregnancy (primigravida) & $8.0^{* *}$ & 2.3 \\
Overweight & $10.5^{*}$ & 4.7 \\
Anemia & $58.7^{* *}$ & 23.7 \\
Others & 1.4 & 0.4 \\
Don't know & $7.2^{* *}$ & 54.9 \\
No. of respondents & $\mathbf{2 7 6}$ & $\mathbf{2 5 7}$ \\
\hline${ }^{* *}=$ p<.01; ${ }^{*}=.01<p<.05$. & &
\end{tabular}

Note: The total percentages add up to more than 100 percent due to multiple responses

Table 3.2 clearly illustrates that the training greatly increased the dai's knowledge of high risk factors for pregnancy. For each risk factor, a higher percentage of trained than untrained dais named that factor; in most cases, the differences were highly significant. For example, around a third of the trained dais could cite age (the pregnant woman being less than 18 years or greater than 35 years old) as a high risk factor, whilst only $3 \%$ of the untrained dais had the same knowledge. Also, more than half of the trained dais gave anemia as a high risk factor, whilst fewer than a quarter of the untrained dais did the same. 
Figure 3.2: Percentage distribution of dais by number of antenatal risk factors named, by training status

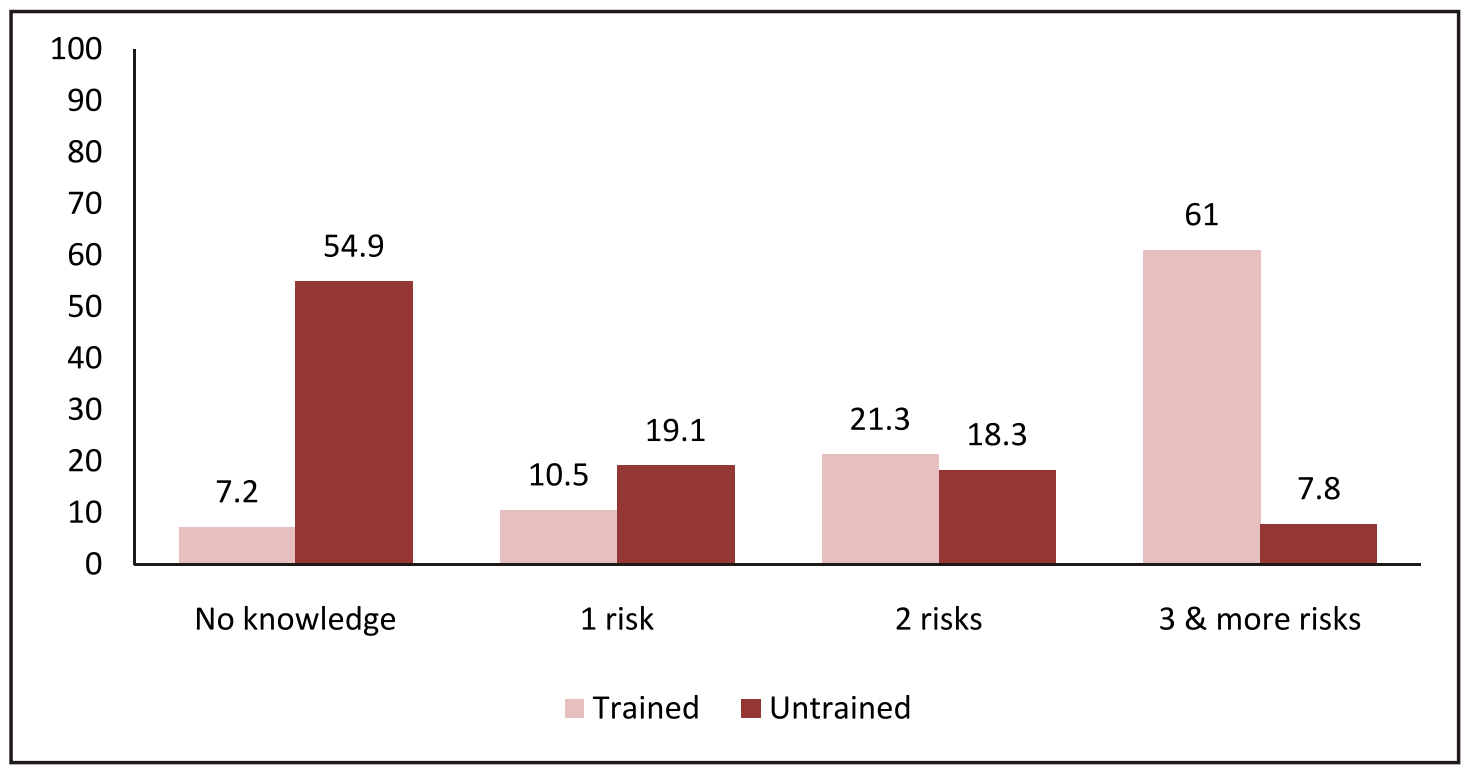

When cumulated (figure 3.2), 61 percent of the trained dais had spontaneous knowledge of three or more pregnancy risk factors, as compared to only 8 percent of the untrained dais. In fact, most of the untrained dais (55 percent) didn't know any pregnancy danger signs.

\section{Action in case of bleeding}

To obtain more detailed information on the level of dai knowledge, interviewers asked more specific questions on two important risk factors - bleeding and eclampsia.

Dais were asked about the immediate steps they would take in case their client was bleeding. The results, depicted in Table 3.3, show that while both trained and untrained dais know to refer, the trained dais were much more likely to know other important steps in the meantime. The trained dais were more aware of how to deal with bleeding, with about half of the dais saying they would raise their client's feet, and about half saying they would give her something to eat, as compared to 4.7 percent and 18.3 percent of the untrained dais respectively. A greater percentage of trained dais knew the more technical actions - such as putting the woman on her left side, keeping her warm, and monitoring the fetal heart rate - than untrained dais, although the percentages of trained dais is still low. 
Table: 3.3: Percentage distribution of dais' responses regarding immediate actions to take in case of bleeding, by training status

\begin{tabular}{lrr}
\hline Action & Trained & Untrained \\
\hline Raise foot end & $52.5^{* *}$ & 4.7 \\
Give something to eat & $46.7^{* *}$ & 18.3 \\
Put woman on her left side & $5.8^{* *}$ & 0.0 \\
Keep woman warm & $5.8^{* *}$ & 0.8 \\
Monitor fetal heart rate & 1.4 & 0.0 \\
Refer & $98.6^{* *}$ & 87.5 \\
Ask the family to arrange transport// money & $22.1^{* *}$ & 1.9 \\
Call the doctor to give injection & $10.5^{* *}$ & 21.4 \\
Others (e.g. don't do pelvis examination, & $5.8^{*}$ & 11.7 \\
$\quad$ accompany her, advise complete rest) & .0 & 0.8 \\
Don't know & $\mathbf{2 7 6}$ & $\mathbf{2 5 7}$ \\
No. of respondents & &
\end{tabular}

Note: The total percentages add up to more than 100 percent due to multiple responses

\section{Action in case of eclampsia}

Similarly, the trained dais were more knowledgeable about the immediate actions to be taken in case their client suffered from an eclamptic fit (Table 3.4). Again, most untrained dais as well as trained ones understood to refer, but the trained dais were much more likely to cite other appropriate actions. More than a third of the trained dais said they would place a wooden spoon between the woman's jaws, whilst less than 1percent of the untrained dais cited this action. More trained than untrained dais also knew about the need to tilt the woman's head, place a woman on her side, stop oral feeding (13 percent compared to 1 percent respectively), darken the room and ensure that it was quiet. Also notable was that 23 percent of the trained dais would arrange for transport and money immediately to refer the woman, whereas only 5 percent of the untrained dais would do the same. 
Table: 3.4: Dais' knowledge of immediate actions to take in case of eclampsia, in percentages

\begin{tabular}{lcc}
\hline Knowledge topic & Trained & Untrained \\
\hline Keep a spoon wrapped with cloth between jaws & $37.7^{* *}$ & 0.4 \\
Tilt the woman's head & $10.9^{* *}$ & 0.0 \\
Stop oral feeding & $12.7^{* *}$ & 0.8 \\
Darken the room & $8.0^{* *}$ & 0.0 \\
Make the room quiet & $8.0^{* *}$ & 0.0 \\
Lie the woman on side & $5.1^{*}$ & 1.2 \\
Monitor fetal heart rate & 0.4 & 0.4 \\
Refer & 95.3 & 91.8 \\
Provide mouth-to-mouth breathing & $5.1^{* *}$ & 0.0 \\
Arrange for transport and money immediately & $22.8^{* *}$ & 4.7 \\
Massage the palm \& sole of the woman & $13.8^{* *}$ & 1.2 \\
Other (e.g. gave pressure on her heart, call doctor for & 6.5 & 3.9 \\
giving injection and drip) & $0.7^{* *}$ & 7.0 \\
Don't' know & $\mathbf{2 7 6}$ & $\mathbf{2 5 6}$ \\
No. of respondents & &
\end{tabular}

Note: The total percentages add up to more than $100 \%$ due to multiple responses

\section{Skills}

During the skills test, dais were asked to focus on the main danger signs of the antenatal period - anemia, jaundice, swelling of the face and hands - and to demonstrate how they would perform an abdominal check-up.

Table 3.5 shows that most of the trained dais (61 percent) could spontaneously demonstrate the correct way of checking for anemia through the eyes, compared to only 12 percent of the untrained dais. A smaller percentage of trained dais checked the eyes, face, nails or palms incorrectly than the untrained dais (of the latter, 78 percent checked the eyes in an incorrect manner). For all these checks, trained dais were significantly more likely than the untrained dais to give a spontaneous, correct application of the check $(p<.01)$. 
Table 3.5: Percentage of dais demonstrating wrong, prompted correct and spontaneous correct responses on checking for anemia in a pregnant woman , by training status (no. of observations: trained $=275$, untrained $=255$ )

\begin{tabular}{lllllll}
\hline & \multicolumn{2}{c}{ No/ wrong } & \multicolumn{2}{c}{ Prompted correct } & \multicolumn{2}{c}{ Spontaneous correct } \\
\cline { 2 - 7 } Skill check & Trained & Untrained & Trained & Untrained & Trained & Untrained \\
\hline Eyes & 30.9 & 78.3 & 8.4 & 9.4 & $60.7^{* *}$ & 12.2 \\
Face & 12.7 & 43.5 & 45.5 & 27.5 & $41.8^{* *}$ & 29.0 \\
Nail & 15.7 & 55.3 & 41.2 & 29.4 & $43.1^{* *}$ & 15.3 \\
Palms & 16.4 & 53.3 & 54.2 & 31.4 & $29.5^{* *}$ & 15.3 \\
\hline
\end{tabular}

${ }^{* *}=p<.01$.

Similarly for jaundice, the trained dais were more likely to spontaneously demonstrate correctly how to check for jaundice, especially when checking the eyes (Table 3.6). The trained dais were less likely to check the dummy incorrectly.

Table 3.6: Percentage of dais demonstrating wrong, prompted correct and spontaneous correct checks for jaundice, by training status (no. of observations: trained = 275 , untrained $=254$ )

\begin{tabular}{lllllll}
\hline \multirow{2}{*}{ Skill check } & \multicolumn{2}{c}{ No/wrong } & \multicolumn{2}{c}{ Prompted correct } & \multicolumn{2}{c}{ Spontaneous correct } \\
\cline { 2 - 7 } & Trained & Untrained & Trained & Untrained & Trained & Untrained \\
\hline Eyes & 49.5 & 75.2 & 10.9 & 6.7 & $39.6^{\star *}$ & 18.1 \\
Face & 15.6 & 44.7 & 46.2 & 33.7 & $38.2^{\star *}$ & 21.6 \\
\hline
\end{tabular}

${ }^{* *}=p<.01$.

The swelling of the face and hands during pregnancy can be an indication of high blood pressure, which is a serious danger sign requiring referral for medical treatment. Dais were taught in the training how to check the hands and feet, and it seems that the effect of the training was positive; 47 percent of the trained dais could properly examine for the above as compared to only 11percent of the untrained dais. Correspondingly, fewer of the trained dais demonstrated the checking incorrectly (34 percent) as compared to the untrained dais (80 percent).

The trained dais consistently scored better on all aspects of the abdominal examination (Table 3.7). Significantly higher percentages of the trained dais could spontaneously demonstrate how to check the size of the uterus, check the position of the baby, examine the baby's heart beat, check for fetal movement, and check the height of the mother as compared to the untrained dais. 
Table 3.7: Percentage of dais demonstrating wrong, prompted correct and spontaneous correct procedures on abdominal checkup, by training status (no. of observations: trained $=\mathbf{2 7 5}$, untrained $=\mathbf{2 7 4}$ )

\begin{tabular}{lcrrrrr}
\hline & \multicolumn{2}{c}{ No/ wrong } & \multicolumn{2}{c}{ Prompted correct } & \multicolumn{2}{c}{ Spontaneous correct } \\
\cline { 2 - 7 } Skill checked & Trained & Untrained & Trained & Untrained & Trained & Untrained \\
\hline $\begin{array}{l}\text { Examined size of } \\
\text { uterus }\end{array}$ & 30.9 & 49.6 & 23.3 & 17.7 & $45.8^{* *}$ & 32.7 \\
$\begin{array}{l}\text { Examined position } \\
\text { of baby }\end{array}$ & 18.9 & 36.6 & 26.2 & 26.8 & $54.9^{* *}$ & 36.6 \\
$\begin{array}{l}\text { Examined } \\
\text { movement of baby }\end{array}$ & 18.5 & 37.3 & 42.5 & 42.0 & $38.9^{* *}$ & 20.8 \\
$\begin{array}{l}\text { Examined heart } \\
\text { beat of baby }\end{array}$ & 30.9 & 83.4 & 36.7 & 10.7 & $32.4^{* *}$ & 5.9 \\
$\begin{array}{l}\text { Examined height } \\
\text { of mother }\end{array}$ & 61.0 & 94.9 & 21.0 & 2.4 & $18.0^{* *}$ & 2.8 \\
\hline$* *=p<.01$. & & & & & &
\end{tabular}

\section{Usual practice}

\section{Antenatal checkup}

In rural Pakistan, reaching a health facility is difficult, and many women consider pregnancy as a normal and routine part of life. Consequently, ante-natal check-ups are not always prioritized; as previously noted, only a little more than half of pregnant women in Pakistan have even one antenatal visit. A local dai can help fill this gap. The SMART project therefore emphasized frequent antenatal visits by dais to their clients, a minimum of three or more. We asked the dais how often they usually go to examine their clients during pregnancy. In the OR interviews, the trained dais reported themselves to be significantly $(\mathrm{p}<.01)$ more likely to visit three or more times, and significantly less likely not to visit at all (Figure 3.3). 
Figure 3.3: Percentage of dais according to reported usual number of antenatal visits and by training status
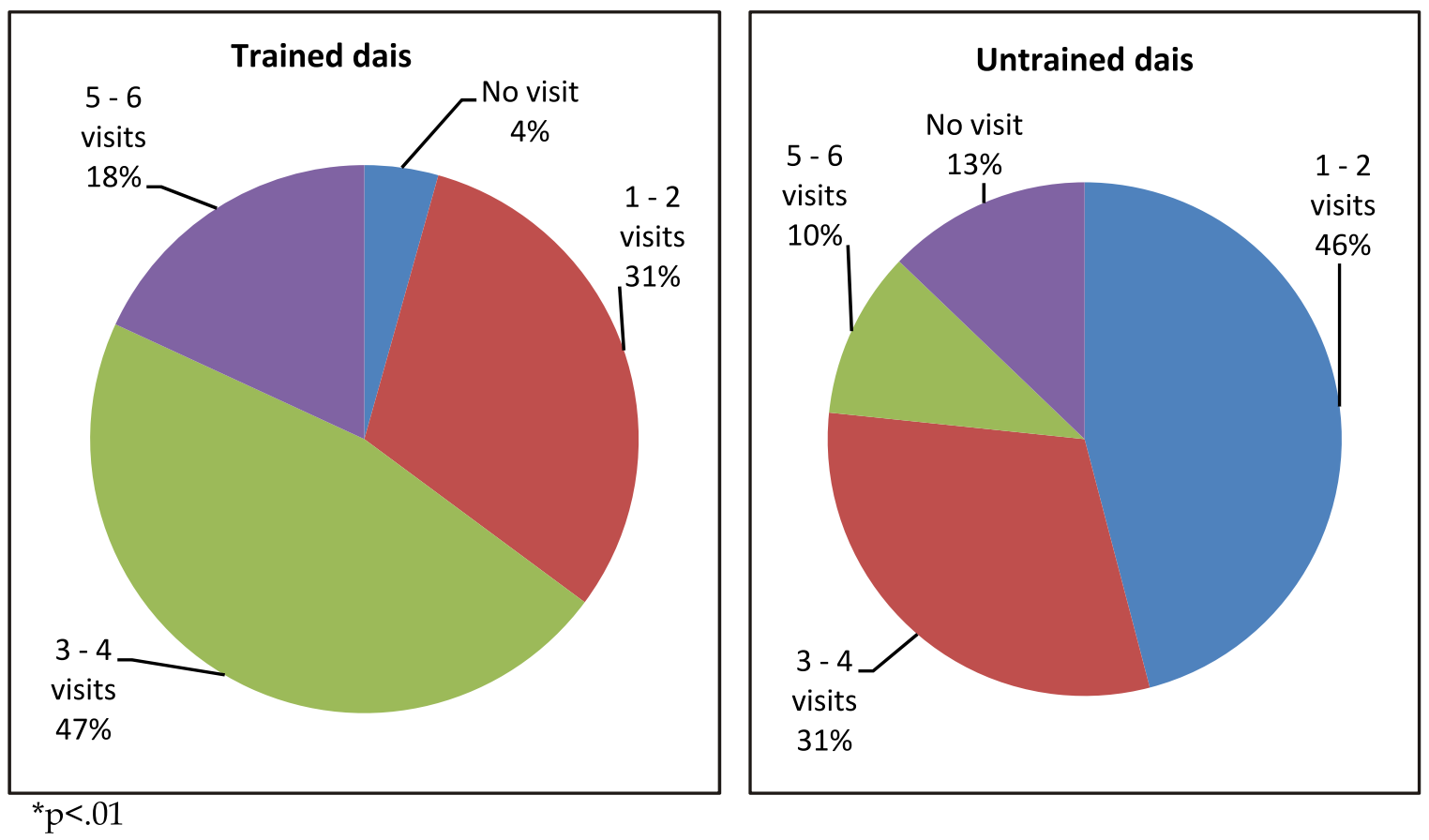

Normally, dais only visit a pregnant woman if she calls for confirmation of pregnancy, or if the pregnant woman has any difficulty during her pregnancy or delivery. In the training, dais were taught to visit all the pregnant women in their vicinity regularly during pregnancy. Table 3.8 shows that more than half of the trained dais usually do that, whilst around a third of the untrained dais went themselves to their clients.

Correspondingly, untrained dais are more likely to visit women only if they are called in case of a problem or when the client comes herself. Combined with the greater frequency of visits, this indicates a considerable improvement in the availability of antenatal care by dais. The difference in response patterns for the two groups is highly significant.

Table: 3.8: Percentage of dais according to reason for antenatal visits, according to training status.

\begin{tabular}{lcc}
\hline Method of meeting & Trained & Untrained \\
\hline I go myself & 55.7 & 36.4 \\
On client's call & 35.8 & 48.5 \\
Client comes herself & 8.5 & 14.3 \\
Others & 0.0 & 0.9 \\
No. of respondents & $\mathbf{2 7 1}$ & $\mathbf{2 3 1}$ \\
\hline
\end{tabular}


During training, dais were taught how to conduct a thorough antenatal check-up. Table 3.9 shows that a third of the trained dais conducted a general physical examination, whereas only a few of the untrained dais did so. Salient aspects of the training that appear in the table below are that the trained dais carry out a complete general exam head to foot and assess fetal heart rate during the antenatal visits much more frequently than the untrained dais. While the trained dais generally do a more thorough examination than the untrained ones, there is substantial scope for improvement, which should be addressed in future trainings.

Table: 3.9: Percentage of dais reporting individual components of antenatal check-up, by training status.

\begin{tabular}{lcc}
\hline Performed checkup & Trained & Untrained \\
\hline General physical examination from head to foot & $33.2^{\star *}$ & 5.7 \\
Assess the size of uterus & $44.6^{\star *}$ & 26.6 \\
Fetal position & $76.4^{\star *}$ & 61.9 \\
Fetal heart rate & $22.5^{\star *}$ & 7.4 \\
Fetal movement & $38.0^{* \star}$ & 16.0 \\
To confirm pregnancy & 9.2 & 5.3 \\
Expected date of delivery & 11.4 & 12.3 \\
Massage of legs & $63.8^{*}$ & 72.5 \\
Other (e.g. passage on abdomen, checked & 3.3 & 7.4 \\
swelling on hands and feet) & $0.0^{\star *}$ & 5.7 \\
Don't know & $\mathbf{2 7 1}$ & $\mathbf{2 4 4}$ \\
No. of respondents & &
\end{tabular}

$* *=\mathrm{p}<.01 ; *=.01<\mathrm{p}<.05$.

Almost all dais, both trained and untrained, gave a wide range of advice to pregnant women during the antenatal checkup. As Table 3.10 shows, the only remarkable difference between trained and untrained dais was that almost half of the trained dais suggested regular antenatal check-ups for the pregnant woman, as compared to less than a quarter of the untrained dais. The trained dais were also more efficient at providing advice regarding good diet (88 percent compared to 66 percent), and personal hygiene (21 percent compared to 6 percent). In the training, dais were taught to advise the pregnant woman on arrangements for delivery (e.g. to clean the delivery place, cloths for mother and child etc.), and to encourage the pregnant woman to arrange for transport and money in case of an emergency. Although the numbers were low, trained dais came out better 
than untrained dais on these categories. Several of the comparisons, while not less striking than desired, are highly signficant.

Table: 3.10: Percentage of dais by advice given to a pregnant woman during antenatal check-ups, by training status

\begin{tabular}{lrc}
\hline Advice & Trained & Untrained \\
\hline Regular antenatal check up & $44.0^{* *}$ & 21.9 \\
Diet & $88.3^{* *}$ & 66.0 \\
Personal hygiene & $20.9^{\star *}$ & 5.7 \\
Breast care & 2.2 & 0.4 \\
Rest /Exercise & $35.2^{* *}$ & 20.2 \\
Dress/Shoe & $7.3^{* *}$ & 0.8 \\
Travel & 2.6 & 0.8 \\
To avoid smoking drugs / X-ray during pregnancy & 4.4 & 1.2 \\
T.T vaccination & $78.0^{* *}$ & 62.8 \\
Preparation for delivery & $18.7^{* *}$ & 2.0 \\
Arrange for transport & $17.9^{* *}$ & 1.2 \\
Arrange for money & $7.0^{* *}$ & 0.4 \\
Avoid to lift heavy weight & $27.1^{*}$ & 18.2 \\
Avoid hot/spicy foods & 12.1 & 7.7 \\
Other (advice iron tablets, no advice, avoid & $4.8^{*}$ & 10.9 \\
intercourse) & $0.0^{* *}$ & 5.7 \\
Don't know & $\mathbf{2 7 3}$ & $\mathbf{2 4 7}$ \\
No. of respondents & & \\
\hline
\end{tabular}

${ }^{* *}=\mathrm{p}<.01 ;{ }^{*}=.01<\mathrm{p}<.05$.

Note: Percentages may be greater than $100 \%$ due to multiple responses

When asked specifically about sending the pregnant woman for a tetanus toxoid (TT) vaccination, most dais responded that they would do so. About 90 percent of trained dais said they would send the woman for a TT shot, compared with three-quarters of the untrained dais. 


\section{Practice during last pregnancy}

${ }^{1}$ Both trained and untrained dais were asked about whether they had seen a pregnant woman in the last six months who had suffered from bleeding during her pregnancy. Of these dais (51 of the 277 trained dais, and 31 of the 257 untrained dais), ninety percent of trained dais referred their clients, whilst only two-thirds of the untrained dais did so. As seen in Table 3.11, both trained and untrained dais gave something to eat or drink, but the percentage of trained dais was higher for this beneficial practice than the untrained dais. Also, the trained dais took more immediate actions at home that would benefit their client, including raising her foot (31 percent as compared to only 3 percent of the untrained dais), and giving milk or juice to drink (41 percent as compared to 26 percent). Trained dais were also more likely to assist the referral by helping arrange money or transport, and by accompanying the client. Because numbers are relatively small, however, not all these difference are statistically significant.

Table 3.11: Percentage of dais according to action taken when their client bled during pregnancy, by training status

\begin{tabular}{lrr}
\hline Action & Trained & Untrained \\
\hline Referred & $90.2^{*}$ & 67.7 \\
Raised the foot end & $31.4^{* *}$ & 3.2 \\
Gave milk or juice to drink & 41.2 & 25.8 \\
Arranged money/transport & 13.7 & 0.0 \\
Accompanied her on referral & 31.4 & 19.4 \\
Other & 9.8 & 25.8 \\
No. of observations & $\mathbf{5 1}$ & $\mathbf{3 1}$ \\
\hline
\end{tabular}

${ }^{* *}=\mathrm{p}<.01 ;{ }^{*}=.01<\mathrm{p}<.05$.

Note: Percentages add up to more than $100 \%$ due to multiple responses

As for eclampsia, very few trained (2) or untrained (1) dais had seen clients suffering from this condition in the last six months. In all three cases, the dais said they referred their client to the doctor for further treatment.

\footnotetext{
${ }^{1}$ Dais were asked a number of questions regarding the last non-referred delivery for which the respondent could be located. For simplicity, the term "last delivery" (or in this case, "last pregnancy") is used for these cases throughout this report, although some refer to a prior delivery.
} 


\section{Client Responses}

\section{Frequency and location of antenatal visits}

The clients of both trained and untrained dais were asked many questions regarding the dais' practice at their last childbirth, to cross-check the responses of the dais. Since these are the same deliveries as those reported by the dais as their "last delivery", they should in principle match by individual case as well as in aggregate.

First of all, clients were asked whether the dai visited them during their last pregnancy for pregnancy related problems (table 3.12). About two-thirds of the trained dais visited their clients during pregnancy, while about half of the untrained dais did so. These percentages are high, but not as high as when the dais self-reported (where only 4.3 percent of the trained and 12.8 percent of the untrained said they didn't visit their client). When the clients were asked what prompted the meeting, somewhat over half responded that the dais visited them without being called, regardless of training status; for untrained dais, this proportion was somewhat higher than they reported themselves. Differences in the circumstances of the meeting were not significant.

Table 3.12: Percentage distribution of client reports regarding dai visits during pregnancy, by dai training status

\begin{tabular}{|c|c|c|}
\hline Topic & $\begin{array}{l}\text { Clients of trained } \\
\text { dais }\end{array}$ & $\begin{array}{l}\text { Clients of untrained } \\
\text { dais }\end{array}$ \\
\hline $\begin{array}{l}\text { Meeting with dai in pregnancy } \\
\text { Met with dai }\end{array}$ & $65.9^{* *}$ & 52.7 \\
\hline No. of respondents & 252 & 237 \\
\hline \multicolumn{3}{|l|}{ Circumstance of meeting } \\
\hline Dai came herself & 53.3 & 53.6 \\
\hline Dai came on client's call & 23.0 & 27.2 \\
\hline Client went to dai & 15.8 & 8.8 \\
\hline Other & 7.9 & 10.4 \\
\hline No. of respondents & 165 & 125 \\
\hline
\end{tabular}


Figure 3.4 shows the number of antenatal visits by the dai during the last pregnancy. The client's reports are similar for trained and untrained dais, and broadly consistent with what was previously reported by the dais themselves. It appears that the difference in visitation between trained and untrained dais is mainly that more trained dais provide 1-2 visits rather than none.

Figure 3.4: Percentage distribution of dais according to frequency of antenatal visits, by training status, from client reports
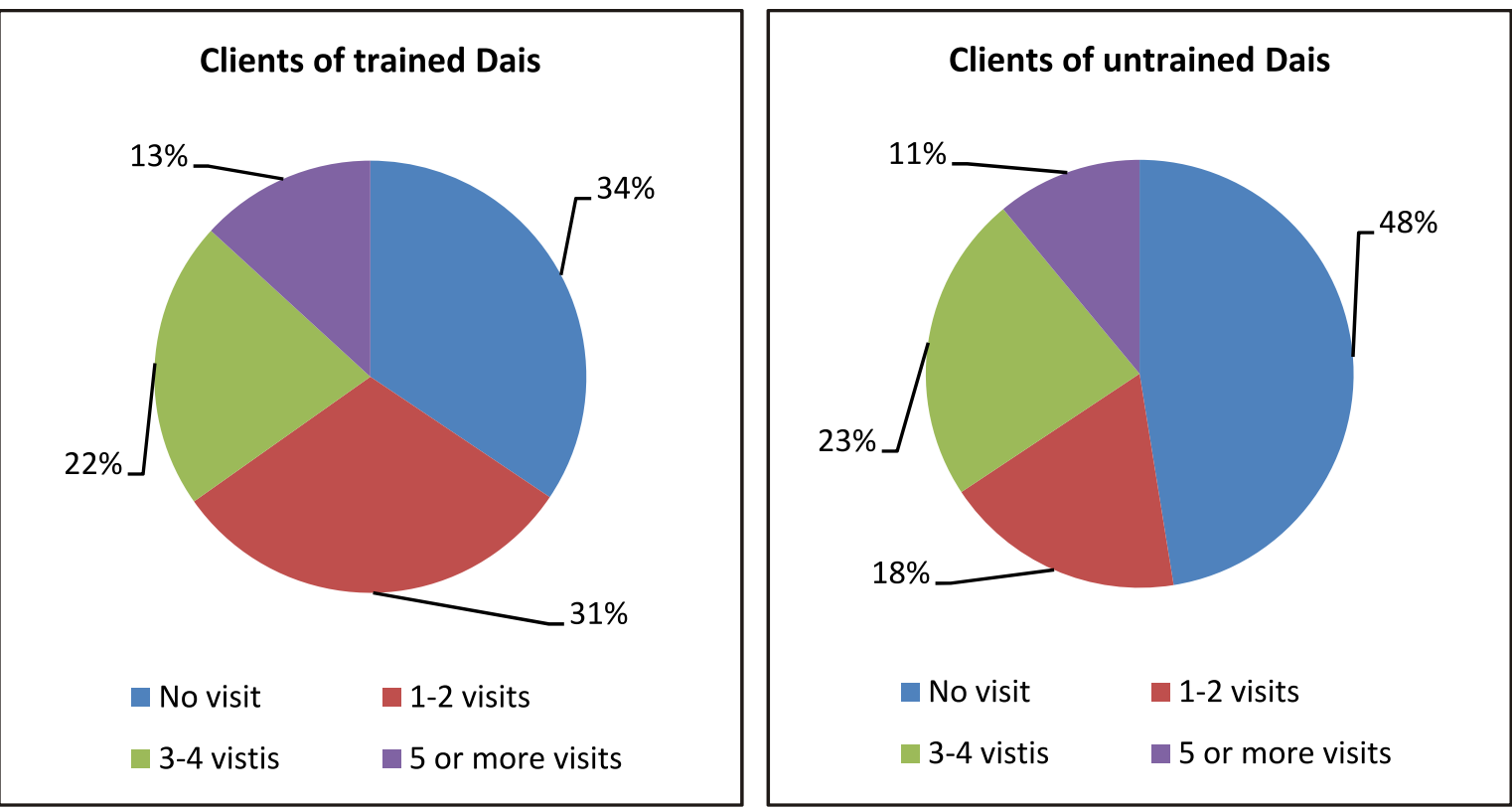

\section{Content of antenatal visits}

Clients were asked about what happened during the antenatal check-up. As Table 3.13 below shows, both the trained and untrained dais seemed to conduct similar checks, with the exception of body pains which the trained dais were more likely to deal with, and leg massage which the untrained dais were more likely to do. Since the clients tended to respond in more general terms than the dais, the responses of the two are difficult to compare. For example, clients of both trained and untrained dais reported abdominal checkups; but they do not report the content of those checkups. 
Table 3.13: Responses of clients of trained and untrained dais regarding the content of antenatal check-up, in percentages

\begin{tabular}{lcc}
\hline Reasons for meeting & Clients of Trained dais & Clients of Untrained dais \\
\hline Asked about general health & 27.9 & 25.6 \\
Body pain & 11.5 & 7.2 \\
Massage of legs & $66.7^{*}$ & 79.2 \\
Abdominal checkup & 47.3 & 48.8 \\
Lower abdominal pain & 16.4 & 12.8 \\
White discharge & 2.4 & 2.4 \\
Advises & 12.1 & 8.8 \\
Bleeding & 1.8 & 0.8 \\
False pains & 9.1 & 9.6 \\
Others & 5.5 & 2.4 \\
No of respondents & $\mathbf{1 6 5}$ & $\mathbf{1 2 5}$ \\
\hline$*=05$ & &
\end{tabular}

${ }^{*}=\mathrm{p}<.05$

When clients were asked about what kind of advice the dais provide during the antenatal check-ups, it seems that the trained dais performed significantly better on providing proper advice for the pregnant woman to take rest and to do gentle exercise, and not to lift heavy weights (table 3.14). Also, the trained dais performed better than the untrained dais at providing advice about proper diet. This is similar to what the dais self-reported.

Clients' responses vis-à-vis advice on arrangement for money ( 0.8 percent trained, 0 untrained) and transport ( 0.8 percent trained, 0.8 percent untrained) during the antenatal visits by the trained and untrained dai does not support the claim of trained dai regarding these items. This discrepancy could be because the dais talked with the main decisionmakers in the family regarding these arrangements, rather than with the pregnant woman herself. 
Table 3.14: Responses of clients of trained and untrained dais on advice provided by dai during antenatal visits, in percentages

\begin{tabular}{lcc}
\hline Advice & Clients of trained dais & Clients of untrained dais \\
\hline Regular antenatal check up & 33.1 & 31.3 \\
Diet & 71.7 & 61.5 \\
Personal hygiene & 5.5 & 0.0 \\
Breast care & 0.8 & 0.0 \\
Rest and gentle exercise & $26.8^{*}$ & 7.7 \\
Dress /Shoes & 0.8 & 1.5 \\
Travel & 0.8 & 0.0 \\
T.T vaccination & 7.9 & 3.1 \\
Advice for arrangement of money & 0.8 & 0.0 \\
Advice to keep arrangement for transport & 0.8 & 0.0 \\
Avoid to lift heavy weight & $32.3^{*}$ & 16.9 \\
Multivitamins, injections/tablets & 13.4 & 13.8 \\
Others (e.g. advice on referrals, advice to walk & 13.4 & 13.8 \\
etc) & & \\
Total No of respondents & $\mathbf{1 2 7}$ & $\mathbf{6 5}$ \\
\hline
\end{tabular}

${ }^{*}=.01<\mathrm{p}<.05$.

Note: Percentages may add up to more than $100 \%$ due to multiple responses

The clients were asked about whether their dais discussed, and gave advice on, minor problems of pregnancy. In general, there was not much difference in the responses of the clients of trained or untrained dais. In some instances - such as morning sickness - 23 percent of the clients of trained dais but only 11 percent of clients of untrained dais said that they had had such a discussion. Both the clients of trained and untrained dais (46 percent and 38 percent respectively) got advice about a varied and healthier diet in the case of mild anemia, and 4 percent of the trained dais gave their clients energy-giving medicines.

However, for the serious problems of pregnancy, the trained dais performed noticeably better according to their clients (table 3.15), although the numbers are small. Of the clients who reported severe anemia, almost half (44 percent) of the clients of trained dais said that their dais referred them to hospital, as compared to only 14 percent of the clients of untrained dais. Many more of the clients of trained dais (39 percent as opposed to 29 percent) were also provided with an energy-giving medicine. For the clients who were diagnosed with hypertension, all of those with trained dais were referred to hospital, compared to only two-thirds of the clients of untrained dais. 
Another stark difference was when the clients were diagnosed with mal-position of the fetus. A third of the clients of trained dais were advised to have an ultrasound, as opposed to only 14 percent of clients of untrained dais. When the clients had bleeding or spotting, 21 percent of those clients of trained dais were taken to hospital, as compared to only 7 percent of clients of untrained dais. These results clearly illustrate that the trained dais responded better to serious complications of pregnancy, as reported by the clients.

Table 3.15: Responses of clients of trained and untrained dais regarding action by dais in response to serious pregnancy complications, in percentages

\begin{tabular}{llcccc}
\hline & & \multicolumn{2}{c}{ Clients of trained dais } & \multicolumn{2}{c}{ Clients of untrained dais } \\
\cline { 2 - 5 } Complication & Action & Cases & \% acting & Cases & \% acting \\
\hline Severe anemia & $\begin{array}{l}\text { Referral to hospital } \\
\text { Provision of }\end{array}$ & 10 & 43.5 & 1 & 14.3 \\
Severe anemia & $\begin{array}{l}\text { energy-giving } \\
\text { medicine }\end{array}$ & 9 & 39.1 & 2 & 28.6 \\
Hypertension & $\begin{array}{l}\text { Referral to hospital } \\
\text { No fetal movement }\end{array}$ & 6 & 100.0 & 5 & 62.5 \\
Referral to hospital & 11 & 61.1 & 8 & 53.3 \\
No fetal movement & $\begin{array}{l}\text { Advised to get } \\
\text { ultrasound }\end{array}$ & 4 & 22.2 & 3 & 20.0 \\
Mal-position of fetus & $\begin{array}{l}\text { Referral to hospital } \\
\text { Advised to have }\end{array}$ & 8 & 53.3 & 3 & 42.9 \\
Mal-position of fetus & $\begin{array}{l}\text { ultrasound } \\
\text { Referral to hospital }\end{array}$ & 15 & 53.6 & 1 & 14.3 \\
Bleeding / spotting & $\begin{array}{l}\text { Took client to } \\
\text { hospital }\end{array}$ & 6 & 21.4 & 8 & 57.1 \\
Bleeding / spotting & & 53.3 & 1 & 7.1 \\
\hline
\end{tabular}

Table 3.16 shows that clients of trained and untrained dais reported that they mostly go for antenatal checkups to their dais, with more of the clients of trained dais saying they used the dais for checkups (non-significant). However, the clients of trained dais were more likely to visit a Rural Health Center (RHC) than the clients of untrained dais (5 percent of clients with trained dais compared to only 1percent of clients of untrained dais visited an RHC). These client responses show that trained dais were following the training and motivated the pregnant women for antenatal checkups in the nearest health facility. 
Table 3.16: Responses of clients of trained and untrained dais regarding sources of antenatal care, in percentages

\begin{tabular}{lcc}
\hline Source of antenatal care & Clients of Trained Dais & Clients of Untrained Dais \\
\hline Dai & 65.1 & 55.9 \\
LHW & 2.6 & 1.1 \\
LHV & 9.2 & 8.5 \\
BHU & 2.1 & 2.8 \\
RHC & $6.7^{*}$ & 1.1 \\
THQ & 0.0 & 1.1 \\
DHQ & 1.5 & 1.7 \\
Private hospital & 25.6 & 28.2 \\
Private Clinic & 21.5 & 21.5 \\
Others & 3.6 & 2.3 \\
No. of respondents & 195 & 177 \\
\hline
\end{tabular}

\section{Tetanus toxoid immunization}

Clients were asked whether they received advice on TT vaccination during the antenatal period. Their responses are recorded in figure 3.5 below, and table 3.17 shows the source of advice for the women who answered 'yes'. These tables show that the clients of trained dais were more likely to receive advice on getting TT vaccination (36 percent compared to 18 percent of clients of untrained dais, highly significant), and that the trained dais were more likely to be the source of this information ( 57 percent of clients of trained dais had received their information from the dais, as opposed to only 33 percent of the clients of untrained dais). When clients were asked about actually receiving TT vaccination, more clients of trained dais had been immunized, 69 percent compared to 61 percent of the clients of untrained dais (data not shown). 
Figure 3.5: Percentage of clients reporting advice received regarding TT vaccination, by dai training status

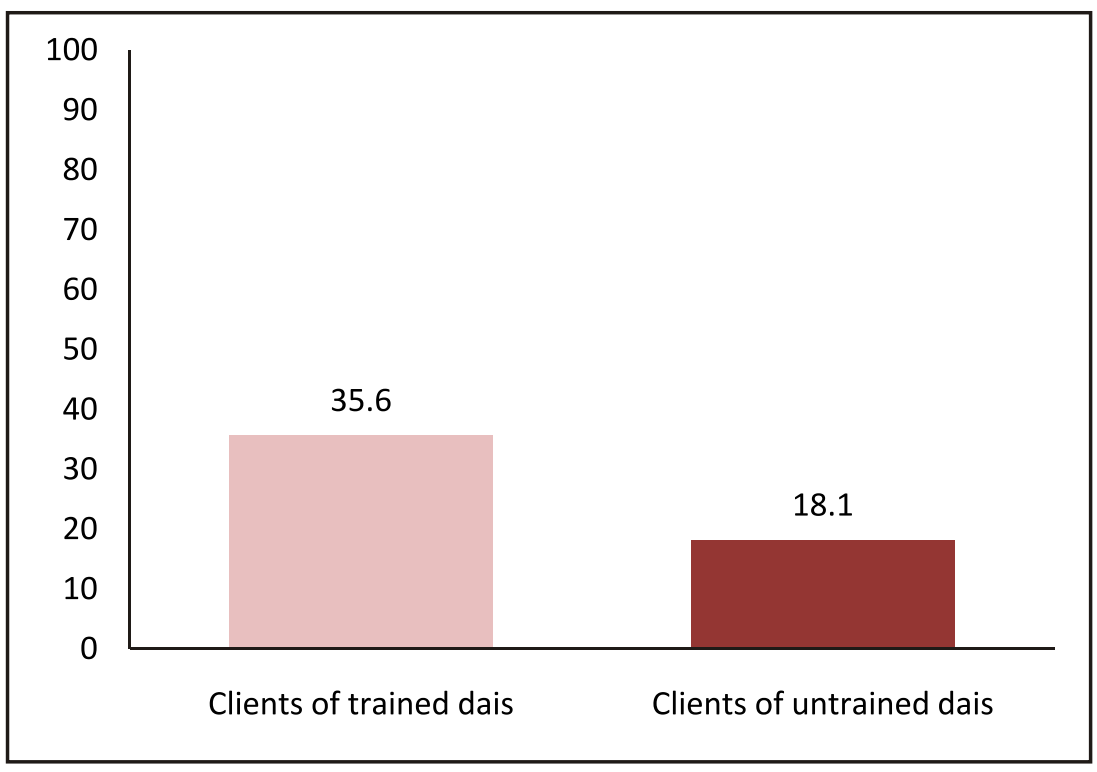

Table 3.17: Responses of clients of trained and untrained dais regarding the source of advice to get TT vaccination, in percentages

\begin{tabular}{lcc}
\hline Source of advice & Clients of trained dais & Clients of untrained dais \\
\hline Dai & $56.6^{*}$ & 32.6 \\
LHW & 19.3 & 25.6 \\
Husband & 1.2 & 4.7 \\
Male service provider & 7.2 & 7.0 \\
Advised by Mother-in-lawIRelative & 8.4 & 9.3 \\
Lady doctor & $1.2^{* *}$ & 11.6 \\
Others & 6.0 & 14.0 \\
No. of respondents & $\mathbf{8 3}$ & $\mathbf{4 3}$ \\
\hline
\end{tabular}

${ }^{* *}=\mathrm{p}<.01 ;{ }^{*}=.01<\mathrm{p}<.05$.

Table 3.18 shows that both the clients of trained and untrained dais had similar distributions of reasons for not getting vaccinated. However, the clients of trained dais were slightly less likely to report opposition of family members or no tradition as reasons for not getting the TT shot (non-significant). This could be because the trained dais supported the mother by providing advice to other family members on the importance of TT. 
Table 3.18: Responses of clients of trained and untrained dais regarding reasons for not receiving TT vaccination, in percentages

\begin{tabular}{lrr}
\hline Reason & $\begin{array}{c}\text { Clients of Trained } \\
\text { dais }\end{array}$ & Clients of Untrained dais \\
\hline Husband/Family members does not allow & 9.2 & 12.2 \\
No tradition & $12.5^{*}$ & 21.1 \\
Cheap cost & 53.9 & 51.7 \\
Poverty & 7.9 & 6.1 \\
Already completed course & $5.3^{* *}$ & 0.6 \\
Scared of abortion & 2.0 & 2.2 \\
Others (e.g. vaccination was not available in & & \\
hospital, or the vaccinator did not come to the & 16.4 & 9.4 \\
house) & & $\mathbf{1 8 0}$ \\
Total No of respondents & $\mathbf{1 5 2}$ & \\
\hline$* *=\mathrm{p}<.01{ }^{*}=.01<\mathrm{p}<.05$. & &
\end{tabular}

\section{Summary}

In all areas of comparison of the trained and untrained dais - knowledge, skills, usual practice, and client responses - the trained dais performed better than the untrained dais. The statistics show that the trained dais knew more about pregnancy danger signs than untrained dais - particularly for the important danger signs of bleeding and eclampsia and about what to do to deal with these danger signs. When the clients themselves were asked, as table 3.15 shows above, the trained dais had actually performed much better at providing good advice and referral to clients with these danger signs. Therefore, the training seems to be alleviating some of the aspects around the first two delays of the three delays model (see section on rationale). Dealing with serious danger signs seems to be an area of strength for the dai training, and that is a huge benefit in the context of Pakistan, where dais are normally the first port of call for a pregnant woman.

The training also was successful in increasing the dais' awareness of what high risk factors are for pregnancy, which again has implications for referral and avoiding bad outcomes in the delivery. During the skills section of the questionnaire, the trained dais performed much better than the untrained dais in checking for anemia, for jaundice, and performing an abdominal examination. Again, this is of great importance since dais are often the only ante-natal care provider for pregnant women. 
The trained dais were more likely to instigate the routine of providing ante-natal visits (as opposed to just being called by the woman because something was wrong). And although the percentages are low, Table 3.16 shows us that the clients of trained dais were more likely to also go to the nearest health facility for an ante-natal check-up. The trained dais were also better at providing advice about good diet, good hygiene and not lifting heavy weights. Although some of the trained dais self-reported that they would provide advice to the woman to arrange transport and money in case of an emergency, very few of the clients reported that the trained dais had given them such advice. This is an area of the training that could be strengthened.

While trained dais report performing a number of important assessments during antenatal checkups than untrained dais do, clients do not report much difference. One plausible explanation for this occurrence may be that the clients were not aware of the kind of technical checks the dais were performing and hence could not recognize and report them. Secondly it may be argued that the untrained dais under-reported the checks they do because they do not know the terminology. In any case, even the trained dais do not report carrying out many aspects of an antenatal examination as much as would be desirable. This

Aspect of the training may need to be improved upon in future endeavors. 


\section{Delivery Care}

The dai is the preferred health care provider for women during delivery in rural Pakistan; about two-thirds of the deliveries in the SMART project area were attended by dais (Population Council 2006). A primary task in the SMART dai training effort was to help the dais address such major causes of maternal mortality as hemorrhage, eclampsia, obstructed labor, and sepsis. The first three of these involve primarily ensuring that the dai is able to recognize the danger signs of these emergencies and ensure that the client reaches an appropriate emergency obstetric care facility. For sepsis, many key steps in prevention can be taken by the dai. In surveys of this type, it is not possible to document obstetric emergencies and responses to them. We therefore focused on the dais' knowledge of obstetric complications, her reported practices during the most recent nonreferred delivery, and the reasons and circumstances of recent referrals (described below in Section 7).

\section{Knowledge}

\section{Stages of labor}

The process of labor is divided into three stages. Differentiation of these stages is important for the efficient management of delivery. When these dais were asked about the number of stages of labor, 70 percent of the trained dais answered correctly that there were three stages of delivery, while fewer than a third (29 percent) of the untrained dais knew the correct number. The untrained dais may have knowledge and experience of labor as far as the process is concerned, but many of them would not know that these processes have been formally named as the stages of labor. All dais were asked to name the stages; 64 percent of trained dais and 27 percent of untrained dais named the stages correctly.

Table 4.1: Percentage of correct dai responses regarding stages of labor, by training status

\begin{tabular}{lcc}
\hline Topic & Trained & Untrained \\
\hline Correctly identified 3 stages of labor & $70.1^{* *}$ & 29.2 \\
Could name the stages of labor & $63.7^{* *}$ & 26.5 \\
No. of respondents & & $\mathbf{2 7 4}$ \\
\hline
\end{tabular}




\section{Complications of delivery}

Dais were asked to name (spontaneously) as many complications as they could of the three stages of labor. Table 4.2 shows the proportions able various complications. In general, although not in all cases, trained dais were more likely to name the various complications. Of particular note are the higher proportion of trained dais mentioning shock/unconsciousness, bleeding, fits/convulsions, retained placenta, and anemia/weakness (all statistically significant); these were generally areas of focus during the dai training. On the other hand, more untrained dais mentioned cord prolapse.

Table 4.2: Percentage of dais according to spontaneous reporting of complications of labor, by training status

\begin{tabular}{lcc}
\hline Complication & Trained dais & Untrained dais \\
\hline Cessation of labor pains & 24.0 & 24.7 \\
Cervical distotia & 49.8 & 51.0 \\
Malposition of fetus & $33.1^{*}$ & 24.7 \\
Rupture of membranes & 17.8 & 12.2 \\
Hydrocephalic baby & $13.8^{*}$ & 7.5 \\
Shock/unconsciousness & $65.5^{\star *}$ & 31.8 \\
Bleeding & $12.7^{* *}$ & 4.7 \\
Meconium-stained discharge & 1.5 & 0.4 \\
Fits/convulsions & $26.2^{* *}$ & 8.2 \\
Cord around baby's neck & 2.2 & 2.7 \\
Cord prolapse & 6.5 & 10.6 \\
Retained placenta & $44.7^{*}$ & 34.9 \\
Flaccid uterus & 1.5 & 0.0 \\
Laceration/tearing & 2.2 & 0.8 \\
Anemia/weakness & $25.5^{* *}$ & 11.4 \\
Other & 7.3 & 4.7 \\
Don't know & 2.2 & 11.4 \\
No. of observations & $\mathbf{2 7 5}$ & $\mathbf{2 5 5}$ \\
\hline ** $^{*}<01$ * $^{*}=01<\mathrm{p}<.05$ & &
\end{tabular}

** $=\mathrm{p}<.01 ;{ }^{*}=.01<\mathrm{p}<.05$

As figure 4.1 shows below, about one tenth of the untrained dais could not name a single delivery complication, while the comparative figure for the trained dais was only 2.5 percent. The other striking figure is that five in six trained dais as compared to slightly over half of the untrained dais could report three delivery complications or more. On average, trained dais could name 3.6 delivery complications, while untrained dais could name $2.5(\mathrm{p}<.01)$. 
Figure 4.1: Percentage distribution of numbers of delivery complications cited by dais, by training status

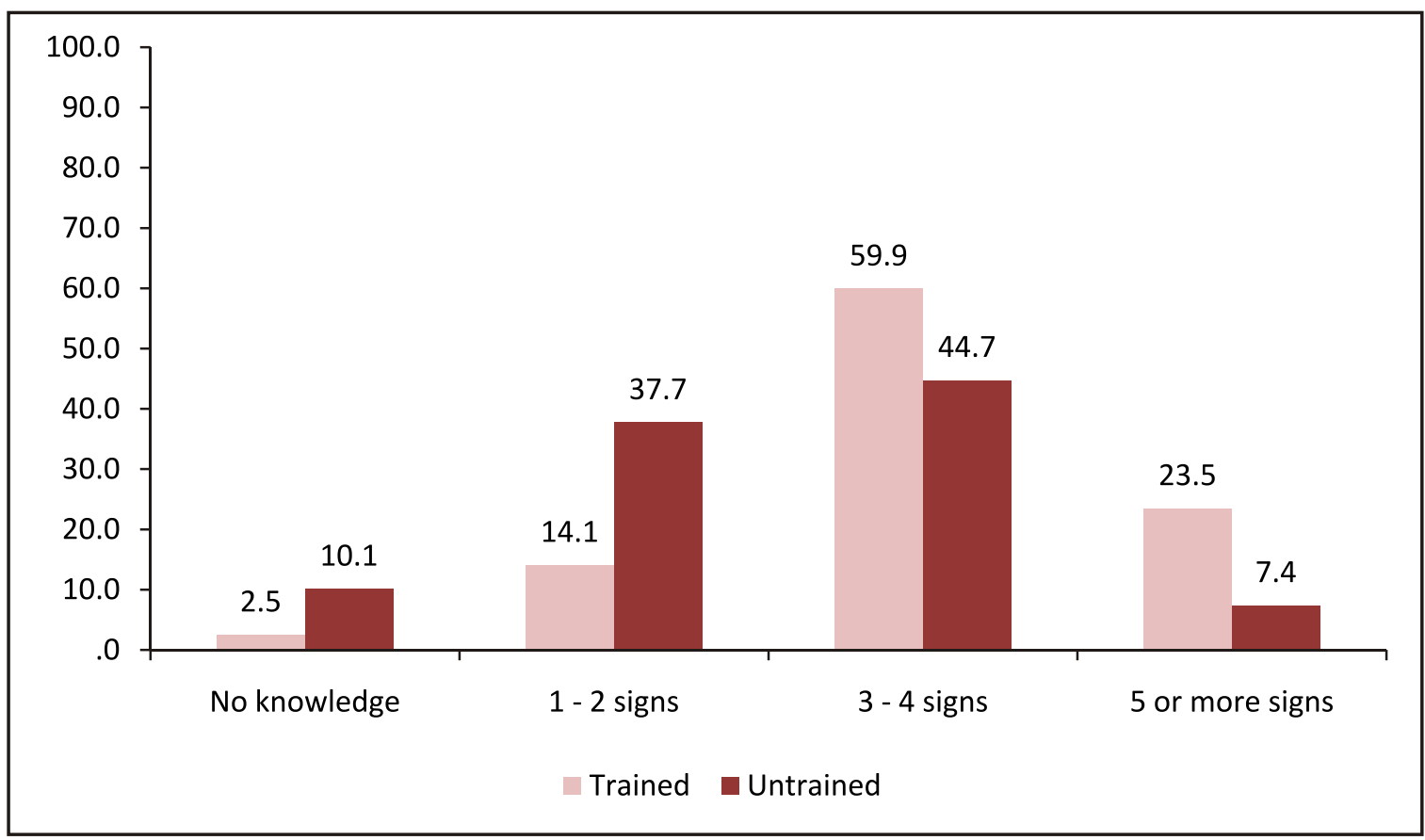

\section{Placenta management}

A question was asked about how the dai would help with the expulsion of the placenta, if it is not expelled completely. During training, they were advised to have the baby put to the breast, and to refer if unsuccessful. About one third of the trained dais but very few untrained dais stated that they would put the newborn to its mother's breast (table 4.3), and more trained than untrained dais say they would refer. Both trained and untrained dais reported a variety of other measures, some of which are ill-advised. For example, pulling the cord and removing the placenta manually should be avoided; fewer trained than untrained dais reported that they would do these things, particularly manual removal. 
Table 4.3: Percentage of dais, according to action, to be taken if placenta not completely expelled, by training status

\begin{tabular}{lrr}
\hline Action & Trained dais & Untrained dais \\
\hline Put baby to breast & $32.1^{* *}$ & $\mathbf{2 . 0}$ \\
Massage the lower abdomen with hand & $57.9^{* *}$ & $\mathbf{3 0 . 2}$ \\
Tie umbilical cord to the thigh of woman & $22.1^{* *}$ & $\mathbf{1 . 2}$ \\
Pull the cord & 21.0 & $\mathbf{2 7 . 8}$ \\
Manual removal & $11.8^{* *}$ & $\mathbf{4 8 . 2}$ \\
Refer & $55.4^{* *}$ & $\mathbf{3 0 . 6}$ \\
others & $5.9^{*}$ & $\mathbf{1 2 . 7}$ \\
No. of observations & 271 & $\mathbf{2 4 5}$ \\
\hline
\end{tabular}

${ }^{* *}=\mathrm{p}<.01 ;{ }^{*}=.01<\mathrm{p}<.05$

\section{Skills}

In the skills assessment, the dais were asked to demonstrate to the trainer the relevant practical tasks which they usually perform at the time of the delivery. The skills relating to delivery were hand washing, use of clean delivery kits, and certain aspects of conducting the delivery.

\section{Hand washing practice}

Dais were asked to demonstrate proper technique for washing hands; six actions were assessed (Table 4.4). For all six actions, the trained dais were more likely to perform correctly without prompting, to a highly significant degree. Correspondingly, more untrained dais did could not do these tasks, or did them wrong. However, while most of the trained dais performed several tasks correctly, about two-thirds did not know how to clean or cut their nails properly, even with prompting; this may need more attention in future trainings. Nevertheless, the large improvements over the untrained dais in applying soap and in rubbing, washing, and drying hands indicates an important difference in understanding of a basic aspect of hygiene. 
Table 4.4: Percentage of dais demonstrating wrong, prompted correct and spontaneous correct practices on hand washing prior to delivery, by training status (no. of observations: trained $=\mathbf{2 7 5}$, untrained $=\mathbf{2 5 1}$ )

\begin{tabular}{lrrrrrr}
\hline & No/Wrong & \multicolumn{3}{c}{ Prompted correct } & \multicolumn{2}{c}{ Spontaneous correct } \\
\cline { 2 - 7 } Practice & Trained & Untrained & Trained & Untrained & Trained & Untrained \\
\hline Nails cleaning & 66.9 & 94.4 & 1.5 & 2.0 & $31.6^{* *}$ & 3.6 \\
Nails cutting & 63.1 & 95.3 & 0.7 & 2.0 & $36.2^{* *}$ & 2.8 \\
Soap application & 3.0 & 6.4 & 37.8 & 70.1 & $59.3^{* *}$ & 23.5 \\
Hands rubbing & 7.5 & 10.7 & 45.9 & 87.7 & $46.6^{* *}$ & 1.6 \\
Hand washing & 0.0 & 1.6 & 42.9 & 76.1 & $57.1^{* *}$ & 22.3 \\
Hand drying & 0.4 & 5.7 & 14.0 & 84.6 & $85.7^{* *}$ & 9.8 \\
\hline$* *=p<.01$. & & & & & &
\end{tabular}

\section{Use of clean delivery kit}

Dais were trained in the use of a simple clean delivery kit (see section 8 below). Proper use of this kit is of considerable importance for a hygienic delivery. Dais were observed opening the kits, and putting on gloves. Table 4.5 shows that the trained dais were much better at opening the kits.

Table 4.5: Percentage of dais demonstrating wrong, prompted correct and spontaneous correct practices on use of clean delivery kit, by training status (no. of observations: trained $=264$, untrained $=248$ )

\begin{tabular}{lrrrrrr}
\hline & \multicolumn{2}{c}{ No/Wrong } & \multicolumn{2}{c}{ Prompted correct } & \multicolumn{2}{c}{ Spontaneous correct } \\
\cline { 2 - 7 } Variables & Trained & Untrained & Trained & Untrained & Trained & Untrained \\
\hline Opening of kit & 5.3 & 26.6 & 41.7 & 58.1 & $53.0^{* *}$ & 15.3 \\
Wearing of gloves & 25.0 & 53.7 & 25.0 & 31.3 & $50.0^{* *}$ & 15.0 \\
\hline$* *=p<01$
\end{tabular}

\section{Delivery practices}

Table 4.6 shows results of three additional aspects of delivery skill; spreading the plastic sheet included in the clean delivery kit; providing support to the perineum; and examining the placenta for complete expulsion. A clean surface used for delivering a woman is important in preventing infection. Seventy percent of the trained dais could spread the plastic sheet correctly compared with 32 percent of the untrained dais.

Providing support to perineum is very important to avoid trauma to both mother and the newborn during delivery. Only about one-fourth of trained dais and 8 percent of the untrained dais could demonstrate spontaneously the correct method of supporting the 
perineum during delivery; 61 percent of trained dais and 79 percent of untrained dais performed this task wrongly or not at all. On the important task of examining the placenta, however, most trained dais performed correctly, while most untrained dais did not.

Table 4.6: Percentage of dais demonstrating wrong, prompted correct and spontaneous correct practices selected aspects of delivery, by training status (no. of observations: trained $=265$, untrained $=250$ )

\begin{tabular}{lrrrrrr}
\hline & \multicolumn{2}{c}{ No/Wrong } & \multicolumn{2}{c}{ Prompted correct } & \multicolumn{2}{c}{ Spontaneous correct } \\
\cline { 2 - 7 } Practice & Trained & Untrained & Trained & Untrained & Trained & Untrained \\
\hline Spreading plastic sheet & 24.1 & 46.8 & 5.7 & 21.4 & $70.1^{* *}$ & 31.9 \\
Support to perineum & 60.8 & 79.2 & 12.1 & 13.2 & $27.2^{* *}$ & 7.6 \\
Examination of placenta & 10.7 & 32.5 & 19.9 & 38.2 & $69.3^{* *}$ & 29.3 \\
\hline$* *=p<.01$. & & & & & &
\end{tabular}

While the trained dais performed these skills consistently better than the untrained dais, there remain some important areas for which their skills need improvement. This suggests another area for further training such as refresher courses given at regular intervals. It also could be improved through formal supervision. It is important to recognize that these women have long been practicing a set of routines that to some extent define their expertise.

To replace these with best practices on a sustained basis will require more than a single training.

\section{Practice during last delivery}

Dais were asked, without prompting, what preparations they took before the last delivery. They then asked what steps they took during the delivery, first without prompting, then on being prompted with a list of 15 possible steps.

Table 4.7 shows the responses regarding preparations at home prior to the last delivery. Trained dais were more likely to perform most preparations than untrained ones; of particular interest are the large differences in washing hands, bringing a clean delivery kit, and cutting nails. Untrained dais are more likely to report bringing supplies other than the clean delivery kit. In some cases, this represents materials that would have been 
found in the clean delivery kits, such as blades or cotton; in other cases, it represents unnecessary supplies. A high proportion of untrained dais report no special preparation.

Table 4.7: Percentage responses of dais regarding preparations at home before last delivery, by training status

\begin{tabular}{lcc}
\hline Preparation & Trained dais & Untrained dais \\
\hline Removed bangles & $10.2^{* *}$ & 0.4 \\
Removed rings & $9.4^{* *}$ & 0.0 \\
Cut nails & $18.4^{* *}$ & 0.4 \\
Cleaned teeth & 1.5 & 0.4 \\
Wrapped hair & 4.1 & 1.6 \\
Washed hands & $50.0^{* *}$ & 11.3 \\
Took clean delivery kit & $53.8^{* *}$ & 0.0 \\
Changed clothes & $24.4^{* *}$ & 8.9 \\
Took gloves & 10.9 & 10.5 \\
Brought herbs (?) & 3.4 & 5.2 \\
Brought spirit, Dettol & 1.1 & 2.4 \\
Brought other supplies & 6.8 & 11.7 \\
Other & 2.6 & 6.5 \\
Did nothing & $12.8^{* *}$ & 60.5 \\
No. of respondents & $\mathbf{2 6 6}$ & $\mathbf{2 4 8}$ \\
\hline ** $=$ p<.01. & &
\end{tabular}

${ }^{*}=p<.01$.

For table 4.8, dais were asked about the steps usually taken during delivery. For those steps not named spontaneously, they were asked if they take any of 15 specific steps. While in general trained dais reported better practice than untrained ones, the differences were mostly not large. Trained dais, recalling their training, might be more likely to report practice spontaneously, but this was not the case to any great extent. In a few areas involving unnecessary and perhaps harmful attempts to assist or hasten labor, however, the trained dais were likely to report not doing the practice, significantly more so than the untrained dais. Two common dai practices of particular importance, namely performing pelvic examinations and giving injections, were followed up with additional questions, and are discussed below. 
Table 4.8: Percentage of dais by usual steps at delivery reported sponanteously, after prompting, or not usually taken, by training status

\begin{tabular}{|c|c|c|c|c|c|c|}
\hline \multirow[b]{2}{*}{ Step usually taken } & \multicolumn{3}{|c|}{ Trained dais } & \multicolumn{3}{|c|}{ Untrained dais } \\
\hline & $\begin{array}{c}\text { Yes } \\
\text { Spont. }\end{array}$ & $\begin{array}{c}\text { Yes } \\
\text { Prompted }\end{array}$ & No & $\begin{array}{l}\text { Yes } \\
\text { Spont. }\end{array}$ & $\begin{array}{c}\text { Yes } \\
\text { Prompted }\end{array}$ & No \\
\hline Give reassurance & 60.0 & 33.8 & 6.2 & 60.0 & 32.9 & 7.1 \\
\hline Give food & 30.5 & 48.4 & 21.1 & 24.3 & 49.4 & 26.3 \\
\hline Ask client to walk & 9.5 & 63.0 & 27.5 & 8.3 & 60.7 & 31.0 \\
\hline Perform pelvic examination & $67.5^{\star *}$ & 8.2 & 24.3 & 81.0 & 7.3 & 11.7 \\
\hline Give injection & $8.9^{* *}$ & 12.0 & 79.1 & 22.8 & 12.2 & 65.0 \\
\hline Massage abdomen with oil/ghee & $7.0^{* *}$ & 16.1 & 76.9 & 15.9 & 37.3 & 46.8 \\
\hline Apply medicine within vagina & $2.6^{* *}$ & 8.2 & 89.1 & 14.6 & 31.5 & $53 . c$ \\
\hline Apply pressure on abdomen & $1.9^{* *}$ & 10.0 & 88.1 & 3.5 & 32.8 & 63.7 \\
\hline Ask client to bear down in $1^{\text {st }}$ stage & $1.1^{* *}$ & 10.3 & 88.6 & 1.2 & 29.8 & 69.0 \\
\hline Apply perineal support at delivery & $6.2^{* *}$ & 65.0 & 28.8 & 1.2 & 67.3 & 31.5 \\
\hline Check fetal position & 24.7 & 56.7 & 18.5 & 18.9 & 58.7 & 22.4 \\
\hline Check preparation for delivery & $12.0^{*}$ & 65.3 & 22.6 & 6.3 & 65.5 & 28.2 \\
\hline Ask woman to sit on foot & $3.7^{* *}$ & 33.7 & 62.6 & 4.8 & 59.4 & $35 . c$ \\
\hline $\begin{array}{l}\text { Check duration of contractions } \\
\text { (hand on abdomen) }\end{array}$ & 20.8 & 50.7 & 28.5 & 17.5 & 51.4 & 31.1 \\
\hline Ask client to empty bladder/bowel & $5.8^{*}$ & 54.5 & 39.6 & 3.9 & 44.1 & 52.0 \\
\hline No. of observations & 275 & 275 & 275 & 256 & 256 & 256 \\
\hline
\end{tabular}

\section{Pelvic examinations}

Pelvic examination is an important step in assessing the progress of labor. However, some protocols should be followed, including the maintenance of aseptic measures through the use of gloves, and not performing it too frequently. The SMART project, concerned about the risk of sepsis, advised the dais not to perform pelvic examinations at all. It also trained them to wear gloves from the clean delivery kits whenever in contact with the client's vagina. Ideally, then, the dais should not have performed pelvic examinations; but if they were to be performed, gloves should have been worn. The least desirable procedure would be performing several pelvic examinations without gloves. Those dais who reported usually performing pelvic examinations were asked if they performed it in the last delivery; if so, whether they wore gloves. Table 4.9 reports the results. Substantially more trained than untrained dais reported not performing the 
examination, or performing it with gloves; as a result, fewer than one-fifth of trained dais reported performing a pelvic examination at the last delivery without gloves, whereas two-thirds of the untrained dais reported doing so. The differences are highly significant.

Table 4.9: Distribution of dais according to practice of pelvic examination, by training status

\begin{tabular}{lrrrr}
\hline \multirow{2}{*}{ Pelvic examination practice } & \multicolumn{2}{c}{ Trained dais } & \multicolumn{2}{c}{ Untrained dais } \\
\cline { 2 - 5 } & No. & Pct. & No. & Pct. \\
\hline None & 62 & 24.4 & 29 & 11.6 \\
Yes, with gloves & 146 & 57.5 & 54 & 21.7 \\
Yes, without gloves & 46 & 18.1 & 166 & 66.7 \\
Total & 254 & 100.0 & 249 & 100.0 \\
\hline
\end{tabular}

Dais were also asked how many times they usually did pelvic examinations, and how many times they did so during the last delivery. Figures 4.2 and 4.3 below show the responses of trained and untrained dais regarding these questions. Both trained and untrained dais tend to report examining the birth canal less often in the last delivery than is their usual practice. Trained dais are significantly less likely to perform the examination at all, and less likely to examine three or more times. The mean number of times the examination was performed by trained dais at the last delivery was 1.11 ; by untrained dais $1.75(\mathrm{p}<.01)$. The difference between the overall distributions is also highly significant, both for usual practice and for practice during last delivery.

In discussions with the dais during a refresher training after these interviews, many trained dais reported that it was difficult for them not to do pelvic examinations, both because they helped the dais understand the course of labor, and because giving the examinations demonstrated their competence to the clients. Many said they reduced the number of such examinations, and were careful to use gloves (as borne out in these data). Upon reflection, the project therefore revised the instruction to the dai, to permit a single pelvic examination if sterile gloves were available. As this revision was made after the OR interviews were conducted, the effect of this revision in standards has not been evaluated. 
Figure 4.2: Distribution of dais by number of times usually performing pelvic examinations, by training status

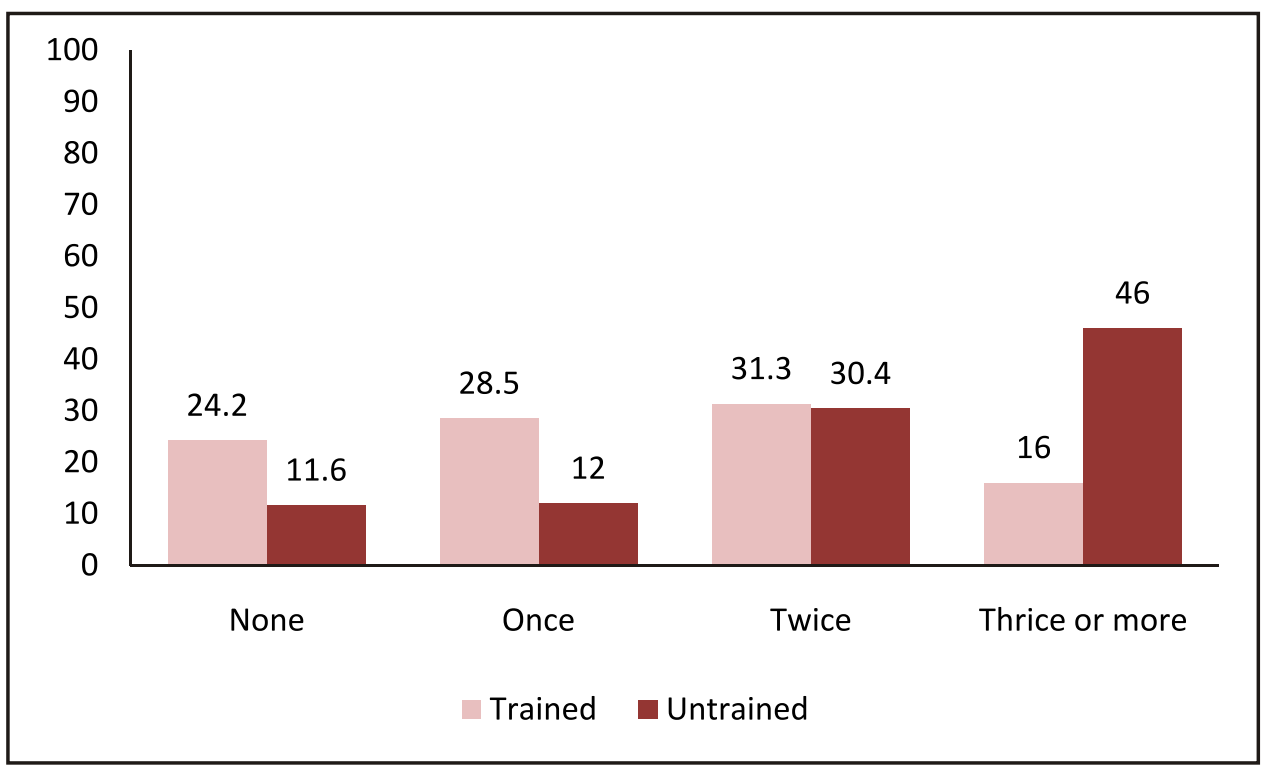

Figure 4.3: Distribution of dais by number of times pelvic examinations performed during last delivery, by training status

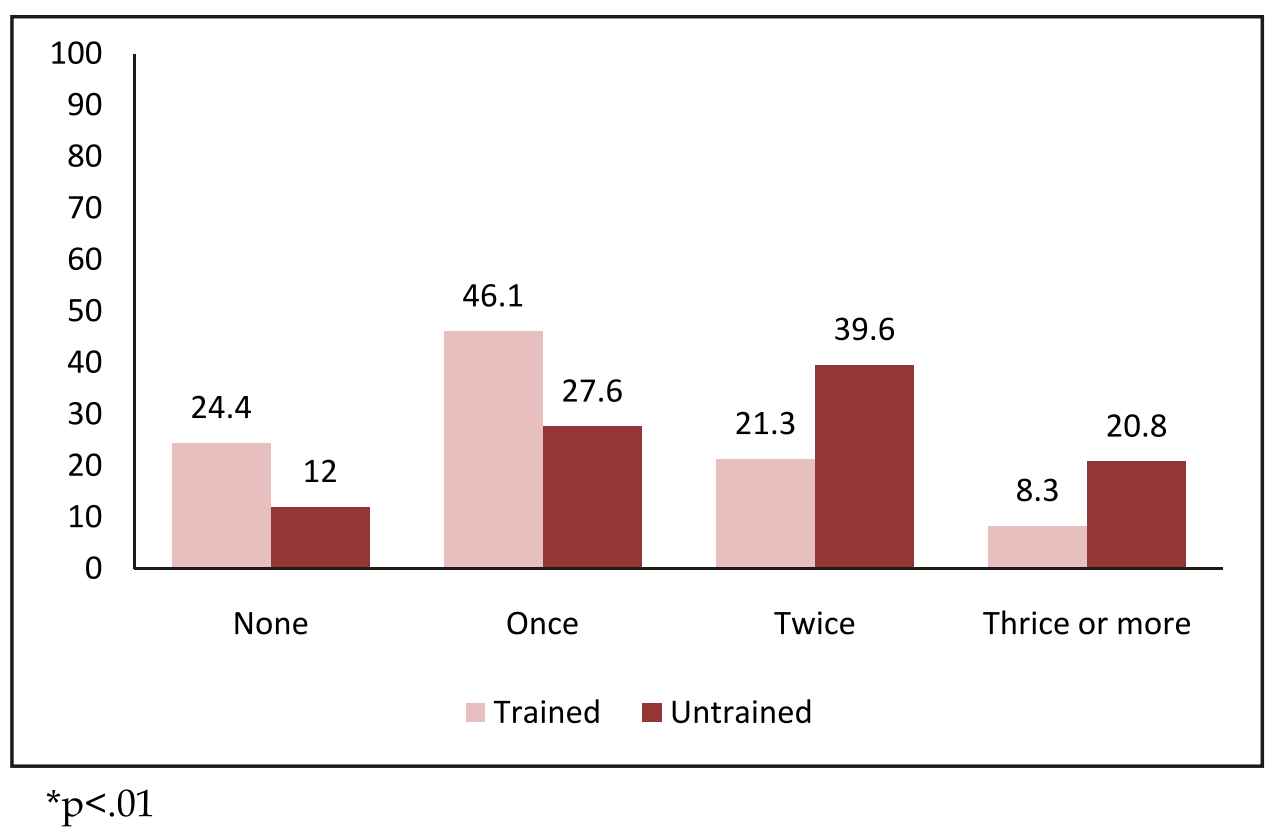

\section{Injections during labor}

Dais in DG Khan also frequently arrange for injections to be given during second stage labor, often by local health dispensers. This is usually for the purpose of shortening the 
duration of labor (typically Syntocinon) or to give energy (typically Neurobion). This is potentially quite dangerous, at worst leading to uterine rupture. Dais were therefore trained not to give injections during second stage of labor. (The use of uterotonics for management of third stage labor was not addressed in this project.)

Figures 4.4 and 4.5 below present a comparison of the dais' responses for the usual number of injections given and the number given during the last delivery. In general, the trained dais reported being more likely not to give injections, and to give fewer when they did. However, the trained dais were less likely to report not giving injections during the last delivery than in reporting their usual practice, suggesting that they may be reluctant to report a practice that they have been trained not to do. In over 90 percent of cases for both trained and untrained dais, injections were given to shorten labor; for 46 percent of trained dais and 64 percent of untrained dais, injections were also given to provide energy to the client (data not shown). Injections in general are popular in Pakistan (as in many countries), and if this practice is to be discontinued, a broader understanding of its dangers among health providers and clients is probably necessary.

Figure 4.4: Distribution of dais by number of times usually giving injections, by training status

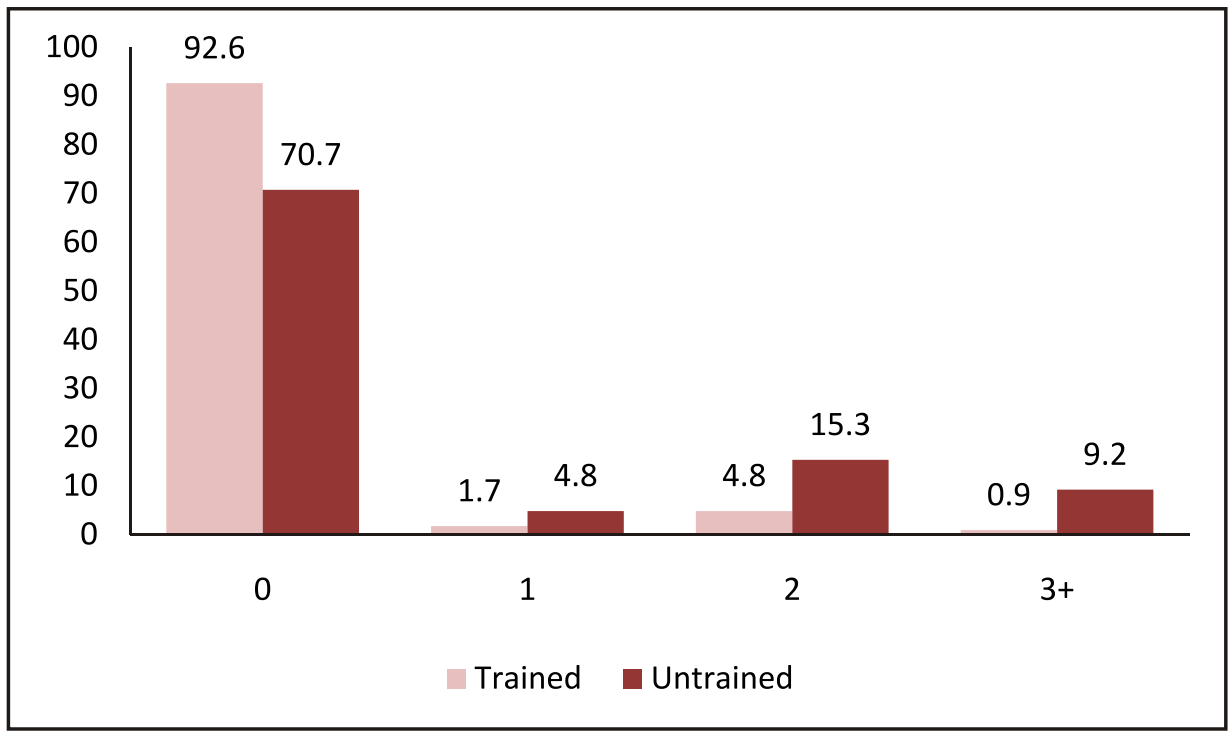

$P<.01$ 
Figure 4.5: Distribution of dais by number of times injections given during last delivery, by training status

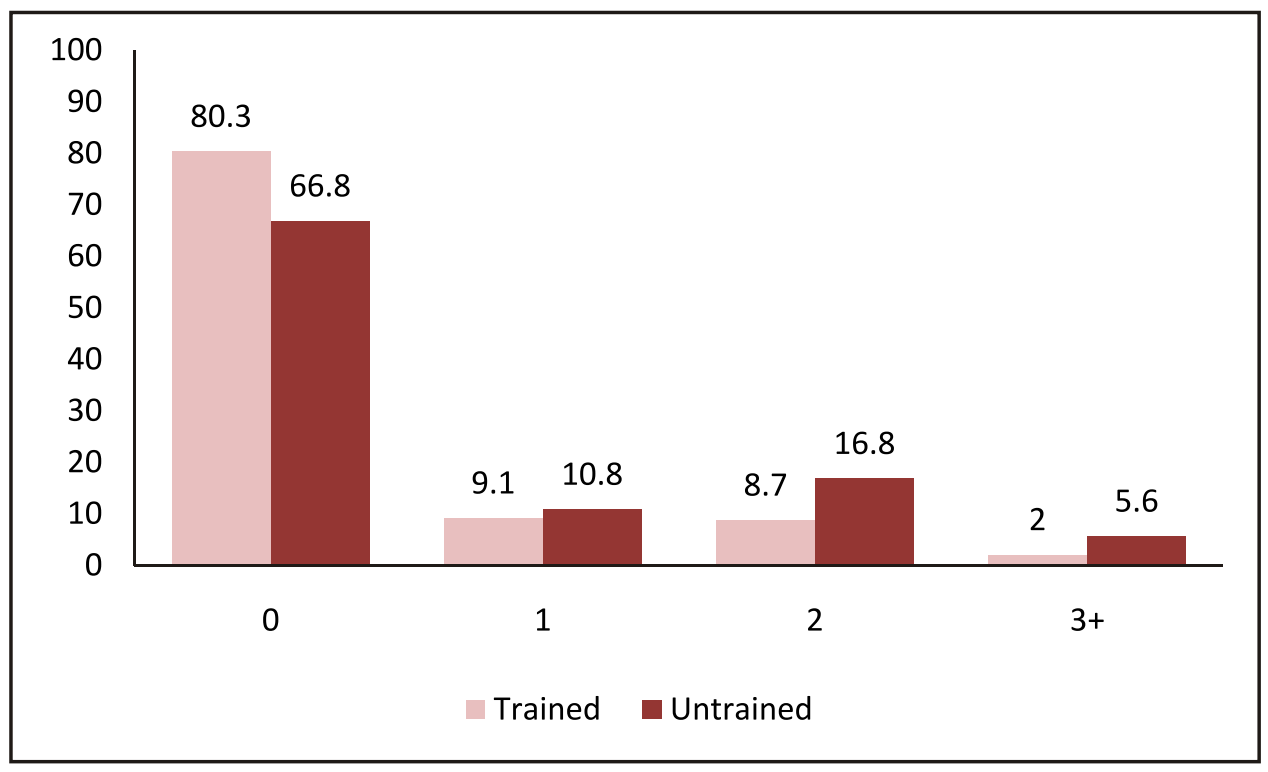

Those dais who had not given an injection to the woman in their last delivery were then asked about why they hadn't done so (table 4.10). About a 12 percent of the trained dais knew that giving injections may cause the uterus to rupture, and about 40 percent stated that the training has advised against it. Untrained dais were more likely to report simply that there was no need for an injection.

Table 4.10: Percentage distribution of dais according to reason for not giving injections during the last delivery, by training status

\begin{tabular}{|c|c|c|}
\hline Reasons for not giving injections & Trained dais & Untrained dais \\
\hline Advised in the training & $38.9^{* *}$ & 0.0 \\
\hline Uterus may rupture & $12.1^{* *}$ & 3.0 \\
\hline $\begin{array}{l}\text { Do not have knowledge about } \\
\text { injections }\end{array}$ & 22.6 & 24.4 \\
\hline No need for injection & $34.2^{* *}$ & 68.1 \\
\hline Others & 2.1 & 5.2 \\
\hline No. of observations & 190 & 135 \\
\hline
\end{tabular}

\section{Use of intravenous drip}

The dais also reported on giving intravenous drip to pregnant women. About half of the 270 trained dais and about 60 percent of the 256 untrained dais responded that they 
usually give drip for augmenting delivery (table 4.11). Fewer untrained dais (39 percent) than untrained ones (55 percent) reported providing uterotonics during second stage labor, a dangerous practice, and fewer also reported putting multivitamins in the drip, which is less harmful.

In most cases the drip is reportedly given by a male service provider. About 10 percent of the dais, however, reported providing the IV drip themselves (Table 4.11). As with injections, eliminating the unnecessary use of IV drip will probably require better education of families and health care providers as well as the dais.

Table 4.11: Percentage of dais according to reported usual practices regarding intravenous drip during labor, by training status

\begin{tabular}{ccc}
\hline Variables & Trained dais & Untrained dais \\
\hline Type of drip given* & & \\
None & 50.4 & 39.6 \\
Plain drip & 2.2 & 0.0 \\
Multivitamins in drip & 33.8 & 42.0 \\
Uterotonics in drip & 38.6 & 55.3 \\
Other & 1.1 & 3.1 \\
No. of observations & $\mathbf{2 7 2}$ & $\mathbf{2 5 5}$ \\
\hline & & \\
Care provider for drip & & \\
Dai & 10.4 & 9.9 \\
Male service provider & 88.1 & 90.1 \\
Other & 1.5 & 0.0 \\
No. of observations & $\mathbf{1 3 4}$ & $\mathbf{1 5 1}$ \\
\hline
\end{tabular}

${ }^{*}$ Note: Percentages may add up to more than $100 \%$ due to multiple responses.

\section{Placenta management}

Dais were also asked about how they knew if the placenta was completely expelled at their last delivery (table 4.12). Dais were trained to immerse the placenta in water, after looking at the outer membranes and checking with their hands. A sizeable proportion of the trained dais (43 percent) said they checked whether the placenta was complete by placing it in water, as compared to a negligible proportion of the untrained dais who did so. More trained than untrained dais reported examining with their hands, while the majority of both groups reported inspecting the outer membranes. Additionally, six percent of the untrained dais do not check the placenta from their last birth at all to make sure it was complete. 
Table 4.12: Percentage of dais according to action taken in last delivery to determine if placenta was completely expelled, by training

\begin{tabular}{lcc}
\hline Checking placenta & Trained & Untrained \\
\hline In the water & $43.3^{* *}$ & 1.6 \\
With hands & $27.0^{* *}$ & 14.9 \\
Outer membranes & $60.5^{* \star}$ & 83.5 \\
Did not check & $\mathbf{0 . 8}^{* *}$ & 5.6 \\
No. of observations & $\mathbf{2 6 3}$ & $\mathbf{2 4 8}$ \\
\hline
\end{tabular}

${ }^{* *}=p<.01$.

\section{Client Responses}

\section{Calling the dai}

Dais were trained to advise the clients to call her as soon as labor begins. For 42 percent of clients of trained dais, the call was given within half an hour, while 31 percent of clients of untrained dais called in that period. Conversely, substantially more clients of untrained dais (14 percent) than trained dais (5 percent) waited more than 10 hours to call. The difference was highly significant.

\section{Clean delivery practices}

Apart from timely referral for obstetric emergencies, ensuring cleanliness at delivery is probably the most important contribution a dai can make to a safe delivery. Table 4.13 shows aspects of this issue as reported by clients.

Nearly all dais, trained or untrained, were reported by clients to wash their hands. The trained dais were somewhat more likely to be reported as washing their hands with soap, with the help of another, and before delivery. Clients reported that 44 percent of trained dais, but few untrained ones, used a clean delivery kit (CDK), and 35 percent spread the sheet from the CDK under the mother during labor. Nearly all clients reported that kits used during delivery were brought by the dai (data not shown). Somewhat more untrained than trained dais were reported to be wearing bangles or rings during the delivery. More than 90 percent of deliveries took place on the floor (as opposed to a bed), regardless of training status, and if the sheet from the CDK was not spread under the mother, she lay on a mat or a plastic bag. 
Table 4.13: Percentage of dais reporting selected clean delivery practices, by training status

\begin{tabular}{lcc}
\hline Clean delivery practice & Trained dais & Untrained dais \\
\hline Handwashing & & \\
With soap & $98.4^{* *}$ & 91.9 \\
With help & 53.7 & 46.3 \\
Before delivery & $73.8^{*}$ & 61.5 \\
Clean delivery kit & & \\
Used & $43.9^{* *}$ & 2.1 \\
Sheet spread under mother & $35.2^{* *}$ & 2.1 \\
Wore bangles & 6.5 & 11.2 \\
Wore rings & 6.9 & 8.2 \\
No. of observations & $\mathbf{2 4 9}$ & $\mathbf{2 3 6}$ \\
\hline
\end{tabular}

$* *=p<.01 ; *=.01<p<.05$.

\section{Use of injections}

Clients tended to report higher use of injections at the last delivery than dais (table $4.14) ; 34$ percent of trained and 41 percent of untrained dais reported receiving injections at last delivery (cf. figure 4.5). If injections were given, the reported reason was generally to speed labor, slightly moreso for trained (95\%) than untrained (90\%) dais. In about 60 percent of reported cases, the dai herself gave the injection. Use of intravenous drip was reported in about 15 percent of cases for clients of both trained and untrained dais; this is substantially lower than the "usual practice" reported by dais.

Table 4.14: Percentage of clients reporting use of injections or drip during last delivery, by training status

\begin{tabular}{lcc}
\hline Practice at last delivery & Trained dais & Untrained dais \\
\hline Received injections & 34.1 & 40.6 \\
Received IV drip & 14.8 & 14.7 \\
No. of observations & $\mathbf{2 4 3}$ & $\mathbf{2 3 2}$ \\
\hline
\end{tabular}

\section{Pelvic examinations}

Client responses regarding pelvic examinations are shown in table 4.15, comparable to the reports from dais shown in table 4.9. Nearly all clients reported being given a pelvic examination, regardless of training status, whereas substantial numbers of trained and untrained dais reported not doing so. Perhaps 
there is a difference in the concept of a "pelvic examination". Far more clients of trained than untrained dais reported significantly greater use of gloves during the examination, although the percentages for both were somewhat lower than for the dai reports. Thus, the difference in training status between those who performed pelvic examinations without gloves, while still substantially greater for untrained dais, is not as great as in the dai reports. Trained dais reported, on average, slightly fewer pelvic examinations than untrained dais (median twice in both cases); the difference is not quite statistically significant.

Table 4.15: Distribution of dais according to practice of pelvic examination, by training status

\begin{tabular}{lcccc}
\hline \multirow{2}{*}{ Pelvic examination practice } & \multicolumn{2}{c}{ Trained dais } & \multicolumn{2}{c}{ Untrained dais } \\
\cline { 2 - 5 } & No. & Pct. & No. & Pct. \\
\hline None & 1 & 0.5 & 1 & 0.5 \\
Yes, with gloves & 104 & 47.3 & 18 & 8.6 \\
Yes, without gloves & 115 & 52.2 & 190 & 90.9 \\
Total & 267 & 100.0 & 250 & 100.0 \\
\hline
\end{tabular}

\section{Placenta management}

Clients were asked about the expulsion of the placenta (and on what she should do if placenta not intact), and about the dai's examination of the placenta. Somewhat more clients of untrained dais (22 percent) than untrained ones (15 percent) reported that the placenta was not spontaneously expelled. The difference was significant at $\mathrm{p}<.05$, and the reason is unclear. Table 4.16 shows what steps the dai took in case the placenta was not spontaneously expelled. Since numbers are small, differences are not statistically significant. Actions to be avoided are manual extraction, which was common regarding training status, and abdominal pressure, which was practiced by 5 untrained dais but only one trained one. Positive practices included abdominal massage, placing the baby at the mother's breast, and giving uterotonic drip or injection; these were (non-significantly) more common among trained dais, although since dais were trained to put the baby to the breast, the low uptake of this advice is disappointing. Use of uterotonics in this situation, as opposed to second-stage labor, is a positive response. The "other" responses mostly involved folk practices that seemed to be neither beneficial nor harmful. 
Table 4.16: Percentage distribution of client reports of dai actions in case the placenta was not expelled spontaneously, by training status

\begin{tabular}{lcc}
\hline Action taken & Trained dais & Untrained dais \\
\hline Massage of abdomen & 42.9 & 30.6 \\
Placenta manually removed & 45.7 & 42.9 \\
Baby placed at mother's breast & 5.7 & 2.0 \\
Strong pressure on abdomen & 2.9 & 10.2 \\
Uterotonic drip or injection & 14.3 & 4.1 \\
Other & 8.6 & 20.4 \\
No. of observations & $\mathbf{3 5}$ & $\mathbf{4 9}$ \\
\hline
\end{tabular}

Note: Percentages may be greater than $100 \%$ due to multiple responses.

About a third of clients were unable to report whether the dai examined the placenta; of those who did, significantly more clients of trained dais (81 percent) than untrained (68 percent) reported that they did. Table 4.17 shows reports of how the placenta was examined. Trained dais were significantly $(p<.01)$ more likely than untrained dais to immerse the placenta in water (the correct procedure), but only 20 percent were reported to have done so. However, since this question was not treated as a multiple response question, the responses cannot be clearly interpreted.

Table 4.17: Percentage distribution of client reports of placenta examination methods, by training status

\begin{tabular}{lcc}
\hline Placenta examination practice & Trained dais & Untrained dais \\
\hline Examined with hands & 29.5 & 25.2 \\
Examined by immersing in water & 19.7 & 2.8 \\
Examined by checking outer membranes & 50.8 & 72.0 \\
No. of observations & $\mathbf{1 3 2}$ & $\mathbf{1 0 7}$ \\
\hline
\end{tabular}

\section{Summary}

As with antenatal care, the untrained dais were superior to the untrained ones in knowledge, skill, usual practice, and practice last delivery. Client responses generally supported the better practices reported by trained dais, although often to a lesser degree than the dais themselves. 
Trained dais were better prepared at delivery. They reported better preparations at home prior to delivery, especially regarding hand washing and taking a clean delivery kit, and their skills in hand washing and use of the clean delivery kit were much better than the untrained dais.

Trained dais had cleaner delivery practices. Beyond better hand washing and other personal hygiene practices, as well as use of clean delivery kits, they were far less likely to perform pelvic examination without gloves, and tended to perform fewer such examinations. Clients also reported better clean delivery practices by trained than untrained dais, including much greater use of the CDKs, and greater use of gloves during pelvic examinations.

In addition, trained dais reported less use of uterotonics during second stage labor than untrained dais, although this was not generally substantiated by the clients. Also, they understood placenta management better than the untrained dais, demonstrated better skills, and were much more likely to check the placenta by immersion in water. Finally, the trained dais could name substantially more of the possible complications of labor; since section 3 suggests that they also knew more about how to manage complications, we expect that their response should be better. We will return to this in section 7 on referrals.

While the practices of the trained dais were better than those of the untrained dais in important ways, they were still inadequate in some key areas. In particular, there is much room for improvement in use of CDKs, discontinuing use of uterotonics during second stage labor, and reducing pelvic examinations, especially without gloves. 


\section{Postpartum Care}

Postpartum care is not usually prioritized in rural Pakistan ${ }^{2}$, and there is consequently a great deal of morbidity and mortality during this sensitive period. For example, the 200607 Demographic and Health Survey reports that only 21.7 percent of mothers received professional postnatal care within 24 hours after birth (NIPS/DHS 2008).

During training, dais were taught about the importance of care during the post-partum period. The training focused specifically on the following: scheduled visits on days 1, 2, $3,10,20$, and 40, routine postpartum examination for mother and child, specific advice on varied diet with plenty of fluids, danger signs such as fever, excessive bleeding and anemia, and advice on family planning. In the present survey, no questions were asked specifically dealing with postpartum knowledge, nor was there postpartum content in the skills test.

\section{Usual Practice and Practice Last Delivery}

\section{Postpartum visitation}

As figure 5.1 shows, significantly more untrained dais reported usually staying for one hour or less immediately following the delivery, as compared to the trained dais $(\mathrm{p}<.05)$. Also, almost 18 percent of the trained dais stayed with the mother for more than four hours, while only 9 percent of the untrained dais did so. However, the differences during the last delivery, while still in the same direction, are no longer significant.

\footnotetext{
${ }^{2}$ Although rest for the mother is encouraged under the cultural tradition of chilla, a 40-day postpartum rest period.
} 
Figure 5.1: Percentage distribution of dais according to number of hours usually remaining with client after delivery, by training status

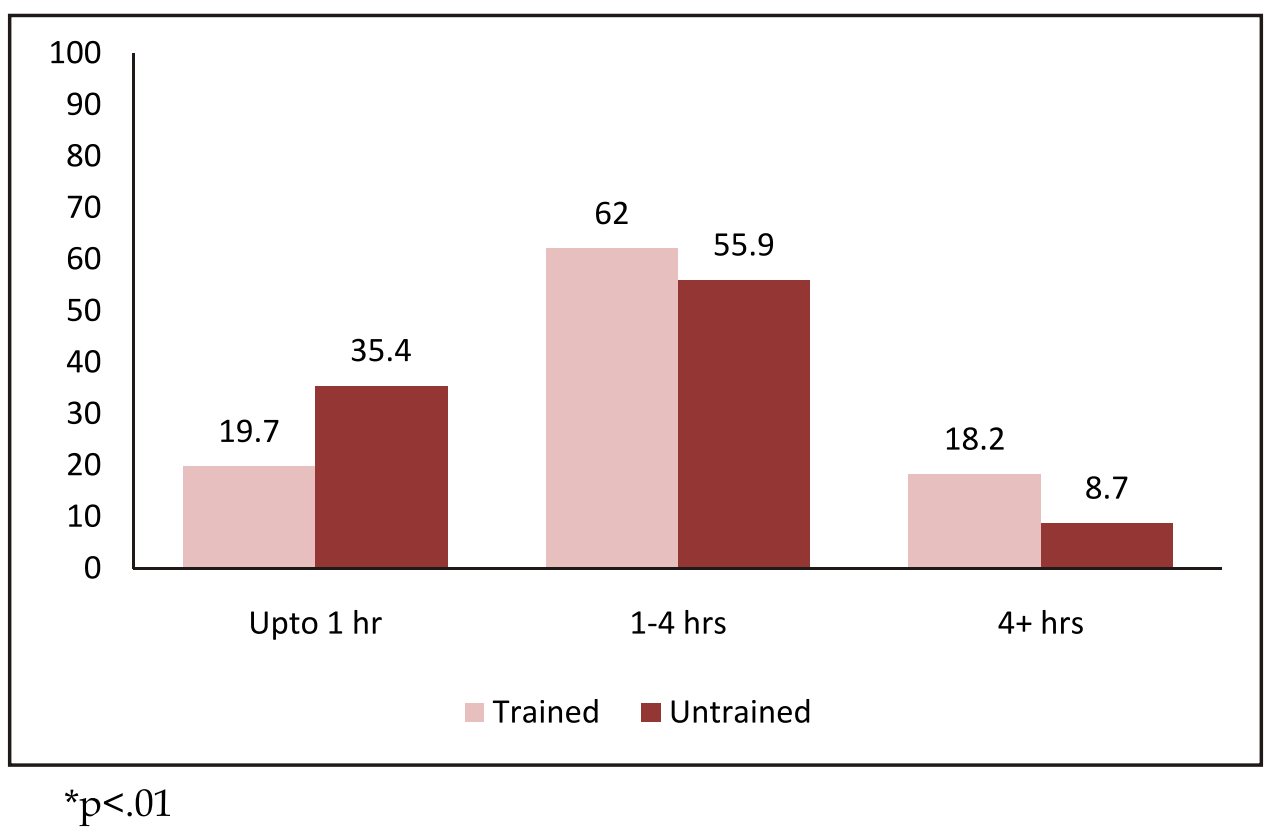

Figure 5.2: Percentage distribution of dais according to number of hours remaining with client after most recent delivery, by training status

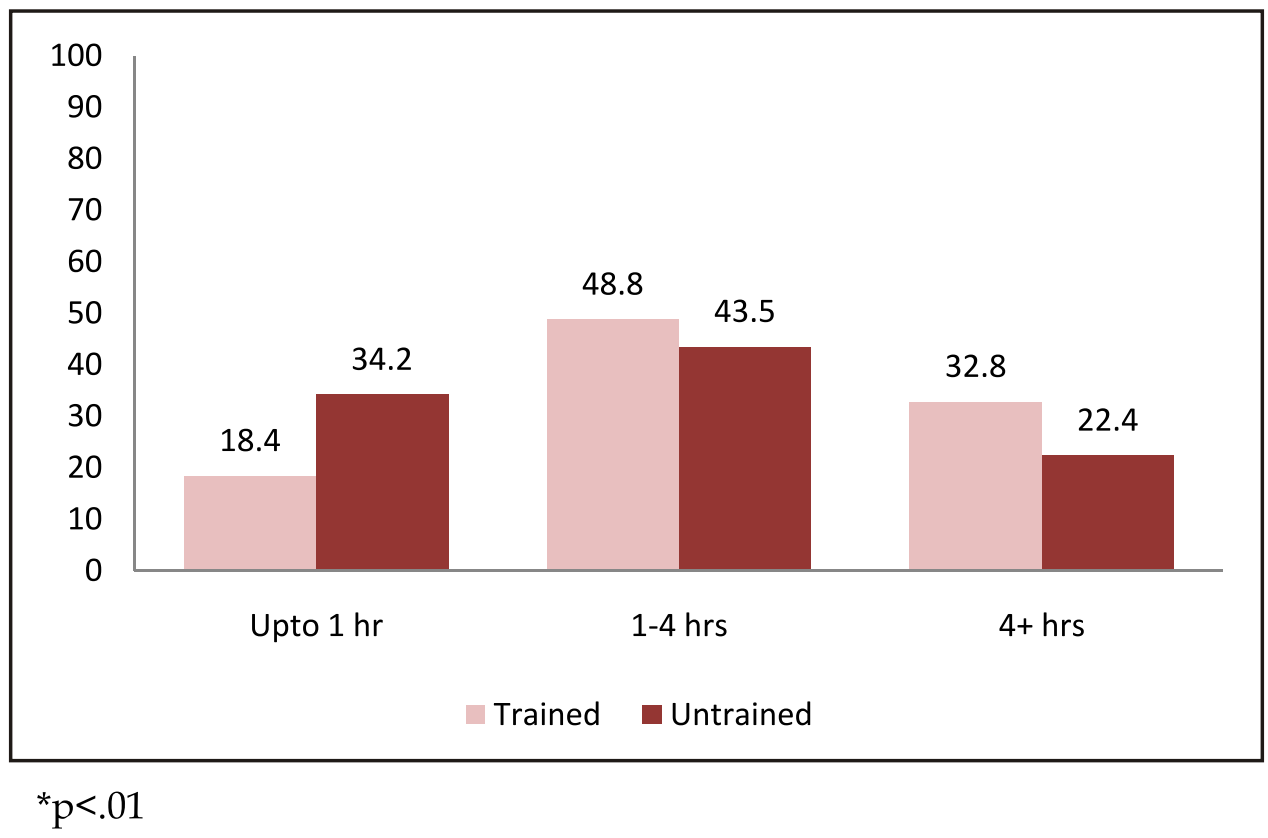

As a routine, dais visit the mother and child after delivery. The training included a specific pattern for these visits; therefore it was anticipated that only the trained dais would be familiar with that pattern. However, because of the time lapse between initial 
training and present assessment the researchers allowed for spillover of information to some of the untrained dais and included the untrained dais in the assessment, excluding the category of; training schedule visits which was not applicable for the untrained dais The table below indicates that this technical knowledge which was an essential component of the dai training was recalled by 29.4 percent of the trained dais. It is reassuring that some dais did remember the correct string of days to visit the mother and child.

Table 5.1: Percentage distribution of dais according to usual postpartum visiting schedule, by training status

\begin{tabular}{lrr}
\hline Visiting schedule & Trained dais & Untrained dais \\
\hline According to the training schedule days & & \\
$(1,2,3.10,20,40$ days $)$ & 29.4 & 0.0 \\
Often & 8.8 & 3.9 \\
Daily from days 2-6 & 21.0 & 41.2 \\
Daily from days 7-11 & 33.1 & 49.0 \\
Does not visit & 0.7 & 3.9 \\
Other & 7.0 & 2.0 \\
Total & $\mathbf{1 0 0 . 0}$ & $\mathbf{1 0 0 . 0}$ \\
No of respondents & $\mathbf{2 7 2}$ & $\mathbf{2 5 5}$ \\
\hline
\end{tabular}

Table 5.2: Percentage distribution of dais according to postpartum visiting schedule after last delivery, by training status

\begin{tabular}{lcc}
\hline Visiting schedule & Trained dais & Untrained dais \\
\hline According to training schedule (day 1, 2, & 19.2 & 0.4 \\
$\quad 3,10,20,40$ ) & & 2.0 \\
Twice & 5.3 & 7.7 \\
Often & 9.0 & \\
Continuous during postpartum period & & 9.7 \\
Daily from days 2-6 & 7.5 & 42.9 \\
& 30.1 & 30.0 \\
Daily from days 7-11 & 17.7 & 2.0 \\
Not visited & 1.5 & 3.2 \\
Living in same house as client & 6.8 & 2.0 \\
Other & 3.0 & $\mathbf{2 7 4}$ \\
No of respondents & $\mathbf{2 6 6}$ & \\
\hline
\end{tabular}

\section{Referrals post delivery}

In previous studies it has been observed that for various reasons the dais are reluctant to refer clients when needed, and health care providers often cite this failure as an important 
cause of maternal and neonatal mortality. It therefore was one of the primary objectives of this study to examine cases referrals by dais. When asked about referrals after delivery (see table 5.3 below), significantly more trained (14 percent) than untrained (8 percent) dais answered that they had referred the mother and/or the baby after their last delivery $(p<.05)$. Seven of the 10 referrals by trained dais for postpartum maternal care were for excessive bleeding, a critical issue (data not shown). Referrals were more common for the neonate than for the mother; trained dais were most likely to refer as a result of the baby's color, while untrained dais tended to refer for fever. While it is difficult to estimate how often referrals would be appropriate, these proportions are doubtlessly lower than the ideal. Nonetheless, the higher proportion for trained than untrained dais indicates some success in encouraging referrals

Table 5.3: Percentage of dais according to person referred after the last delivery, by training status

\begin{tabular}{lrc}
\hline Person referred & Trained & Untrained \\
\hline Mother & 3.6 & 1.6 \\
Baby & 10.1 & 6.2 \\
Either & $13.7^{*}$ & 7.8 \\
No of respondents & $\mathbf{2 7 7}$ & $\mathbf{2 5 7}$ \\
\hline
\end{tabular}

${ }^{*}=.01<p<.05$.

\section{Content of postpartum visits}

Table 5.4 illustrates the difference between trained and untrained dais in the type of postpartum checks they conducted during their last delivery (spontaneous responses). A similar proportion of trained and untrained dais checked for fundal height. For other important checks - most notably for fever, anemia, breast engorgement and quantity of bleeding - the trained dais performed much better than the untrained dais. For example, more than half of the trained dais checked for the quantity of bleeding, as opposed to less than a quarter of the untrained dais, and almost 20 percent of the trained dais checked the woman's fever as compared to less than 5 percent of the untrained dais. Both the amount of bleeding and fever are important indicators of life-threatening post-partum complications. More untrained dais than trained dais checked for tearing, probably because the trained dais were taught to check for tearing immediately during delivery as opposed to continuously throughout the post-partum period. A substantial proportion of the untrained dais (about a fifth) did not perform any checks at all, while only 5 percent of the trained dais fell into this category. 
Table 5.4: Percentage of dais according to maternal conditions checked postpartum, by training status

\begin{tabular}{lcc}
\hline Condition & Trained & Untrained \\
\hline Fundal height & 64.1 & 67.4 \\
Anemia & $32.8^{* *}$ & 4.2 \\
Fever & $18.7^{* *}$ & 4.2 \\
Breast engorgement & $7.6^{* *}$ & 0.4 \\
Quantity of bleeding & $53.4^{* *}$ & 22.6 \\
Urine/ Bowel & 4.6 & 1.3 \\
Tearing & $8.8^{* *}$ & 23.0 \\
No check & $5.0^{* *}$ & 18.0 \\
No. of respondents & $\mathbf{2 6 2}$ & $\mathbf{2 3 9}$ \\
\hline
\end{tabular}

${ }^{* *}=p<.01$.

Dais were asked to spontaneously list the type of advice they imparted to the mother during their last delivery. Most notably, a third of the untrained dais gave no advice to the mother, whilst nearly all trained dais gave some sort of advice. More trained than untrained dais provided advice on referral to their last client. Most of the trained dais (82 percent) provided the mother with advice on good diet (which includes a varied diet and plenty to drink), while less than half of the untrained dais did so. This could both affect the mother's milk and her recovery following delivery, since there are several diet beliefs on what should or should not be eaten post-partum. The trained dais were more likely than untrained ones to give advice on most areas, which was mentioned by few dais regardless of training status.

Table 5.5: Percentage of dais according to postpartum advice given during last delivery, by training status

\begin{tabular}{lrr}
\hline Advice & Trained & Untrained \\
\hline Diet & $82.1^{* *}$ & 47.7 \\
Cleanliness & $23.6^{* *}$ & 10.4 \\
Not to lift any weight & $32.7^{* *}$ & 13.3 \\
Referred & $11.8^{* *}$ & 3.7 \\
To take rest & $33.5^{*}$ & 22.8 \\
Walk slowly & $18.3^{* *}$ & 9.1 \\
Advice about family planning & 2.7 & 2.1 \\
No advice & $6.1^{* *}$ & 31.5 \\
No. of respondents & $\mathbf{2 6 3}$ & $\mathbf{2 4 1}$ \\
\hline
\end{tabular}

${ }^{* *}=p<.01 ;{ }^{*}=.01<p<.05$ 


\section{Family planning}

Although few dais spontaneously mentioned family planning as part of the post-partum advice they provided, when specifically asked whether they provided information on family planning during the previous six months, most of the trained dais (87 percent) said they did so, whilst less than half (45 percent) of the untrained dais provided this advice. For those who did give family planning advice, methods the dais reported discussing with their clients are shown in table 5.6. Trained dais were more likely to name each specific method. For both trained and untrained dais, the methods discussed are generally consistent with the prominence of the methods in the national program. There is little evidence, however, that either trained or untrained dais gave advice that was specifically appropriate for the postpartum period.

Table 5.6: Percentage of dais according to family planning methods discussed with clients in previous six months, by training status

\begin{tabular}{lcc}
\hline Method & Trained dais & Untrained dais \\
\hline Pills & $74.0^{* *}$ & 57.9 \\
Injections & $75.3^{* *}$ & 58.8 \\
IUD & 83.0 & 76.3 \\
Tubectomy & 47.2 & 36.0 \\
Vasectomy & $8.5^{*}$ & 1.8 \\
Condom & $34.5^{* *}$ & 15.8 \\
Withdrawal & 4.7 & 4.4 \\
Other & $4.7^{*}$ & 12.3 \\
No. of observations & $\mathbf{2 3 5}$ & $\mathbf{1 1 4}$ \\
\hline
\end{tabular}

${ }^{* *}=\mathrm{p}<.01 ;{ }^{*}=.01<\mathrm{p}<.05$.

Dais were also asked where they referred their clients for family planning (data not shown). The responses for trained and untrained dais were quite similar. Nearly half of each reported not giving specific locations; of the others, the most commonly cited were Rural Health Centers, Family Welfare Centers, and the District Headquarters Hospital.

\section{Client Responses}

In an effort to cross-match responses, clients were asked several of the same questions as the dais regarding post partum care. The only difference was that dais were often asked to respond with prompted choices, whereas the clients were mostly asked open-ended questions (for example, 'what did the dai do following delivery?', as opposed to 'did the dai press your legs, check your abdomen, etc'). 
As table 5.7 shows, clients reported no significant difference in hours of normal stay between trained and untrained dais. About a third of either trained or untrained dais stayed with the mother for an hour or less, while 29 percent of trained dais and 26 percent of untrained dais stayed between 2 and 4 hours. About a quarter of either trained or untrained dais stayed for more than 5 hours. When compared to what the dais selfreported, it seems that the trained dais preferred to say they stayed between 2-4 hours, as opposed to one hour or less - only 20 percent of the trained dais reported staying one hour or less, compared to about a third of the mothers reporting the same thing. Also, there were fewer trained and untrained dais who reported staying for five hours or more.

Table 5.7: Percentage distribution of clients according to reported length of dais' usual stay with clients immediately after delivery, by dai training status

\begin{tabular}{lcc}
\hline Length of stay & Clients of trained dais & Clients of untrained dais \\
\hline$<=1$ hour & 35.1 & 38.6 \\
$2-4$ hours & 29.0 & 26.3 \\
$5+$ hours & 24.2 & 22.9 \\
Live in the same house (dai was relative) & 5.2 & 5.1 \\
Other responses & 6.5 & 7.2 \\
No. of respondents & $\mathbf{2 4 8}$ & $\mathbf{2 3 6}$ \\
\hline
\end{tabular}

When asked what kind of work the dais performed immediately following delivery, the clients responded with a variety of activities, as listed in table 5.8 below. This shows that dais are an important support for the mother, and have a caring and nurturing role during the post-partum period. Mothers reported that most of both trained and untrained dais massaged their abdomen and pressed the mother's legs. However, substantially more clients of trained dais (55 percent) than untrained dais (47 percent) reported that the dai washed the mother's and child's clothes. Also, more clients of the trained dais said that the dais gave them something to eat and looked after them in other ways, showing that the trained dais were following what they had learnt in the training. The training had also emphasized that it was unwise to wash the baby straight away because of risks of hypothermia, and that it was sufficient to clean the baby by wiping it with a clean cloth. The figures below show that the trained dais performed better than the untrained dais, in that fewer of them washed the newborn, and more of them cleaned the baby in other ways. 
Table 5.8: Percentage of client responses according to actions taken immediately following delivery, by dai training status

\begin{tabular}{lcc}
\hline Action & Clients of trained dais & Clients of untrained dais \\
\hline $\begin{array}{l}\text { Massaged mother's abdomen } \\
\text { Washed the mother's and child's }\end{array}$ & 84.9 & 84.3 \\
$\quad$ clothes & 55.2 & 46.5 \\
$\begin{array}{l}\text { Pressed mother's legs } \\
\text { Gave mother something to eat }\end{array}$ & 90.4 & 95.2 \\
$\begin{array}{l}\text { Looked after mother (e.g. cooking for } \\
\text { the mother, looking after other } \\
\text { children etc.) }\end{array}$ & 17.2 & 11.3 \\
$\begin{array}{l}\text { Bathed baby } \\
\text { Cleaned baby (normally just wiping the } \\
\text { face and body) }\end{array}$ & $28.5^{*}$ & 19.1 \\
$\begin{array}{l}\text { No. of respondents } \\
{ }^{*}=.01<p<.05 .\end{array}$ & 17.2 & 17.8 \\
\end{tabular}

When asked how many days after delivery the dais visited them, most of the clients of both trained and untrained dais said that the dais' first postpartum visit was on the second day (table 5.9). There was no significant difference between clients of trained and untrained dais. While it appears that clients report fewer postpartum visits than the dais claim, because of different coding categories it is difficult to compare the two reports on this topic (data not shown).

Table 5.9: Percentage distribution of client responses of which day trained and untrained dais visited them post-partum, by dai training status

\begin{tabular}{lcc}
\hline Day & $\begin{array}{c}\text { Clients of Trained } \\
\text { dais }\end{array}$ & $\begin{array}{c}\text { Clients of Untrained } \\
\text { dais }\end{array}$ \\
\hline $2^{\text {nd }}$ day & 82.6 & 80.5 \\
$3^{\text {rd }}$ day & 4.5 & 3.4 \\
No visit & 2.8 & 2.5 \\
Relative (live in same house) & 5.7 & 5.5 \\
Other & 4.5 & 8.1 \\
No. of observations & $\mathbf{2 4 7}$ & $\mathbf{2 3 6}$ \\
\hline
\end{tabular}

Clients were asked what examinations the dais made in the postpartum visit. According to the mother's responses, trained dais performed better than untrained dais during the post-partum visits in terms of checking for anemia, fever and particularly for the quantity 
of bleeding. However, the percentages of trained dais who performed these checks were very low, and much lower than they (the trained dais') had themselves reported doing. A third of the trained dais had reported checking for anemia (see table 5.3 above) while only 5 percent of the mothers reported the trained dais doing so; similarly 19 percent of the trained dais reported checking for fever in the last delivery, while only 2 percent of the clients reported that the dais had done so. This could be because the trained dais had not explained what they were doing, and the mother therefore didn't know what the dai had done these checks for. This has implications for the training in terms of teaching dais to inform the mother about what checks they are performing. Also, a proportion of mothers reported that the trained and untrained dais did not perform any medical checks; dais, whether trained or untrained, were much less likely to report not performing checks.

Table 5.10: Percentage of client responses according to specific checks performed by dais post-partum, by dai training status

\begin{tabular}{lcc}
\hline Check performed & Clients of trained dais & Clients of untrained dais \\
\hline Fundal height & 54.9 & 49.8 \\
Anemia & $4.6^{*}$ & 0.5 \\
Fever & 2.1 & 0.0 \\
Breast engorgement & 1.3 & 0.0 \\
Quantity of bleeding & $19.0^{* *}$ & 1.8 \\
Urine/bowel & 0.0 & 0.0 \\
No medical checks & 6.8 & 7.7 \\
No. of respondents & $\mathbf{2 3 7}$ & $\mathbf{2 2 1}$ \\
\hline
\end{tabular}

${ }^{* *}=\mathrm{p}<.01 ;{ }^{*}=.01<\mathrm{p}<.05$.

Separately, clients were asked what advice the dais gave them during postpartum visits. It seems that the training component on advice was very successful, since according to the client responses, many more of the trained dais gave proper post-partum advice as compared to untrained dais. As table 5.11 demonstrates, 11 percent of the trained dais gave advice to the mother on cleanliness, while only 2 percent of the untrained dais did so. Almost half of the trained dais gave advice on good diet, while less than a fifth of the untrained dais did the same. And many more of the trained dais suggested to the mother not to lift weights and to take rest as compared to the untrained dais. Although the percentages of trained dais are not as high as they self-reported for all the advice-giving, it is still higher than the untrained dais. However, many more mothers reported that the 
trained dais did not provide any advice (43 percent) as compared to what the dais had reported themselves.

Table 5.11: Percentage of client responses according to advice given dais during post partum visits, by dai training status

\begin{tabular}{lcc}
\hline Advice & Clients of Trained dais & Clients of Untrained dais \\
\hline Refer & 1.7 & 0.0 \\
Cleanliness & $11.1^{* *}$ & 2.3 \\
Good diet & $42.3^{* *}$ & 16.7 \\
Take rest & $20.9^{* *}$ & 10.0 \\
Not to lift weight & $17.5^{* *}$ & 7.7 \\
No advice & $46.2^{* *}$ & 71.0 \\
No. of respondents & $\mathbf{2 3 4}$ & $\mathbf{2 2 1}$ \\
\hline
\end{tabular}

${ }^{* *}=p<.01$.

Clients were asked whether dais advised them regarding family planning. About a fifth (21 percent) of the clients of trained dais reported that their dais had provided advice on family planning (data not shown). This figure is significantly higher than the percentage of clients of untrained dais (6 percent). However, the figure is lower than that reported by the dais themselves ( 87 percent and 43 percent, respectively). For those who reported having received family planning advice ${ }^{3}$, table 5.12 indicates methods mentioned. It seems that the trained dais who advised on family planning were also somewhat better than the untrained dais at providing a wider range of contraceptive choice, including advice on vasectomy and withdrawal. Substantially more trained dais provided advice on condoms, and a few more trained than untrained dais provided advice on Copper IUDs, tubectomy, and the pill. The numbers, however, are not large enough to yield statistical significance.

\footnotetext{
${ }^{3}$ For this and the following table on family planning, because the numbers are small; the dataset includes all clients interviewed rather than only those reported as the dai's most recent delivery.
} 
Table 5.12: Percentage of client responses according to family planning method mentioned in postpartum visits, by dai training

\begin{tabular}{lcc}
\hline Method & Clients of trained dais & Clients of untrained dais \\
\hline Pill & 46.5 & 40 \\
Condom & 16.2 & 8 \\
Injection & 54.5 & 60 \\
Copper IUD & 51.5 & 40 \\
Tubectomy & 24.2 & 20 \\
Vasectomy & 1.0 & 0.0 \\
Withdrawal & 2.0 & 0.0 \\
Other & 6.1 & $\mathbf{4}$ \\
No. of respondents & $\mathbf{9 9}$ & $\mathbf{2 5}$ \\
\hline
\end{tabular}

Of those who were given advice, rather few had accepted a method by the time of the interview. Among all clients interviewed, 17 clients of trained dais, compared with 5 clients of untrained dais, had adopted a method $(\mathrm{p}<.01)$. While these numbers are small, it must be noted that these clients had all fairly recently delivered.

Table 5.13 shows the reasons for not adopting family planning. The most common response was that they were currently in the postpartum period, and presumably therefore not in need of family planning. Others reported currently breastfeeding, not yet menstruating, or husband away, presumably similar reasons. Some clients reported concerns with health or side effects. Only a few said that family planning is a sin. 
Table 5.13: Percentage of client responses according to reason for not adopting family planning, by dai training status

\begin{tabular}{lcc}
\hline Reason & Clients of trained dais & Clients of untrained dais \\
\hline Opposition of husband/family & 8.9 & 0.0 \\
Husband is away from home & 10.1 & 5 \\
Fear of side effects & 5.1 & 5 \\
Experienced side effects & 3.8 & 0.0 \\
Health problem & 7.6 & 15 \\
Natural spacing & 2.5 & 0.0 \\
Currently breastfeeding & 12.7 & 10 \\
Menstruation not yet started & 1.3 & 0.0 \\
Family planning is sin & 2.5 & $15^{*}$ \\
Currently postpartum & 45.6 & 45 \\
Other & 8.9 & 5 \\
Total & 100.0 & 100.0 \\
No. of observations & $\mathbf{7 9}$ & $\mathbf{2 0}$ \\
\hline
\end{tabular}

${ }^{*}=.01<\mathrm{p}<.05$.

Note: Percentages may be greater than $100 \%$ due to multiple responses.

\section{Summary}

Dais in Pakistan play an important supportive role for the mother during the post-natal period, and there is thus an opportunity to make the mother healthier during this period. The data presented in this section indicate that, according to dais reports, the trained dais perform better than untrained dais in postpartum visitation, the content of postpartum visits, and family planning. On some points, the clients confirm this finding, while on others less so or not at all.

Both as a usual practice and specifically after their last delivery, trained dais reported staying longer after childbirth than untrained dais, and visiting more often afterwards during the postpartum period. Clients, however, reported little difference between the two sets of dais. Both dais and clients, however, indicate that few dais, trained or untrained, fail to visit at all during the postpartum period.

Trained dais also reported doing considerably more checks during postpartum visits than untrained dais, and advising on many more topics. On these topics, clients also reported better performance by trained than untrained dais. However, they reported fewer checks 
and less advice than the dais in self-reporting; this may represent some combination of over-reporting by the dais and under-reporting on the part of the clients.

Trained dais also reported themselves to be much more likely to advise on family planning than untrained dais. The clients reported lower levels of such advice, but agreed that the trained dais were also likely to discuss family planning. Moreover, while only a few clients had already adopted a family planning method during this brief period after delivery, the clients of the trained dais reported significantly more use than those of the untrained dais. An important limitation on this count is that the national program provides few options for postpartum family planning; consequently the dais were not taught such possibilities as the lactational amenorrhea method or progestogen-only pills.

Hence, it is not clear to what extent the dai training encouraged the dais to stay longer after delivery, or to visit more often. But it is clear from both dai and client reports that the content of the trained dais' visits, including family planning, was superior to that of the untrained dais, particularly regarding counseling.

Finally, the trained dais reported referring during the post-delivery period significantly more often than untrained dais, and while the numbers are small, it appeared that the reasons for referral reflected their training. Since the client follow-up for referral was for delivery only, we were unable to obtain the clients' perspective on this. 


\section{Neonatal Care}

Care of the newborn, unlike maternal care, is not considered an essential component of the dai's competence, either by the dai herself or by her clients. However, during the training this topic was given importance through didactic training, use of models, role playing case studies, etc., and included in the curriculum and examinations. Dais were immediately appreciative of this aspect of their training; unlike delivery care, they were not initially confident of their knowledge and skills in this area.

Among the areas stressed in neonatal care were: wrapping and warming; cord care; delaying bathing; breastfeeding (giving first milk, immediate breastfeeding, exclusive breastfeeding); management of difficult breathing; and examining the baby.

\section{Knowledge}

Only one complex neonatal knowledge question was included in the dai questionnaire: a multiple response question about the advantages of mother's first milk (colostrum) given immediately after birth. In response, 66 percent of trained dais, compared with 38 percent of untrained dais, gave the best answer: it protects the baby from diseases. The trained dais were also more likely than the untrained ones to cite general health (93.8 percent to 69.4 percent) and ease of digestion (32.5 percent to 17.3 percent). The untrained dais were more likely (11.4 percent to 0.0 percent) to feel that colostrum gives no benefit or is harmful. Overall, the trained dais gave an average of 2.1 correct answers to benefits of colostrum, while the untrained ones averaged 1.3 correct answers.

\section{Skills}

The skills test involved two elements of neonatal care: the dais were asked to clean the (model) neonate, and to examine it. The dai could either do the task correctly without prompting (spontaneous correct), correctly after prompting (prompted correct), or were unable to perform the task correctly or at all (no/wrong).

\section{Cleaning}

In the CDK there four cotton balls and four gauze pieces. Two cotton balls (one for each eye) are used to clean the eyes of neonate starting from inside toward outside. An 
additional two cotton balls are for cleaning of the ears. One gauze piece is used for cleaning the mouth by wrapping it around the little finger and the other is used for cleaning the nose. The remaining two gauze pieces are used to hold the cord at the time of the cord tie.

According to table 6.1, the trained dais were significantly more likely than untrained ones to perform each of the cleaning tasks. Particularly substantial differences were noted for cleaning the eyes and mouth, and for wrapping the baby in a clean cloth.

Table 6.1: Percentage of dais demonstrating wrong, prompted correct and spontaneous correct responses on cleaning of neonates, by training status (no. of observations: trained $=271$, untrained $=253$ )

\begin{tabular}{|c|c|c|c|c|c|c|}
\hline \multirow[b]{2}{*}{ Cleaning task } & \multicolumn{2}{|c|}{ No/wrong } & \multicolumn{2}{|c|}{$\begin{array}{l}\text { Prompted } \\
\text { correct }\end{array}$} & \multicolumn{2}{|c|}{$\begin{array}{l}\text { Spontaneous } \\
\text { correct }\end{array}$} \\
\hline & Trained & Untrained & Trained & Untrained & Trained & Untrained \\
\hline Eyes & 32.2 & 62.5 & 5.9 & 4.0 & $61.9^{* *}$ & 33.6 \\
\hline Mouth & 35.1 & 61.3 & 8.9 & 9.1 & $56.1^{* *}$ & 29.6 \\
\hline Ears & 37.6 & 63.1 & 20.3 & 10.7 & $42.1^{* *}$ & 26.2 \\
\hline Nose & 46.5 & 67.1 & 13.7 & 4.4 & $39.9^{* *}$ & 28.6 \\
\hline Body & 27.7 & 45.1 & 23.6 & 14.2 & $48.7^{* *}$ & 40.7 \\
\hline Wrapped in clean cloth & 24.6 & 52.6 & 25.0 & 16.2 & $50.4^{\star *}$ & 31.2 \\
\hline
\end{tabular}

\section{Examination}

Table 6.2 shows the results of the skills test on examining the newborn. The test involved handing the doll to the dai and asking her to examine it. Few if any, trained or untrained, did not attempt, but many did not know how to examine a particular part correctly. In addition, some needed to be prompted to examine some parts. The only really proper response is "spontaneous correct"; it doesn't much matter if the dai knows how to examine a part, if she doesn't do so. For all parts, the trained dais were more likely to do the examination correctly, both spontaneously and, when necessary, prompted; most differences were statistically significant. Conversely, the untrained dais were more likely not to do the examination correctly, usually to a substantial degree. Of particular importance is the difference between trained and untrained dais in remembering to check the respiratory rate, and to do it correctly. 
Table 6.2: Percentage of dais demonstrating wrong, prompted correct and spontaneous correct responses on examination of neonates, by training status (no. of observations: trained $=272$, untrained $=252$ )

\begin{tabular}{|c|c|c|c|c|c|c|}
\hline \multirow[b]{2}{*}{ Examination task } & \multicolumn{2}{|c|}{ No/wrong } & \multicolumn{2}{|c|}{$\begin{array}{l}\text { Prompted } \\
\text { correct }\end{array}$} & \multicolumn{2}{|c|}{$\begin{array}{c}\text { Spontaneous } \\
\text { Correct }\end{array}$} \\
\hline & Trained & Untrained & Trained & Untrained & Trained & Untrained \\
\hline Head & 17.3 & 37.3 & 39.1 & 29.8 & $43.5^{\star *}$ & 32.9 \\
\hline Face & 21.8 & 48.0 & 30.3 & 26.2 & $48.0^{* \star}$ & 25.8 \\
\hline Eyes & 27.7 & 46.0 & 19.6 & 19.4 & $52.8^{* *}$ & 34.5 \\
\hline Lips & 33.1 & 49.4 & 35.7 & 33.9 & $31.3^{* *}$ & 16.7 \\
\hline Ears & 35.1 & 52.2 & 32.1 & 26.9 & $32.8^{* *}$ & 20.9 \\
\hline Hands & 25.4 & 36.0 & 23.9 & 23.6 & $50.7^{*}$ & 40.4 \\
\hline Back & 33.2 & 43.0 & 41.7 & 34.3 & 25.1 & 22.7 \\
\hline Feet & 24.6 & 34.4 & 26.5 & 24.8 & $48.9^{*}$ & 40.8 \\
\hline $\begin{array}{l}\text { Checked respiratory } \\
\text { rate }\end{array}$ & 28.0 & 56.0 & 39.9 & 32.1 & $32.1^{* *}$ & 11.9 \\
\hline
\end{tabular}

\section{Usual practice}

The dais were asked about their usual practice in five situations. Percentage of dais giving correct responses on four of these, for which a single answer was called for, are shown in table 6.3. Responses on the fifth, for which multiple responses were possible, is shown in table 6.4.

Table 6.3. Percentage of dais according to usual practice during neonatal period, by training status

\begin{tabular}{lrc}
\hline Practice & Trained dais & Untrained dais \\
\hline Advise nothing to apply on cord & $50.9^{* *}$ & 8.9 \\
Timing of first bath after 6 hours & $66.1^{* *}$ & 49.0 \\
Mother's milk first food for baby & $92.6^{\star *}$ & 42.5 \\
Mother's milk given in first hour & $82.1^{\star *}$ & 43.8 \\
No. of observations & $\mathbf{2 7 3}$ & $\mathbf{2 5 5}$ \\
\hline${ }^{* *}=\mathrm{p}<.01$. & &
\end{tabular}

As with other measures, the trained dais consistently gave better responses than the untrained ones, by wide margins in three of the four cases. Regarding what to apply on the cord, present best practice is to advise nothing; in many cases, both trained (31.1 percent) and untrained (36.0 percent) dais reported giving methylated spirits, which is not harmful. However, significant proportions of untrained dais applied antimony (22.7 percent) or ghee (17.8 percent), which is poor practice; many fewer trained dais did so. 
The trained dais were asked to delay the first bath by at least six hours. While more trained than untrained dais generally wait that long, a substantial proportion do not; the source of this resistance requires further investigation.

The difference between groups regarding giving breast milk as the first food, and giving within an hour, is striking and important. It appears that in this case the dai training was highly effective at changing established practice. Among untrained dais, 36.5 percent advise goat's milk as the first food, and 35.1 percent advise waiting at least 6 hours to begin breastfeeding.

Since birth asphyxia is a leading cause of neonatal mortality, and one for which referral to a health facility is not usually an option, the response of a dai when a baby is not breathing, or not breathing properly, is of critical importance. Table 6.4 shows dais' reports on usual practice when a newborn is not breathing properly.

Table 6.4: Percentage of dais according usual practice if a newborn is not breathing properly, by training status

\begin{tabular}{lcc}
\hline Usual Practice & $\begin{array}{c}\text { Trained } \\
\text { dais }\end{array}$ & $\begin{array}{c}\text { Untrained } \\
\text { dais }\end{array}$ \\
\hline Hang baby upside down and slap & $15.4^{* *}$ & 59.8 \\
Put baby face down on arm & $27.2^{* *}$ & 6.6 \\
Use mouth-to-mouth resuscitation & $83.5^{* *}$ & 48.1 \\
- Using gauze & $14.3^{* *}$ & 3.3 \\
Remove obstruction with bulb sucker & $2.6^{*}$ & 0.4 \\
Refer & 15.1 & 14.9 \\
Other & $10.3^{* *}$ & 21.6 \\
No. of observations & $\mathbf{2 7 2}$ & $\mathbf{2 4 1}$ \\
\hline${ }^{* *}=\mathrm{p}<.01 ;{ }^{*}=.01<\mathrm{p}<.05$. & &
\end{tabular}

Appropriate response to poor breathing depends on the nature of the problem. If the newborn is not breathing at all, mouth-to-mouth resuscitation, preferably with a piece of gauze between mouths, may be essential in the absence of resuscitation devices. The great majority of trained dais, and nearly half of untrained ones, report doing so, although the use of gauze is not common, even among the trained dais. The traditional practice of holding a baby upside down and slapping it to restore breathing, which is not helpful and may lead to cranial hemorrhage, is widely reported by untrained dais, much less so by trained ones. It is recommended to hold the baby on the arm in a flat position with face 
down to facilitate the drainage of any secretions in the oral or nasal cavity. Use of a bulb sucker to remove mucous was shown in training, but trainees were not given bulbs; consequently, it appears they do not use them. Referral, while not appropriate with asphyxia, may be appropriate for other types of disorders, such as dyspnea (difficult breathing) or intermittent apnea.

\section{Practice last delivery}

Several questions were asked about care of the newborn after the most recent delivery. These included questions on cleaning and warming, examination, cord care, first bath and first feeding.

\section{Cleaning and warming.}

Table 6.5 shows the proportions of dais who cleaned specific body parts of the newborn after their last delivery. Reported practice last delivery is consistently substantially higher than correct skills test results (from table 6.1), presumably because we were unable to ascertain whether practice was correct, only if the body part was attended to. In reported practice in last delivery as for correct skills test, results were substantially better for the trained than the untrained dais, except for cleaning of the body, which both trained and untrained dais nearly always did.

Table 6.5: Percentage of dais by neonatal body parts cleaned after last delivery, by training status

\begin{tabular}{lcc}
\hline Body part cleaned & Trained dais & Untrained dais \\
\hline Eyes & $95.8^{* *}$ & 76.0 \\
Mouth & $95.4^{* *}$ & 78.9 \\
Ears & $82.1^{* *}$ & 65.4 \\
Nose & $89.7^{\star *}$ & 71.1 \\
Body & 94.7 & 95.5 \\
No. of observations & $\mathbf{2 6 2}$ & $\mathbf{2 4 6}$ \\
\hline${ }^{* *}=p<.01$. & &
\end{tabular}

Another substantial difference is in the reports of what the dai cleaned with (figure 6.1); trained dais often reported cleaning with material from the clean delivery kit (37.5 percent) or cotton (12.0 percent), while 2 percent of untrained dais reported use of cotton and none reported cleaning with material from the clean delivery kit. Most untrained 
dais (87 percent) reported cleaning with an old cloth, while 41.3 percent of trained dais reported doing so.

Figure 6.1: Percentage distribution of dais according to material used to clean the newborn, by training status
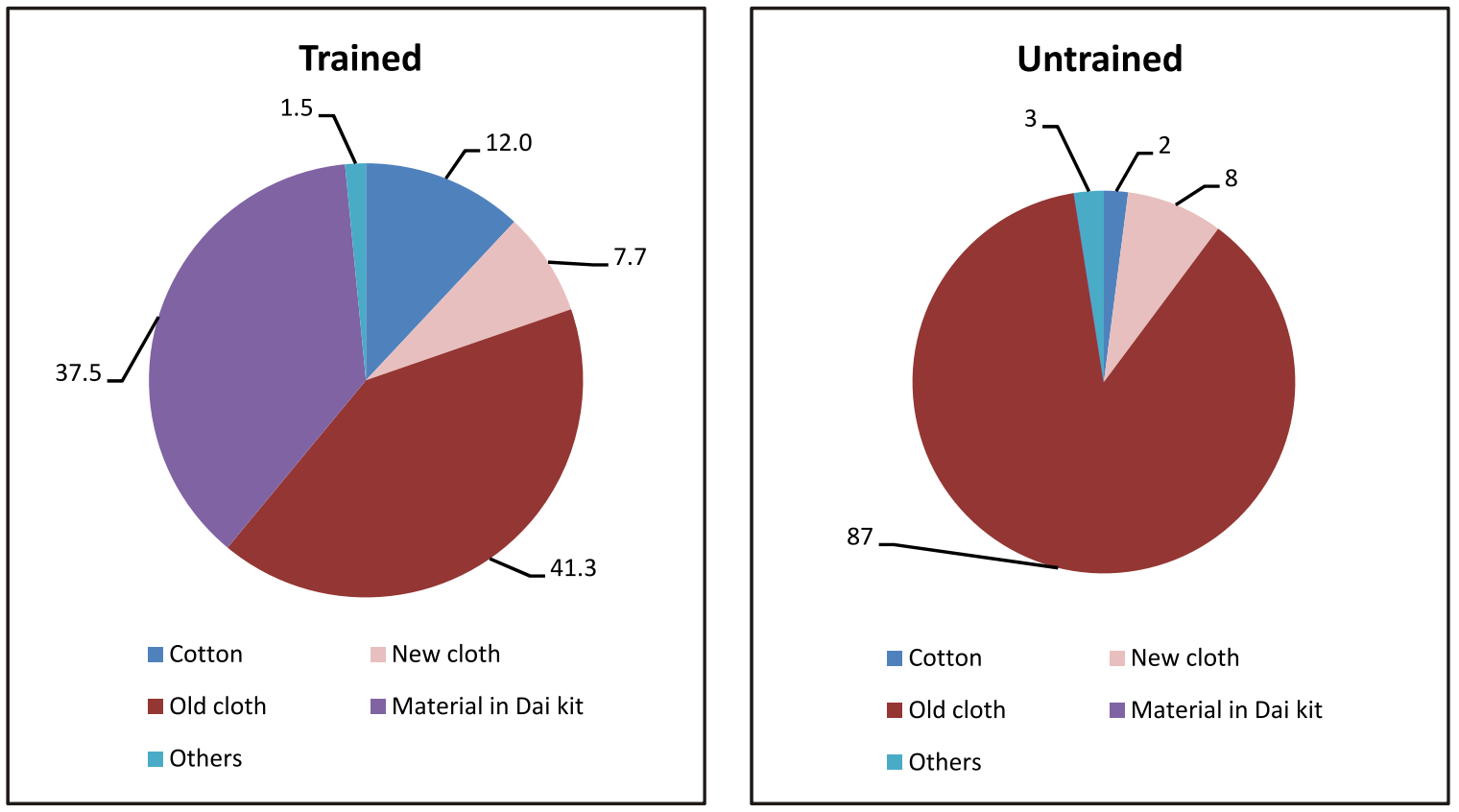

For keeping the baby warm, the procedure we taught was to clean the baby with a clean cloth, then wrap it with another cloth and lay it beside the mother. Of the trained dais, 24.8 percent reported doing this compared with 7.3 percent of untrained dais. Most dais, trained or untrained, mentioned cleaning with one cloth and wrapping with another; the difference was in whether the procedure also included laying the baby by the mother. By comparison, 50.4 percent of trained and 31.2 percent of untrained dais did this procedure correctly in the skills test, including laying the baby with the mother.

\section{Examining the baby.}

For the last delivery the dais were asked, "What did you check in the newborn immediately after birth?" The list of possibilities was somewhat different than those checked in the skills test, since some checks (e.g., appearance/color) are not possible on the model. Table 6.6 shows the responses. The trained dais were nearly always more likely to report checking each item than untrained ones. (The exception was the genitals; we assume that these are nearly always checked to determine the sex of the baby, whether 
or not examined for abnormalities.) Of note is that the trained dais were considerably more likely than untrained dais to report checking the appearance/color of the neonate (an important warning sign for early neonatal mortality), as well as facial components such as eyes, ears, etc. However, considerably fewer trained dais reported checking the respiration of the newborn after the last delivery than performed the task spontaneously and correctly in the skills test.

Table 6.6: Percentage of dais according to components of neonatal examination done in last delivery, by training status

\begin{tabular}{lcc}
\hline Examination component & Trained dais & Untrained dais \\
\hline Appearance/color of neonate & $43.9^{* *}$ & 24.8 \\
Activity of neonate & 16.7 & 11.0 \\
Respiration & 17.0 & 14.2 \\
Heart beat & $7.6^{* *}$ & 2.0 \\
Head & 12.9 & 10.2 \\
Facial parts & $45.1^{* *}$ & 22.8 \\
Lower back & 6.1 & 4.1 \\
Abdomen & $13.3^{* *}$ & 2.8 \\
Nipple (breast) & 1.1 & 0.4 \\
Genital organs & $31.4^{* *}$ & 44.7 \\
Congenital abnormality & 33.3 & 26.8 \\
Cord & $20.1^{*}$ & 12.6 \\
Other & 1.1 & 0.4 \\
No. of observations & $\mathbf{2 6 4}$ & $\mathbf{2 4 6}$ \\
\hline ** p<.01; ${ }^{*} .01<p<.05$. & &
\end{tabular}

\section{Cord care}

After the most recent delivery, the dais were asked how they tied the cord, when they cut the cord (before or after expulsion of placenta), how, and if not with a new blade, how the instrument was cleaned. Table 6.7 shows the results. The great majority of trained dais apparently followed training instructions to tie the cord before and after the place of the cut, while only one-fifth of untrained dais did so. On the other hand, the vast majority of dais, trained or untrained, cut the cord after expulsion of the placenta and with a new blade. 
Table 6.7: Percentage of dais according to cord care practice during last delivery, by training status

\begin{tabular}{lcc}
\hline Cord care practice & Trained dais & Untrained dais \\
\hline Cord tied in 2 places/"according to training" & $79.3^{* *}$ & 20.6 \\
Cord cut after expulsion of placenta & 93.1 & 95.9 \\
Cord cut with new blade & $97.7^{*}$ & 93.1 \\
No. of observations & $\mathbf{2 6 1}$ & $\mathbf{2 4 5}$ \\
\hline
\end{tabular}

${ }^{* *}=p<.01 ;{ }^{*}=.01<p<.05$.

\section{Feeding and first bath}

Consistent with their responses on usual practice, most trained dais (90.4 percent) but only a minority of untrained dais (41.4 percent) reported giving breast milk as the first feed in the last delivery. (The untrained dais primarily gave goat's milk (46.2 percent) at that time.) Regarding timing of first bath, 67 percent of trained dais and 44.0 percent of untrained ones delayed the first bath for at least 6 hours (figure 6.2); the difference is highly significant.

Figure 6.2: Percentage distribution of dais according to timing of first bath for the newborn, by training status
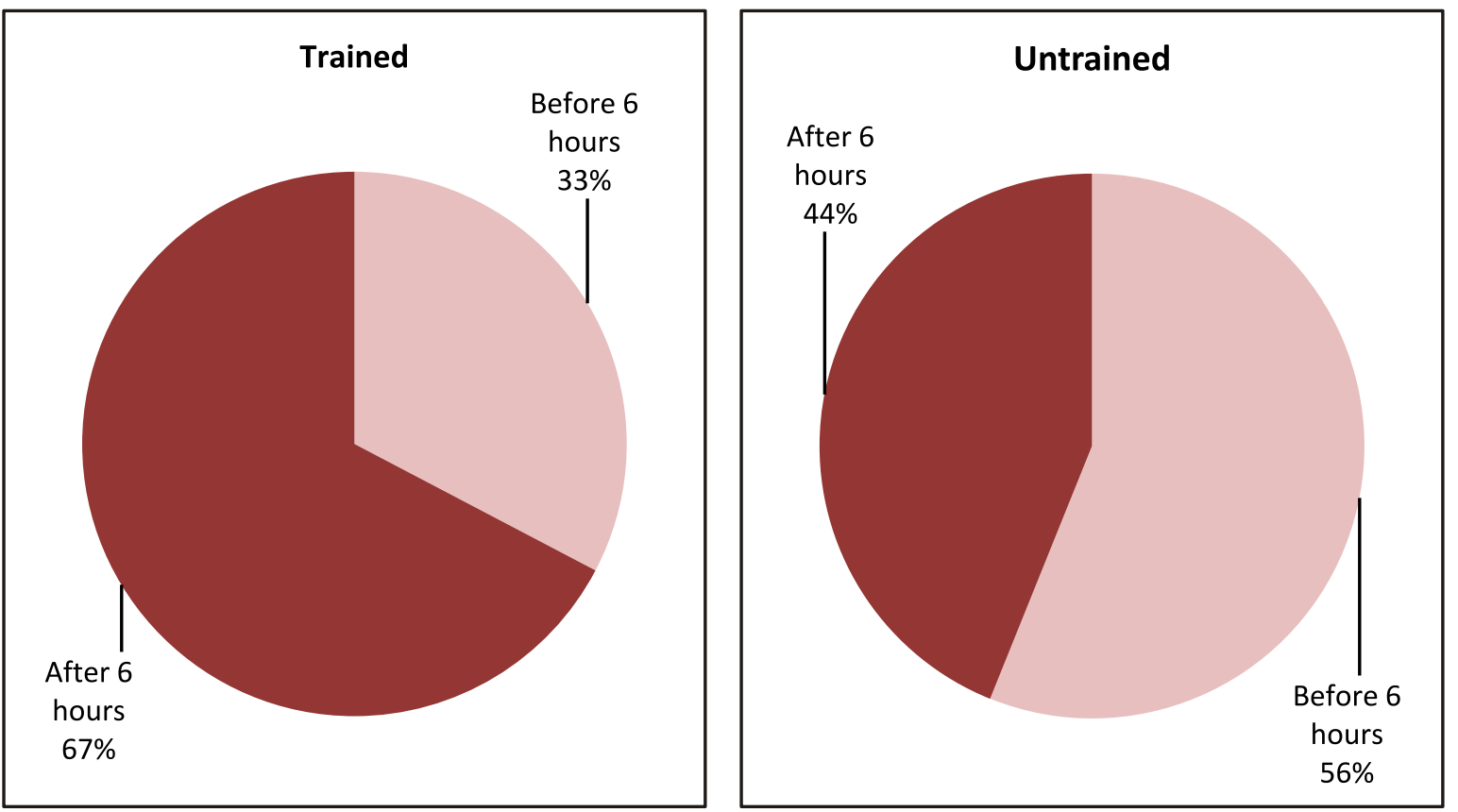


\section{Client Responses}

Clients were asked several of the same questions as the dais regarding neonatal care at last delivery; the comparison should provide confirmation in general terms of the dais' reports, or otherwise. It should be remembered from previous discussion, however, that dais and clients may have different biases. We assume the dai will be trying to present her practice in a good light, according to her understanding; the trained dais will be more likely to report doing what she learned in training, whether or not she actually did it. The client, on the other hand, will try to support her dai, whether trained or untrained; but she is limited in this both by her understanding of what the dai ought to do, and by her observations and recollections of exactly what happened during such an intense period. Moreover, it should also be noted that the trained dais were practicing in communities where a quite intensive community education package was being implemented, so that clients in those communities may have had a better understanding of what the dai ought to do. We must bear these things in mind as we consider the comparisons between dai and client responses.

\section{Cleaning and warming.}

Table 6.8 shows the parts of the baby's body that the mother reports were cleaned by the dai. As with the dai reports, client reports indicated that the trained dais were more likely than untrained ones to clean each body part except the body itself, where they were about the same. However, all proportions are somewhat lower, consistent both with the hypothesis that the dai may over-report practices that she believes she should do, and with the hypothesis that the clients may not be fully observant.

Table 6.8: Percentage of clients reporting neonatal body parts cleaned by dai after last delivery, by dai training status

\begin{tabular}{|c|c|c|}
\hline Body part cleaned & $\begin{array}{l}\text { Trained dais } \\
N=344\end{array}$ & $\begin{array}{l}\text { Untrained dais } \\
N=348\end{array}$ \\
\hline Eyes & $76.6^{* *}$ & 58.0 \\
\hline Nose & $72.5^{\star *}$ & 55.0 \\
\hline Ears & $63.1^{* *}$ & 48.1 \\
\hline Mouth & $76.2^{\star \star}$ & 58.9 \\
\hline Body & 88.1 & 88.3 \\
\hline Does not know & 4.9 & 6.5 \\
\hline No. of observations & 244 & 231 \\
\hline
\end{tabular}


Similarly, clients reported the trained dais to be much more likely to clean with material from the clean delivery kit (20.2 percent) or with cotton (7.6 percent) than the untrained dais (0.6 percent and 2.0 percent respectively). Conversely, 92.5 percent of untrained dais and 60.8 percent of trained dais used an old cloth.

Regarding steps to keep the baby warm, however, there was no significant difference. Most clients reported that the dai, regardless of level of training, cleaned the baby with one cloth and wrapped in another, without mentioning laying the baby with the mother.

\section{Cord care.}

The dais were trained to cut the cord after expulsion of the placenta with a new blade, or if a new blade is not available, to clean the instrument by boiling or with detol. They were trained to tie the cord in two places, and to tell the mother not to put anything on the placenta. Table 6.9 gives the clients' reports on various aspects of cord care. Both trained and untrained dais routinely cut the cord after expulsion of placenta and with a new blade; when a new blade is not used, neither effectively cleans the tool used. More trained than untrained dais tie the cord in two place, but the proportion is still fewer than half. More clients of trained dais reported being advised not to dress the cord, or to make some attempt to do so cleanly, than untrained dais, who were more likely to advise oil, ghee, or antimony; to some extent, this tendency is reflected in client reports regarding what they actually did. 
Table 6.9: Percentage of clients reporting specified cord care practices by dais after last delivery, by training status

\begin{tabular}{|c|c|c|}
\hline Cord care practice & Trained dais & Untrained dais \\
\hline Cut after expulsion & 96.3 & 95.3 \\
\hline Cut with new blade & 92.7 & 93.9 \\
\hline If no blade, cleaned tool $(n=17,13)$ & 5.9 & 15.4 \\
\hline Cord tied in two places & $38.2^{\star *}$ & 12.9 \\
\hline \multicolumn{3}{|l|}{ Dai advised mother on cord dressing* } \\
\hline To apply nothing & 7.0 & 1.7 \\
\hline $\begin{array}{l}\text { To use boiled water/spirit/ } \\
\text { antibiotic/powder }\end{array}$ & 19.8 & 13.6 \\
\hline To use oil/ghee/antimony/ash & 42.0 & 48.9 \\
\hline Gave no advice & 29.2 & 34.0 \\
\hline Other & 2.1 & 1.7 \\
\hline \multicolumn{3}{|l|}{ Client did** } \\
\hline Nothing & 14.3 & 5.6 \\
\hline Boiled water/spirits/antibiotic powder & 20.6 & 18.1 \\
\hline Oil/ghee/antimony & 61.8 & 72.4 \\
\hline Other & 3.4 & 3.9 \\
\hline No. of observations & 246 & 235 \\
\hline
\end{tabular}

\section{Establishment of breastfeeding.}

Table 6.10 largely confirms the dais' reports that trained dais promote initial breastfeeding far more than untrained ones. Mothers delivered by trained dais are much more likely to give colostrum immediately (i.e., within about the first hour) after birth than mothers of untrained ones; conversely, mothers delivered by untrained dais are much more likely to give ghuttee (pre-lacteal) prior to starting breastfeeding. Finally, mothers delivered by trained dais are much more likely to initiate breastfeeding within the first hour after delivery.

Table 6.10: Percentage of clients reporting specified practices regarding initial establishment of breastfeeding, by dai training status

\begin{tabular}{lrr}
\hline Breastfeeding practice & \multicolumn{1}{c}{ Trained dais } & Untrained dais \\
\hline Given mothers' milk soon after delivery & $55.6^{* \star}$ & 22.7 \\
Given pre-lacteal (ghuttee) first & $49.8^{\star *}$ & 78.0 \\
Initiated breastfeeding within first hour & $45.9^{\star *}$ & 19.8 \\
No. of observations & $\mathbf{2 4 4}$ & $\mathbf{2 3 2}$ \\
\hline${ }^{* *}=p<.01$. & &
\end{tabular}




\section{Other neonatal practices.}

In other practices as well, clients of trained dais reported better practices than clients of untrained dais, at least to some extent. Clients of trained dais reported waiting at least 6 hours before the first bath in 53.7 percent of cases, compared with 41.1 percent of clients of untrained dais.

Clients of trained dais reported 59 cases of breathing problems in their newborn, compared with 67 clients of untrained ones. In this case, 27 (45.8 percent) clients of trained dais and 20 (29.9 percent) of clients of untrained dais reported that the dai gave mouth-tomouth resuscitation; other differences were not substantial, but favored the trained dais.

Of the clients who did not already know about getting their babies immunized, 36.0 percent of those delivered by trained dais were advised to do so, compared with 11.3 of clients of untrained dais.

Finally, delivery charges reported by clients were similar: the mean for trained dais was 352 rupees, compared with 377 for untrained dais. The median was the same for both.

\section{Summary}

By all measures - knowledge, skill, reported usual practice, reported practice in last delivery, and clients' reports on last delivery - dais trained in the SMART curriculum performed better on nearly all aspects of neonatal care than those not trained. The broad agreement among the various measures - particularly the comparisons of dais and clients' reports - gives us some confidence that there are real differences in practice. However, not all differences are equally substantial, or equally important.

For cleaning, most dais, trained or untrained, cleaned the most important parts of the newborn. However, the trained dais are more likely to specifically clean each part (except for the body), and since the skills test demonstrates that the trained dais are more likely to clean correctly, the combined effect is probably quite substantial. However, even for trained dais there is still room for improvement in the type of material used for cleaning.

Similarly, trained dais were more likely to report examining each important body part, and the skills test indicates that they are more likely to do so properly. (We could not 
usefully ask the clients for confirmation on this.) Thus, it is probable that the trained dai is considerably more likely to notice when something is wrong with the newborn baby.

For cord care, the differences may not be so important. Nearly all dais in our study, trained or untrained, cut the cord with a new blade after expulsion of the placenta. While the trained dai is somewhat more likely to tie the cord in two places, and to use better practices for cord dressing, these differences may not have large health implications.

Since birth asphyxia is such a major cause of neonatal mortality, the dais' practice when a newborn is not breathing properly is of great importance. While it is clear that the trained dai has far superior knowledge, and reports much better practice, it is less clear what happens in actual practice. Our questionnaires do not allow for a clear determination regarding whether the right practice is followed for the particular breathing problem.

The trained dais are more knowledgeable about how to keep the baby warm, and the need to delay the first bath. However, their reported better warming practice is not confirmed by the clients, and the difference in timing of first bath is not great. It is not clear whether there is or is not any important change in dai practice that would reduce the possibility of hypothermia.

Perhaps the most impressive change has occurred in initiation of breastfeeding. While immediate initiation of breastfeeding and avoidance of pre-lacteals is not rare among mothers delivered by untrained dais, it is far more common among the clients of trained dais, according to both dai and client reports. The apparent willingness and ability of the dai to change such important and long-established customs is worth noting among efforts to deal with this issue in Pakistan. 


\section{Referral}

Both the dais and the referred clients were asked a similar set of questions regarding specific referrals. Because the dais were asked in detail about their referrals during the previous six months (up to four, if she had done that many), but only the most recent referred client was interviewed, the set of client interviews is a smaller subset of the dai reports. Since trained dais referred more often than untrained dais (see below) there are more reports from the former. We obtained reports of 298 referrals from trained dais and 194 referrals from untrained dais; and we interviewed 169 clients of trained dais and 114 clients of untrained dais. On the whole, given the relatively small numbers and the difference in the datasets, the dai and client reports matched fairly well. We will therefore present the data from dais and clients together, comparing by training status.

\section{Frequency of referral and reasons}

As indicated in Results section 1 above, the trained dais reported conducting, on average, 13.4 cases during the previous 6 months, compared with 12.9 cases reported by untrained dais; the difference was not statistically significant. These included both deliveries conducted at home, and deliveries referred. For deliveries conducted at home, the means were 12.2 and 12.0 cases for trained and untrained dais, respectively. This confirms that the two groups of dais had similar levels of clientele. However, a particularly important aim of the dai training was to improve the ability of the dais to recognize the need for referral to appropriate health facilities in case of emergency, and increase their willingness to do so. This section examines this issue. Dais were asked how many cases they had referred to a health facility during the past six months. For up to four of these cases, some detail was asked about the referral.

Table 7.1 shows the distribution of reported referrals during the previous six months by training category. The total number of referrals was 313 (9.5 percent of all reported deliveries) for trained dais compared with 209 (6.8 percent) for untrained dais. (This number is somewhat larger than the number of referrals for which data is available, because we obtained data on a maximum of four referrals for any one dai.) About twothirds of trained dais had referred at least one client during that period, compared with slightly fewer than 50 percent of untrained dais. Conversely, 40 percent of trained dais had referred at least two clients during the preceding six months, compared with 18 percent of untrained dais. The mean number of reported referrals was 1.15 for trained 
dais and 0.82 for untrained ones, i.e., the trained dais referred about 40 percent more of their clients. These data are sound: we did not find a case where a dai, trained or untrained, reported a referral that was disputed by the client. The difference is highly significant $(\mathrm{p}<.01)$, but not extremely large; however, if this difference in frequency is coupled with substantially better judgment regarding the reasons and timing of the referrals, the combined effect could be extremely important in saving lives.

Table 7.1: Number and percentage distribution of dais according to number of deliveries referred in six months prior to interview, by training status

\begin{tabular}{lrrrr}
\hline \multirow{2}{*}{ No. of referred deliveries } & \multicolumn{2}{c}{ Trained dais } & \multicolumn{2}{c}{ Untrained dais } \\
\cline { 2 - 5 } & \multicolumn{1}{c}{ No. } & \multicolumn{1}{c}{ Pct. } & No. & \multicolumn{1}{c}{ Pct. } \\
\hline 0 & 105 & 33.5 & 130 & 51.0 \\
1 & 83 & 26.5 & 79 & 31.0 \\
2 & 47 & 17.2 & 26 & 10.2 \\
3 & 24 & 8.8 & 13 & 5.1 \\
4 & 9 & 3.3 & 1 & 0.4 \\
5 & 2 & 0.7 & 3 & 1.2 \\
6 & 3 & 1.1 & 2 & 0.8 \\
8 & 0 & 0.0 & 1 & 0.4 \\
Total no. of referred deliveries & $\mathbf{3 1 3}$ & $\mathbf{1 0 0 . 0}$ & $\mathbf{2 0 9}$ & $\mathbf{1 0 0 . 0}$ \\
Total no. of dais & $\mathbf{2 7 3}$ & -- & $\mathbf{2 5 5}$ & -- \\
Mean no. of referrals per dai & $\mathbf{1 . 1 5 ^ { * * }}$ & -- & $\mathbf{0 . 8 2}$ & -- \\
\hline$* *=p<01^{*}{ }^{*}=01<<.05$ & & & &
\end{tabular}

${ }^{* *}=p<.01 ;{ }^{*}=.01<p<.05$.

\section{Reasons for referral}

Both dais and their clients were asked the reason to go to a health facility, and the answers, in whatever form they were given, were recorded in pre-coded categories by the interviewers (who were trained Lady Health Visitors), with more than one reason allowed. Table 7.2 shows the results. Among referrals for delivery, the most common reasons for referral were prolonged labor and failure of the cervix to dilate adequately. These were more commonly reported by the clients than the dais, and for clients of untrained than trained dais. Referral for clients of untrained dais was also more commonly reported for rupture of the water bag. Dais were more likely to report referral for problems of pregnancy than untrained dais. On the whole, there is little evidence that the trained dais tended to refer for better reasons than the untrained dais. 
Table 7.2: Percentage distribution of referred clients according to reason for referral, by source of report and training status

\begin{tabular}{lrrrr}
\hline \multirow{2}{*}{ Reason for referral } & \multicolumn{2}{c}{ Dai reports } & \multicolumn{2}{c}{ Client reports } \\
\cline { 2 - 5 } Prolonged labor & Trained & Untrained & Trained & Untrained \\
Cervix not dilating & 18.6 & 20.3 & 30.2 & 26.8 \\
Bleeding & 31.1 & 40.1 & $40.1^{*}$ & 53.6 \\
Cessation of labor pains & 7.4 & 7.8 & 10.5 & 8.2 \\
Malposition of fetus & 9.8 & 9.9 & 10.5 & 15.2 \\
Convulsions/fits & 7.1 & 7.3 & 7.4 & 5.4 \\
Retained placenta & 0.0 & 0.5 & 0.0 & 0.9 \\
Rupture of water bag & 2.7 & 1.0 & 1.9 & 0.9 \\
Unconsciousness/shock & $4.4^{*}$ & 9.9 & 9.3 & 15.2 \\
Meconium-stained discharge & 0.0 & 0.5 & 0.0 & 0.9 \\
Problem of pregnancy & 1.0 & 0.0 & 0.0 & 0.0 \\
Problem of puerperium & 27.4 & 22.9 & 14.8 & 15.2 \\
Problem of newborn & 2.7 & 1.0 & 2.5 & 0.9 \\
Other & 7.1 & 6.3 & 4.9 & 4.5 \\
No. of observations & 13.5 & 9.9 & 16.0 & 8.9 \\
\hline${ }^{*}=.01<$ p $<.05$. & $\mathbf{2 9 6}$ & 192 & 162 & $\mathbf{1 1 0}$ \\
\hline
\end{tabular}

\section{Initiating the referral}

\section{Timing and referred facility}

The importance of referral enhanced when a client is referred at an appropriate time, while effective care is still possible. Health care providers frequently complain that dais often delay referral, jeopardizing effective treatment. Changing this behavior was a great challenge for this training, and facilitators tried to inculcate the importance of timely referral. It is also imperative to guide the referred client to a facility that is open and has the capability of addressing the presenting problem. Dais sometimes may avoid referral, especially to a public health facility, as they receive discouraging feedback on late referral. During training, a liaison was therefore established between dais and public as well as private health care providers to reduce distances, make the dais more comfortable with the providers, and improve the reception given by the providers.

Both dais and their clients were asked about the duration of labor prior to referral (for those clients referred during labor) and the place to which the client was referred. Table 
7.3 shows that according to both dai and client reports, trained dais tended to refer earlier than untrained dais, with more referring within four hours and fewer after 10 hours $(\mathrm{p}<.01$ for both dais and clients). This reflects some success of the dai training in reducing the "first delay," i.e., the delay in making a decision to go to a health facility.

Table 7.3: Percentage distribution of referred clients according to timing of referrals by source of report and dai training status

\begin{tabular}{lcccc}
\hline & \multicolumn{2}{c}{ Dai reports } & \multicolumn{2}{c}{ Client reports } \\
\cline { 2 - 5 } Timing of referral (duration of labor) & $\begin{array}{c}\text { Trained } \\
\text { dais }\end{array}$ & $\begin{array}{c}\text { Untrained } \\
\text { dais }\end{array}$ & $\begin{array}{c}\text { Trained } \\
\text { dais }\end{array}$ & $\begin{array}{c}\text { Untrained } \\
\text { dais }\end{array}$ \\
\hline Up to 4 hours & 16.8 & 11.9 & 25.0 & 7.4 \\
5-8 hours & 14.1 & 12.4 & 16.4 & 13.0 \\
9-12 hours & 11.7 & 10.8 & 13.6 & 15.7 \\
$>12$ hours & 17.4 & 32.5 & 25.7 & 35.2 \\
Other & 3.7 & 3.6 & 7.1 & 5.6 \\
Referred other than during labor & 36.2 & 28.9 & 12.1 & 23.1 \\
No. of observations & $\mathbf{2 9 8}$ & $\mathbf{1 9 4}$ & $\mathbf{1 4 0}$ & $\mathbf{1 0 8}$ \\
\hline
\end{tabular}

In a considerable majority of cases, the dai made the decision to go the hospital or clinic. According to both dai and client reports, upwards of 80 percent of the time the dai is reported as the primary decision maker, with husbands, mothers-in-law, and the woman herself being less likely to make decisions. However, this is probably biased by the nature of the study, which focuses on the dais' roles. For example, in a PAIMAN project study of maternal and neonatal practices in ten districts throughout Pakistan, 37.4 percent of mother reported that the dai made the decision to seek health care in case of complication in DG Khan, a higher proportion than in any of the other nine districts (data not shown).

Table 7.4 shows that, according to both dais and clients, a higher proportion of untrained dais chose private services as the option for referrals, whereas a higher proportion of the trained dais referred to public health facilities. (The overall differences were significant for the dais, non-significant for the clients.) However, most referrals, by trained or untrained dais, were to private facilities. Of particular significance is referral to the DHQ hospital, which in DG Khan was the only facility with complete emergency obstetric care facilties; according to both dais and clients, trained dais were more likely to refer to this facility. 
Table 7.4: Percentage distribution of referred clients according to referred facility by source of report and dai training status

\begin{tabular}{lrrrr}
\hline \multirow{2}{*}{ Referred facility } & \multicolumn{2}{c}{ Dai reports } & \multicolumn{2}{c}{ Client reports } \\
\cline { 2 - 5 } & Trained dais & Untrained dais & Trained dais & Untrained dais \\
\hline BHU & 4.7 & 2.1 & 2.4 & 1.8 \\
RHC & 9.1 & 3.1 & 5.3 & 2.6 \\
DHQ Hospital & 11.7 & 4.6 & 8.9 & 2.6 \\
Private hospital & 34.6 & 37.6 & 36.1 & 40.4 \\
Private clinic & 32.6 & 45.9 & 41.4 & 41.2 \\
Other & 7.4 & 6.7 & 5.9 & 11.4 \\
No. of observations & $\mathbf{2 9 8}$ & $\mathbf{1 9 4}$ & $\mathbf{1 6 9}$ & $\mathbf{1 1 4}$ \\
\hline
\end{tabular}

In most cases (between 62 and 70 percent), dais and clients agree that the dai accompanied the client to the hospital, regardless of training status. When the dai did not accompany the woman, it was most often because the client did not not wish it; according to both dais and clients, this was somewhat more likely for untrained dais. Dais gave a number of reasons for accompanying the client, the most common being in terms of their duty. Clients reported that the dai gave reassurance or looked after the client, but in a substantial proportion of cases (37 percent for trained dais, 44 percent for untrained dais) they reported that the dai did nothing (data not shown).

\section{Time to reach the facility}

The "second delay," i.e., the time to reach an appropriate facility once a decision has been made, can be reduced by ensuring that funds and transport are available or on call before a decision is made to refer. Dais were therefore trained to advise the mother's household to make such arrangements. Various options were discussed with dais for saving money for using it at the time of emergency and beforehand arrangement of vehicle for transportation of the client.

From table 7.5, both dais and clients reported that money had usually been arranged before any emergency arose. Trained dais were significantly more likely to report this than untrained dais, but for client reports, the difference was small and non-signficant; perhaps this represents some reporting bias on the part of the trained dais. According to both dais and clients, more than 90 percent of the time the money was arranged in less than an hour. 
Table 7.5: Percentage distribution of referred clients according to time required to arrange money for emergency referral, by source of report and dai training status

\begin{tabular}{lcccr}
\hline & \multicolumn{2}{c}{ Dai reports } & \multicolumn{2}{c}{ Client reports } \\
\cline { 2 - 5 } Time required & Trained dais & Untrained dais & Trained dais & Untrained dais \\
\hline Already arranged & 82.9 & 68.0 & 72.7 & 69.4 \\
$<1$ hour & 12.1 & 25.3 & 19.3 & 27.9 \\
$1-3$ hours & 2.3 & 3.1 & 5.6 & 1.8 \\
$>3$ hours & 1.7 & 0.5 & 0.0 & 0.9 \\
Other & 1.0 & 3.1 & 2.5 & 0.0 \\
No. of observations & $\mathbf{2 9 8}$ & $\mathbf{1 9 4}$ & $\mathbf{1 6 1}$ & $\mathbf{1 1 1}$ \\
\hline
\end{tabular}

As shown in table 7.6, in slightly over 90 percent of all referrals transport was arranged within an hour. According to both dais and clients, clients of trained dais were significantly more likely to have arranged transport in advance than untrained dais.

Table 7.6: Percentage distribution of referred clients according to time required to arrange transport for emergency referral, by source of report and dai training status

\begin{tabular}{lrrrrr}
\hline \multirow{2}{*}{ Time required } & \multicolumn{2}{c}{ Dai reports } & \multicolumn{2}{c}{ Client reports } \\
\cline { 2 - 3 } \cline { 2 - 3 } Already arranged & Trained dais & Untrained dais & & Trained dais & Untrained dais \\
\hline 1 hour & 65.8 & 49.7 & & 57.1 & 44.1 \\
$1-3$ hours & 25.5 & 42.5 & 35.4 & 47.7 \\
$>3$ hours & 5.7 & 5.7 & 3.7 & 8.1 \\
Other & 1.0 & 1.0 & 0.0 & 0.0 \\
No. of observations & 2.0 & 1.0 & 3.7 & 0.0 \\
\hline
\end{tabular}

About two/thirds of the dais - slightly more untrained than trained - reported accompanying their clients on the referral. A variety of answers were given regarding why they accompanied the clients, of which the most common was that it was their duty. These reasons did not differ substantially between trained and untrained dais (data not shown).

The time required for the transport to reach the referral facility can be critical for the life of the mother. Clients (but not dais) were asked how long this journey took. In most cases, the required time was between 30 and 60 minutes. In up to 15 percent of cases, the 
reported time was more than one hour, which may represent a high level of danger. There were no noticeable differences between trained and untrained dais in this.

Table 7.7: Percentage distribution of referred clients according to time required to reach referral facility, by dai training status

\begin{tabular}{lcc}
\hline Time required & Trained dais & Untrained dais \\
\hline$<30$ minutes & 22.4 & 21.6 \\
30-60 minutes & 60.9 & 64.0 \\
$>60$ minutes & 16.8 & 14.4 \\
No. of observations & $\mathbf{1 6 0}$ & $\mathbf{1 1 2}$ \\
\hline
\end{tabular}

\section{Management of referred case at facility}

\section{Obtaining treatment}

In most cases, treatment was given at the first place the client was taken (table 7.8).

However, in about one-tenth of cases, the woman needed to be taken to a second facility, and in a few cases even a third. Interestingly, the clients of trained dais were somewhat more likely to report needing to be taken to a second or third place than clients of untrained dais, although numbers are fairly small and the difference is non-significant.

Table 7.8: Percentage distribution of referred clients according to referral place where treatment was given, by source of report and dai training status

\begin{tabular}{lrrrr}
\hline & \multicolumn{2}{c}{ Dai reports } & \multicolumn{2}{c}{ Client reports } \\
\cline { 2 - 5 } Referral place where treatment given & \multicolumn{1}{c}{$\begin{array}{c}\text { Trained } \\
\text { dais }\end{array}$} & $\begin{array}{c}\text { Untrained } \\
\text { dais }\end{array}$ & $\begin{array}{c}\text { Trained } \\
\text { dais }\end{array}$ & $\begin{array}{c}\text { Untrained } \\
\text { dais }\end{array}$ \\
\hline First referral place & 89.4 & 89.5 & 82.6 & 90.7 \\
Second referral place & 9.6 & 9.9 & 12.3 & 7.4 \\
Third referral place & 1.0 & 0.5 & 5.2 & 1.9 \\
No. of observations & $\mathbf{2 9 3}$ & $\mathbf{1 9 1}$ & $\mathbf{1 5 5}$ & $\mathbf{1 0 8}$ \\
\hline
\end{tabular}

After reaching the treatment facility, treatment usually began within half an hour (table 7.9). Clients were somewhat more likely to report short waiting times, regardless of dai training. Only a small proportion of clients had to wait more than an hour before beginning treatment; however, it was not possible to learn whether specific, critical treatments were delayed. 
Table 7.9: Percentage distribution of clients according to time between reaching treatment facility and initiation of treatment, by source of report and training status

\begin{tabular}{lcccc}
\hline & \multicolumn{2}{c}{ Dai reports } & \multicolumn{2}{c}{ Client report } \\
\cline { 2 - 5 } Time to initiation treatment & $\begin{array}{c}\text { Trained } \\
\text { dais }\end{array}$ & $\begin{array}{c}\text { Untrained } \\
\text { dais }\end{array}$ & $\begin{array}{c}\text { Trained } \\
\text { dais }\end{array}$ & $\begin{array}{c}\text { Untrained } \\
\text { dais }\end{array}$ \\
\hline Within 30 minutes & 69.6 & 68.9 & 76.1 & 80.5 \\
30 to 60 minutes & 18.6 & 22.3 & 21.4 & 17.7 \\
More than 60 minutes & 2.4 & 3.1 & 2.5 & 1.8 \\
Other & 9.5 & 5.7 & n.a. & n.a. \\
No. of observations & $\mathbf{2 9 6}$ & $\mathbf{1 9 3}$ & $\mathbf{1 5 9}$ & $\mathbf{1 1 3}$ \\
\hline
\end{tabular}

\section{Outcome of referral}

The recognition of a complication which, in fact, requires an advanced intervention is a key factor in improving maternal and neonatal survival as well as reducing the load on overburdened health facilities. According to both dais and clients, a slightly higher proportion of referral cases of untrained dais resulted in normal delivery (with or without episiotomy) or of treatment for antenatal or postnatal problems (table 7.10). Conversely, more referrals from trained dais resulted in Caesarean section, other intervention requiring hospital care, or further referral. These differences are significant in the dai report $(\mathrm{p}<.01)$, but not quite significant in the client reports. Performance of Caesarean section as the result of referral implies that the referral was correct and important; therefore the difference between trained and untrained dais in this regard is of particular note. Clients were somewhat more likely to report normal delivery than dais. 
Table 7.10: Percentage distribution of referred clients according to procedures taken at delivery facility, by source of report and training status

\begin{tabular}{lrrrr}
\hline & \multicolumn{2}{c}{ Dai reports } & \multicolumn{2}{c}{ Client reports } \\
\cline { 2 - 5 } Procedure at referral facility & $\begin{array}{c}\text { Trained } \\
\text { dais }\end{array}$ & $\begin{array}{c}\text { Untrained } \\
\text { dais }\end{array}$ & $\begin{array}{c}\text { Trained } \\
\text { dais }\end{array}$ & $\begin{array}{c}\text { Untrained } \\
\text { dais }\end{array}$ \\
\hline Delivery & & & & \\
$\quad$ Normal delivery & 48.6 & 51.5 & 56.6 & 60.2 \\
$\quad$ Delivery with episiotomy & 6.8 & 12.9 & 9.4 & 15.9 \\
$\quad$ Caesarean section & 11.5 & 6.7 & 13.2 & 5.3 \\
Further referral & 1.7 & 0.0 & 1.9 & 0.0 \\
Treatment given for problems of pregnancy & 19.3 & 23.2 & 12.6 & 15.0 \\
neonatal or postpartum health & 5.1 & 3.1 & n.a. & n.a. \\
D\&C & 7.1 & 2.6 & 6.3 & 3.5 \\
Other & $\mathbf{2 9 6}$ & $\mathbf{1 9 4}$ & $\mathbf{1 5 9}$ & $\mathbf{1 1 3}$ \\
No. of observations & & & &
\end{tabular}

The sense that trained dais were more likely to refer difficult cases is strengthened by birth outcome in cases where referral resulted in delivery (as opposed to antenatal or postnatal/postpartum treatment). Outcome was more likely to be a stillbirth or abortion for trained than untrained dais, according to both dais and clients (significant at $\mathrm{p}<.05$ for dais, non-significant for clients). Clients, however, were somewhat more likely to report live births than dais (table 7.11).

Table 7.11: Percentage distribution of referred deliveries according to outcome of delivery, by source of report and training status

\begin{tabular}{lrrrr}
\hline & \multicolumn{2}{c}{ Dai reports } & \multicolumn{2}{c}{ Client reports } \\
\cline { 2 - 5 } Outcome of delivery & Trained dais & Untrained dais & Trained dais & Untrained dais \\
\hline Live birth & 75.3 & 84.7 & 82.1 & 89.6 \\
Stillbirth & 11.5 & 10.4 & 10.0 & 7.3 \\
Abortion & 13.2 & 4.9 & 7.9 & 3.1 \\
No. of observations & $\mathbf{2 3 5}$ & $\mathbf{1 4 4}$ & $\mathbf{1 4 0}$ & $\mathbf{9 6}$ \\
\hline
\end{tabular}

Clients were asked about the total expenditure for the referral (table 7.12). For poor rural dwellers, these were substantial: the median reported expenditure was Rs4,000 - about \$US66 (\$1 = Rs60). About 30 percent of clients reported expenditure of Rs6,000 (\$100) or more, while the maximum reported expenditure was Rs30,000. There was no systematic or significant difference between clients of trained and untrained dais. 
Table 7.12: Distribution of expenditure for client referrals, by dai training status

\begin{tabular}{lcc}
\hline Expenditure (rupees) & Trained dais & Untrained dais \\
\hline $0-1,000$ & 9.4 & 6.3 \\
$1,001-2,000$ & 18.8 & 12.5 \\
$2,001-3,000$ & 12.5 & 22.3 \\
$3,001-5,000$ & 28.1 & 31.3 \\
$5,001-10,000$ & 16.3 & 18.8 \\
$>10,000$ & 15.0 & 8.9 \\
No. of observations & $\mathbf{1 6 0}$ & $\mathbf{1 1 2}$ \\
\hline
\end{tabular}

Finally, both dais and clients were asked about their treatment at the facility. The considerable majority of their responses were positive, but some - especially clients were critical of providers' attitudes, work efficiency, or greed.

\section{Summary}

How often dais refer clients to appropriate facilities for maternal emergencies, and how well they judge the need for referral in particular cases, is the most critical issue faced in any attempt to improve the dais' performance. We have previously seen that the trained dais have substantially better knowledge of the complications of pregnancy and delivery than the untrained dais; this section explores the degree to which that knowledge has been put into practice.

Perhaps the most important indicator here is the most basic: trained dais referred about 40 percent more cases than untrained ones. The ratio of referrals to total deliveries was 9.5 percent for trained dais compared with 6.8 percent for untrained dais; an international "rule of thumb" suggests that about 15 percent of all pregnancies result in complications requiring medical attention. To the extent that these are the "right" referrals, the impact of referral is enhanced. We have fairly limited evidence regarding this, since we had no access to trained medical opinion. However, there is some evidence that clients referred by trained dais were more likely to experience Caesarean section births, and their deliveries were more likely to end in stillbirth or abortion, suggesting a higher likelihood that clients referred by trained dais were more likely to have been in serious danger.

There is also significant indication that dai training reduced the time between the onset of an emergency and the initiation of treatment. From both dai and client reports, clients of 
untrained dais were more likely to be referred within four hours of the initiation of labor. Clients of trained dais were more likely to have arranged for money (at least according to dai reports) and transport (according to both dais and clients) than clients of untrained dais, resulting in a reduction of the time between making the decision to refer and the initiation of travel. While dai training did not seem to effect travel time or the time to obtain treatment at the facility, the reduced time involved in initiating the referral represents a substantial benefit of the dai training.

In sum, dai training has resulted in improved knowledge of the complications of delivery; increased propensity to refer in case of perceived complications; reduced time to initiate the referral; and perhaps an increased proportion of more dangerous cases being referred. Given that the trained dais conduct a high proportion of all deliveries in their communities, it would seem that this should have resulted in lower maternal mortality and fewer stillbirths in those areas. We will review the evidence for this in the conclusion to this report.

Other data from this section, while not indicating significant effects of dai training, provide useful data on the experience of childbirth in rural DG Khan. The influence of the dai on referral, as reported by both dais and clients, is striking, even if perhaps overstated. The strong propensity to go to the private sector rather than the public sector for maternal emergencies speaks strongly to the reputations of the respective sectors. While most women are able to reach a referral facility in less than one hour, and are treated in that place within 30 minutes, significant numbers of women need to travel for substantial times, be shifted to a second or third referral facility, or wait a substantial time to be treated. Finally, the cost of referral, in relation to typical incomes in this setting, would seem likely to be an inhibiting factor in the decision to go to a facility. While few families would be unwilling to spend such sums to save the mother, if the client or her family believe it likely that going to a health facility will in fact result in an unnecessary expense, treatment needed to save lives may be delayed or rejected. 


\section{Other Topics}

\section{Use of clean delivery kits}

The SMART project worked with Greenstar Social Marketing Ltd. on slight revisions of its standard clean delivery kits (CDKs), which were produced and sold to the SMART project at 18.50 rupees. The SMART dais were carefully trained in the use of these kits. They were given five kits free at the end of training, with the expectation that they would then buy the kits themselves on local markets. Later, the project arranged for the kits to be sold to the trained dais at their homes at cost; but there was a period between when many trained dais ran out of the original stock. Hence the trained dais went through a period when they were using free kits supplied by the project, followed by a period when they had to use their own initiative and funds, followed by a period when the kits were readily available, but at cost.

The dais were not asked directly whether they used a CDK at the last delivery. They were, however, asked questions about practice in last delivery where use of the kit, if any, should have been part of the answer. They were asked more general questions about their use and opinion of the kits. Clients, on the other hand, were asked directly whether the dai used a kit at the reference delivery, as well as indirect questions which might have elicited the use of the kits.

Table 8.1 shows three comparisons between trained and untrained dais on use of the CDKs for the reference delivery. Unsurprisingly, dai reports indicate far more use of the CDKs by trained than untrained dais. Client reports confirm a substantial difference, but at lower levels. In addition, 36 percent of clients of trained dais and 1 percent of clients of untrained dais reported that the dai spread the plastic sheet from the CDK beneath her for delivery. The differences between dai and client reports on trained dais may be because of overstatement by the dais, or understatement by clients, or both. 
Table 8.1: Percentage reporting use of clean delivery kits according to situation, by source of report and dai training status

\begin{tabular}{lrrrr}
\hline \multirow{2}{*}{ Situation for kit use } & \multicolumn{2}{c}{ Dai reports } & \multicolumn{2}{c}{ Client reports } \\
\cline { 2 - 5 } & \multicolumn{1}{c}{ Trained } & Untrained & Trained & Untrained \\
\hline Dai brought kit & $54.0^{* *}$ & 0.0 & $37.2^{* *}$ & 0.7 \\
Used gloves in pelvic examination ${ }^{4}$ & $76.4^{* *}$ & $24.4^{*}$ & $43.1^{* *}$ & 8.0 \\
Used kit in cleaning baby & $37.5^{* *}$ & 0.4 & $19.9^{* *}$ & 0.6 \\
\hline${ }^{* *}=p<.01 ;{ }^{*}=.01<p<.05$. & & &
\end{tabular}

When asked directly if her dai used a clean delivery kit, 40 percent of trained dais and 1 percent of untrained dais said they did. In nearly all cases, the dai was reported to have brought the kit herself.

Dais were asked in some detail about their general use and views on the clean delivery kits. Nearly 95 percent of trained dais, compared with 3 percent of untrained dais, reported having used the kits; nearly all reported that they are useful. Reasons why were reported almost entirely in terms of cleanliness. About two-thirds of trained dais reported consistently using the kits; of these, similar percentages reported getting their kits in training (31 percent), from medical stores (34 percent) and from the SMART representatives (29 percent). Of those not consistently using the kits, about 22 percent reported in terms of cost. The proportion willing to buy their kits from medical stores is encouraging (data not shown).

Most trained dais (71 percent) and many untrained dais (43 percent) report that the women want to use the CDKs; in addition to cleanliness, many cite the availability of all necessary items in one place as reasons. For those who said women don't want to use the kits, poverty was cited as the main reason. Most (72 percent) trained dais said they want to use in the future, compared with about one-fourth of untrained dais. About half of those who do not cited cost as the reason (data not shown). Thus, it appears that a majority of the trained dais have been convinced that the kits are a good thing, and a substantial percentage, perhaps a majority, do so regularly.

\footnotetext{
4 Of these, 67.3 percent of trained and 1.9 percent of untrained dais reported that the gloves were obtained from the CDK. Clients were not asked this question.
} 


\section{Use of dai booklet}

After the SMART training, each dai was given a brief pictorial booklet showing proper procedures, for reference. At the OR interview, dais were asked if they had the booklet (and if so, to show it), whether the booklet was useful to her (how, or why not) and whether she had used it with village women (how, or why not). As Table 8.2 shows, nearly all trained dais, and almost no untrained dais, had received the booklet; nearly two thirds of those could produce it at the interview. The great majority had used the booklets both for themselves and for the village women. Dais say," We use this booklet by showing the pictures to groups of women." They also shared, "When we go for conducting delivery, we carry the booklet and explain wrong practices." However, some dais also reported not using this booklet because "It was for me," "I don't have the booklet" or "I lost it/it is torn."

Even given the expected "courtesy bias", it appears that the dai booklet is an appreciated and useful tool for the dai.

Table 8.2: Percentage of dais according to response on questions related to the dai booklet, by training status

\begin{tabular}{lcc}
\hline Question regarding dai booklet & Trained & Untrained \\
\hline Do you have the booklet? & $94.5^{* *}$ & 0.4 \\
If so, is the booklet useful for you? & 97.8 & 100.0 \\
If so, have you used it for your village women? & 90.0 & 0.0 \\
\hline${ }^{* *}=p<.01$. &
\end{tabular}

\section{Relations with LHW}

One of the routine tasks of the Lady Health Worker is to be present at deliveries among the women in her catchment area, to assist the dai but not to do the delivery, for which she is not qualified. The SMART project provided training on MNH for the LHWs in the areas in which the dais were trained, including reiterating this task. LHWs were instructed only to assist at the time of delivery, and in case of complications to help in referral of clients to an appropriate facility. Assistance at delivery can include cleaning and weighing the baby, assisting in resuscitation if needed, and supporting adoption of family planning. However, there appears in most situations to be a distance between 
LHWs and dais, who may not respect each other's roles. So it is of interest to see whether the training of both LHWs and dais on this point is successful in reducing this distance.

The data on this point suggest that any such effect was minimal. As a general practice, 8.9 percent of trained dais and 0.8 percent of untrained dais say that the LHW accompanies them for delivery. Clients, reporting on the reference delivery, say the LHW was present in 3.1 percent of deliveries conducted by trained dais, and 0.9 percent of deliveries conducted by untrained dais. These responses are not inconsistent, with both dais and clients confirming that the LHW is rarely present at delivery, whether or not the dai and the LHW received SMART training. The rather small number (total 44) of reports available on what the LHW does at delivery, it appears that the LHW mostly provides advice and guidance, and sometimes helps with cleaning and care of the baby (data not shown).

\section{Effect of training on dai}

The SMART dai training included a substantial component of "client centered" care, including efforts to establish a supportive relationship between dai and client. The trained dais were asked several questions about the effect of their training: Whether they felt any change in themselves, or in talking with their clients; whether they had told anyone in their community that girls need to be fed as much as boys; and whether their clientele had increased. Positive responses were followed up. Clients were asked about the attitude of the dai at the time of delivery.

The responses of the dais were highly positive: 95 percent said they felt change within themselves, 95 percent reported change while talking with clients; 92 percent reported talking about diet; and 54 percent said their clientele had increased.

However, among clients' responses there is little difference between trained and untrained dais regarding dais' behavior, perhaps merely because it was uniformly positive in either case. Multiple responses were allowed, but most clients simply reported "good behavior", with little difference between trained and untrained dais. 


\section{Summary}

This collation of separate topics provides additional evidence for a positive effect of the SMART dai training in some but not all areas. Use of the clean delivery kits is a matter of considerable importance for preventing infection of both mothers and newborns. It is likely that the client reports may be fairly accurate on this topic, since the CDK is quite noticeable at several points in the process. Even 40 percent use of the kits in any given delivery may have a substantial impact in preventing illness, and responses suggest that with regular supervision and supplies, this proportion could be increased.

The dai booklet seems to be appreciated, and dai reports indicate that it is used both for referral and client education. However, it is difficult to determine in a study of this type whether the booklet had a significant impact on the dais' practice.

Involving the LHW with the dai in delivery care is one of the aims of the Ministry of Health, but it is not an easy relationship to establish. The interventions of the SMART project seem to have had a statistically significant but not important impact in this area.

Finally, the dais consistently report that the training influenced them, both in their attitudes towards their jobs and in their treatment of clients. This is consistent with a strong emotional bond that was apparent during the training itself. However, given the "courtesy bias" routinely seen in responses to questions like these, it is difficult from the questionnaire to determine the nature and extent of real change. On the other hand, there is no evidence of rejection of this component of training. 


\section{Discussion}

The primary strength of the design of this study is in the controls; since the dais' communities were randomly allocated to treatments, the dais themselves were randomly allocated to be trained or not. Hence statistically significant differences between trained and untrained dais can, with reasonable assurance, be ascribed to the training. On basic characteristics there is little difference between the two groups, and the scores on the basic knowledge tests between the untrained dais and the trained dais prior to training were nearly identical. An additional strength of the design is the ability to relate dai reports on specific practice, both for referred and non-referred deliveries, to client reports for the same events.

The results in general clearly show important effects. As a generality, these show striking differences between trained and untrained dais in knowledge and skills; large, but often somewhat reduced, differences in dai reports of general practice; and further reduced but still substantial differences in dai reports on practices during the reference delivery. Client reports often support the existence of a substantial difference, but not always, and generally not to the same extent as the dais' reports.

The explanation for this seems fairly straightforward. Knowledge is not always put into action, and it is unsurprising that dais remember what they were trained to do to a greater extent than they put that knowledge into practice. However, the fact of such large differences in knowledge, and such high retention of the knowledge 19 months after training, is important and encouraging. It is also unsurprising that reports of specific practice in a given case may be less likely to reflect good practice than reports of general practice. This finding is routine in household surveys in cases where the respondent has a motive for "shading the truth", but may be reluctant to be consciously untruthful. Finally, with respect to the discrepancy between the trained dais and their clients, there are reasons to suspect overstatement on the part of the dai and understatement on the part of the client. The dai knows she is being evaluated by her trainers, and wants to please; the client is likely not to be particularly observant during a time of high physical and emotional stress, and may tend to report what she understands is common practice. In this case, reality may lie somewhere in between. The reliability of client reports may depend strongly on topic; in some cases, such as cord care, the client may not notice 
exactly what the dai does, whereas in others, such as whether a clean delivery kit was used, she may be more likely to notice and report correctly.

But regardless of the specifics for each item, one major finding is clear: overall, the dai training had a large, positive effect on her practice.

This general finding, however, has two important qualifications. First, the differences between trained and untrained dais are greater in some areas than in others, so the effects are by no means uniform. Second, there are situations, particularly where a behavior is completely unfamiliar to the untrained dais, where the difference is highly significant statistically, but where nevertheless the performance of the trained dai is inadequate. There remains substantial room for improvement.

Among the important contributions of the dai training are the following:

- Knowledge and skill. In all areas, the trained dais, even at 19 months after training, showed substantially greater knowledge and skill than the untrained dais. This is shown not only on tests, but in answers to complex questions; for example, in the variety of answers on what to do if the placenta is not expelled, or in case of asphyxia. There are synergies here; for example, whether a necessary referral is made depends not only on whether the dai knows the importance of a complication, but also whether she can properly recognize that complication. Improved knowledge and skills do not necessarily lead to better practice, but they are a necessary underpinning.

- Antenatal care. The superior knowledge of the trained dais regarding risk factors and danger signs during pregnancy provide a sound basis for better referral.

- Delivery care. The use of cleaner delivery practices, including substantial use of clean delivery kits, the substantial reduction in pelvic examinations performed without gloves, and other practices, probably make an important difference in avoiding sepsis for both mothers and newborns.

- Postpartum. The increased frequency of postpartum referrals is an important outcome of the dais training. In addition, the greater attention paid to family planning may be an important contribution to future reductions in maternal mortality. 
- Neonatal care. Greater attention to cleanliness in delivery and neonatal care practices is an important component in reducing neonatal mortality. It is also possible that there are important differences in management of asphyxia. In the long run, the sharp improvement in establishing exclusive breastfeeding early is an important, and perhaps most surprising, outcome of this training.

- Referral at delivery. The trained dais made substantially more referrals, made them earlier, and made them on a sounder basis of knowledge. While we cannot tell whether each referral was "right", it is likely that this outcome may be the single most important in reducing maternal mortality.

- "Client-centered" approach. From this study, the effect of training on the dais' interactions with their clients is hard to assess directly. But the dais' own statements support the trainers' assessment that this aspect of the training was critical to persuading the dais to buy in to their training.

However, many areas need improvement, including some where the dais' improvement, while notable, remains far from adequate. Among these are:

- Use of uterotonics. The use of uterotonics, particularly oxytocin, to hasten thirdstage labor is widespread in DG Khan, and our training was only modestly effective in curbing this dangerous practice. An approach is needed, perhaps through public education, to remove the impression that this represents sound, modern practice.

- Pelvic examinations. As with uterotonics, we made only modest progress in reducing the use of pelvic examinations, although we did succeed in increasing the proportion done with gloves. Eventually we concluded that convincing the dai to do a single, clean pelvic examination might be the best compromise.

- Clean delivery kits. While we greatly increased the use of this simple, cheap innovation, large numbers of deliveries were still done without it. Better logistics would have improved this situation.

- Cleaning and warming the newborn. While some progress was made in keeping the neonate clean, more could be done, and there did not seem to be a strong effect on measures that might avoid hypothermia. 
In other ways, we learned about some important aspects of birth practice, unrelated to training. On the positive side, it appears that most households to make some arrangements for money and transport in case of emergency. Also, even untrained dais generally visit mother in both antenatal and postpartum periods. We also noted how important the role of the dai is in the decision to seek medical care, or not, as well as a strong preference for the private sector in the referral process. On the negative side, the widespread prevalence of unclean pelvic examinations and use of uterotonics in third stage labor has been noted. Also, even though both dais and LHWs were trained in cooperation at delivery, there was little evidence that this occurs.

The likely mortality impact of these effects for mothers and newborns depends on the specific practice. Some specific practices, such as whether the umbilical cord is completely untreated or treated with antiseptic, may only rarely make a difference. Other practices, such as initial proper establishment of breastfeeding, may have impact well beyond the neonatal period. In general, it is well understood that by far the most important thing that a dai with limited training and facilities can do to save a mother's life is to refer her to a hospital. Here, therefore, the difference in the frequency of referrals suggests that dai training can have an important effect on maternal mortality from this alone. If, moreover, knowledge gained from the dai training results in referrals that are more timely and for better reasons, that effect will be multiplied. It is impossible from interviews such as these to ascertain whether a particular referral is justified or not, but there are some indications that the referrals of the trained dais may be more timely and correct than those of the untrained dais. Given the difference in knowledge, it would be surprising if this were not so. The project's evaluation system did not have sufficient sample sizes to estimate maternal mortality directly, so the actual effect of the dai training cannot be estimated.

For neonatal mortality, on the other hand, saving lives of babies born at home is more likely to involve sound delivery and postnatal care at home than emergency referral, as shown in the work of Abhai Bang in India and Zulfiqar Bhutta in Pakistan. Knowing how to deal with birth asphyxia, avoiding hypothermia, preventing sepsis, and establishing breastfeeding are among the critical practices needed to avert neonatal death, and they depend strongly on the steps taken by the midwife. Time may be too short to refer a neonate, or the trip to difficult; few physicians in D.G. Khan have sound training in neonatology, and the chance of cross-infection in facilities is substantial. It appears from 
the study results on these issues that the dai training may well have averted a substantial amount of neonatal mortality.

In fact, the neonatal mortality rate in the area of the dai training declined from 41.2 deaths per 1000 live births to 29.2. The total estimated live births per year was about 10,000; the trained dais reported conducting 3,604 deliveries during the previous 6 months, or 7,208 on a per year basis, i.e., around $72 \%$ of the number of births in the area. Not all of the daiconducted deliveries would have been in the project area, but since the dais live in and serve that area, probably the great majority would have been. Hence it is plausible that the dai training might have been a major factor in the observed reduction in neonatal mortality in the CBI area. 


\section{IV: Conclusions}

1. Dai training worked. The training of the "SMART dais" was sufficiently effective to result in changes in knowledge and behavior in many aspects of maternal and neonatal care that not only were statistically significant, but large enough and in sufficiently important areas as to potentially, and perhaps actually, have affected maternal and neonatal mortality substantially.

2. Testing of the SMART dai approach is needed in other settings. The SMART dai training was led by a team from Population Council who were committed and well-versed in both the technical and interpersonal aspects of the training. The package has now been introduced in other settings, with Population Council not involved beyond the training of trainers; but these have not been rigorously evaluated. It would be evaluate this training approach under more normal training circumstances.

3. There remains need to strengthen the dai training in areas where it is less effective. While the trained dais nearly always outscored the untrained ones, there were several areas where many or most dais did not translate their training into practice. In such areas as arranging money and transport in advance, using clean delivery kits, performing fewer and cleaner pelvic examinations, avoiding injections, improving postpartum care (including family planning), keeping newborns warm, and others, there was considerable scope for improvement. How to do so needs to be explored, but may include refresher courses given at regular intervals and improved formal supervision. It is important to recognize that these women have long been practicing a set of routines that to some extent define their expertise. To replace these with best practices on a sustained basis will require more than a single training.

4. The SMART dai training needs to be linked with supportive linkages with health facilities. The study reported by Johkio and colleagues in Sindh indicated that a program focused on linking dais with health centers had a substantial effect by itself on maternal mortality. In this project, no such linkage was made. It is possible that a linkage with Department of Health staff, if disrespectful and unsupportive, might have a negative effect on dai performance. But if an effective system can be 
established that ensures regular contact and supply (including the clean delivery kits) and reinforces positive practices, it is highly likely that the combined effect could be greater than that observed in this trial. 


\section{V: References}

Arif et al. 2006. Arif MS, Miller PC, Munir N, Masood I. Smart report 3: Changes in knowledge and behavior of women and families. Islamabad, Population Council, 2006.

Bang et al., 2005. Bang AT, Reddy HM, Deshmukh MD, Baitule SB, Bang RA. Neonatal and infant mortality in the ten years (1993 to 2003) of the Gadchiroli field trial: effect of home-based neonatal care. Jl. Perinatol. 2005 Mar; 25 Suppl 1:S92-107

Bhutta et al. 2004. Bhutta S., Jafarey SN, Midhet F. Safe motherhood: a situation analysis and recommendations for evidence-based approaches, in ZA Bhutta ed., Maternal and child health in Pakistan: challenges and opportunities. Karachi, Oxford University Press, 2004.

Bhutta et al. 2008. Bhutta ZA, Memon ZA, Soofi S, Salat MS, Cousens S, Martines J. Implementing community-based perinatal care: results from a pilot study in rural Pakistan. Bull World Health Org. 2008 Jun;86(6):452-9.

Hashmi A, Bradley S \& A Mir. 2005. "Why do rural women prefer traditional birth attendants? Qualitative investigation in rural DG Khan." Islamabad, Population Association of Pakistan annual conference poster presentation, 2005.

Johkio et al. 2005. Johkio AH, Winter HR, Cheng KK. An intervention involving traditional birth attendants and perinatal and maternal mortality in Pakistan. N. Eng. J. Medicine. 2005 May 19; 352(20): 2091-9.

Maine, D and Rosenfield A. The safe motherhood initiative: why has it stalled. Am. J. Public Health. 1999 April;89(4):480-2.

PDHS 2008. National Institute of Population Studies (NIPS) and Macro International Inc. Pakistan Demographic and Health Survey 2006-07. Islmaabad, Pakistan: National Institute of Population Studies and Macro International, 2008.

Population Council 2006. (Comparison of findings from published reports on baseline surveys conducted in 10 districts in Pakistan for the PAIMAN project.) 
PSLM 2005. Federal Bureau of Statistics. Pakistan Social and Living Standards Measurement Survey 2004-05. Islamabad, Pakistan, 2005.

Rashida, G and Miller PC. Smart report 1: Project overview. Islamabad, Population Council, 2006.

Thaddeus and Maine 1994. Thaddeus S and Maine D. Too far to walk: maternal mortality in context. Social Science and Medicine. 1994 April;38(8):109-110.

Wajid et al. 2006. Wajid A., Shah ZH, Hashmi A, Tasneem Z, Shireen L. Smart report 2: The interventions. Islamabad, Population Council, 2006. 


\section{Annexure}

\section{List of Field Teams}

Team members work on OR TBAs in D.G Khan

$\begin{array}{ll}\text { Zeba Tasneem } & \begin{array}{l}\text { Team leader } \\ \text { Tubna Mahmood }\end{array} \\ \text { Farzana } & \begin{array}{l}\text { Supervisor } \\ \text { Supervisor }\end{array} \\ \text { Safia Zafar } & \text { Interviewer } \\ \text { Asia Sarwer } & \text { Interviewer } \\ \text { Shashtia Jabeen } & \text { Interviewer } \\ \text { Ghazala } & \text { Interviewer } \\ \text { Khatujia Bano } & \text { Interviewer } \\ \text { Zatoon Bibi } & \text { Interviewer } \\ \text { Shagufta Parveen } & \text { Interviewer } \\ \text { Shagufta Sakhani } & \text { Interviewer } \\ \text { Amina Bibi } & \\ \text { Imran } & \text { Male logistic person } \\ \text { Rafique Ahmed } & \text { Male logistic person } \\ \text { Saeed } & \text { Male logistic person } \\ \text { Amir } & \text { Male logistic person } \\ \text { Abdul Rehman } & \text { Male logistic person }\end{array}$

Data Entry team

Zia -ul-Islam in charge

Rehan Niazi

Arif

Mohsin 


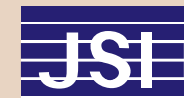 \\ JSI Research \& Training Institute, Inc.}

CA\#391 A-00-05-01037 is funded by the United States Agency for International Development and implemented by JSI Research \& Training Institute, Inc.

In conjunction with Aga Khan University, Contech International, Johns Hopkins University / CCP, The Population Council, Save the Children USA 